\begin{tabular}{|l|l|}
\hline $\begin{array}{l}\text { 2. To: (Rocolving Organkzation) } \\
\text { Fluor Hanford, Inc. }\end{array}$ & $\begin{array}{l}\text { 3. From: (Originating Organization) } \\
\text { FFS Criticality and Shielding }\end{array}$ \\
\hline $\begin{array}{l}\text { 5. Proj/Prog./Dept/Dlv.: } / 10844 / 4 J 60 \\
\text { Plutontum Finishing Plant }\end{array}$ & $\begin{array}{l}\text { 6. Dealgn Authority/Dedgn Agent/Cog. Engr.: } \\
\text { A. L. Ramble }\end{array}$ \\
\hline
\end{tabular}

8. Originator Remarke:

For approval and release.

\begin{tabular}{|c|c|c|c|}
\hline \multicolumn{4}{|c|}{$\begin{array}{l}\text { 4. Related EDT No:: } \\
\text { N/A }\end{array}$} \\
\hline \multicolumn{4}{|c|}{$\begin{array}{l}\text { 7. Purchase Ordor No.: } \\
\text { N/A }\end{array}$} \\
\hline \multicolumn{4}{|c|}{$\begin{array}{l}\text { 8. Equip./Component No.: } \\
\text { N/A }\end{array}$} \\
\hline \multicolumn{4}{|c|}{ 10. Syetem/Bido/fandilly; } \\
\hline \multicolumn{4}{|c|}{$\begin{array}{l}\text { 12. Major Asem. Dwg. No.: } \\
\text { N/A }\end{array}$} \\
\hline \multicolumn{4}{|c|}{$\begin{array}{l}\text { 13. Permilformk Application No.: } \\
\text { N/A }\end{array}$} \\
\hline \multicolumn{4}{|c|}{$\begin{array}{l}\text { 14. Requlred Rocipones Date: } \\
\text { N/A }\end{array}$} \\
\hline (F) & (G) & (H) & (1) \\
\hline $\begin{array}{l}\text { Approval } \\
\text { Dedot } \\
\text { nator }\end{array}$ & $\begin{array}{l}\text { Reaeon } \\
\text { orTinge } \\
\text { mittal }\end{array}$ & $\begin{array}{l}\text { Orlig } \\
\text { netor } \\
\text { Difpo- } \\
\text { eton }\end{array}$ & $\begin{array}{l}\text { Recoiv- } \\
\text { of } \\
\text { Difpo- } \\
\text { altion }\end{array}$ \\
\hline $\mathbf{s}$ & 1 & 1 & \\
\hline & & & \\
\hline & & & \\
\hline & & & \\
\hline & & & \\
\hline & & & \\
\hline & & & \\
\hline
\end{tabular}

\begin{tabular}{|l|l}
\hline $\begin{array}{c}\text { (A) } \\
\text { liem } \\
\text { No. }\end{array}$ & (B) Document/Drawing No. \\
\hline 1 & HNF-6271 \\
\hline & \\
\hline & \\
\hline & \\
\hline & \\
\hline & \\
\hline & \\
\hline
\end{tabular}

DATA TRANSMITTED

16.

\begin{tabular}{|c|c|c|}
\hline (C) Shoel & (D) Rev. & (E) Title or Description of Data Tranamitted \\
\hline
\end{tabular}

\begin{tabular}{|c|c|}
\hline Approval Dedgnator (F) & \\
\hline 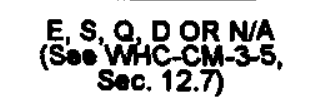 & $\begin{array}{l}\text { 1. Approval } \\
\text { 2. Aptoane } \\
\text { 3. Intormation }\end{array}$ \\
\hline
\end{tabular}

Reacoin for Transmittal (G)

KEY

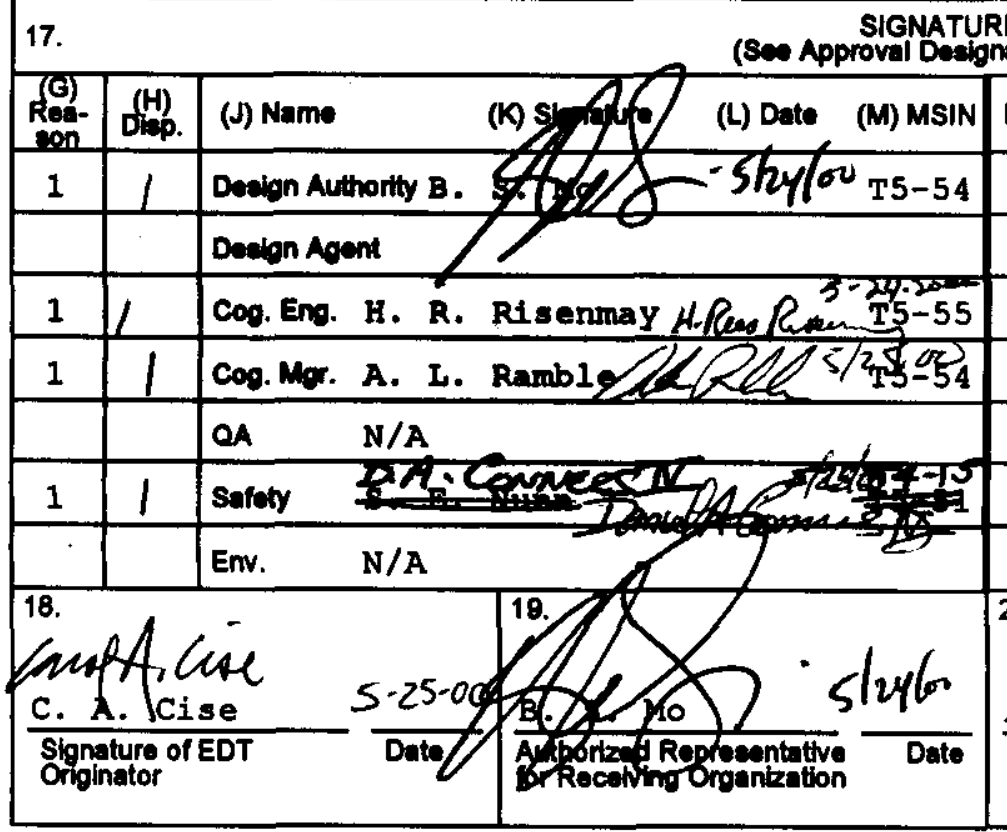

BD-7400-172-2 (10/97)

\section{Rovlow \\ 5. Pout-Roviow \\ 6. Dit. (Recolot Acknow. Required)}

Dleposation $(H) \&(I)$
1. Approved

2. Approved wloomment

3. Diepproved wicomment
4. Roviwwed no/comment 5. Rovilwed w/comment 6. Recaipt acknowisdged SIGNATUREJDISTRIBUTION SIGNATURESDISTRIBUTION
(Ses Approval Deaignator for required signatures)

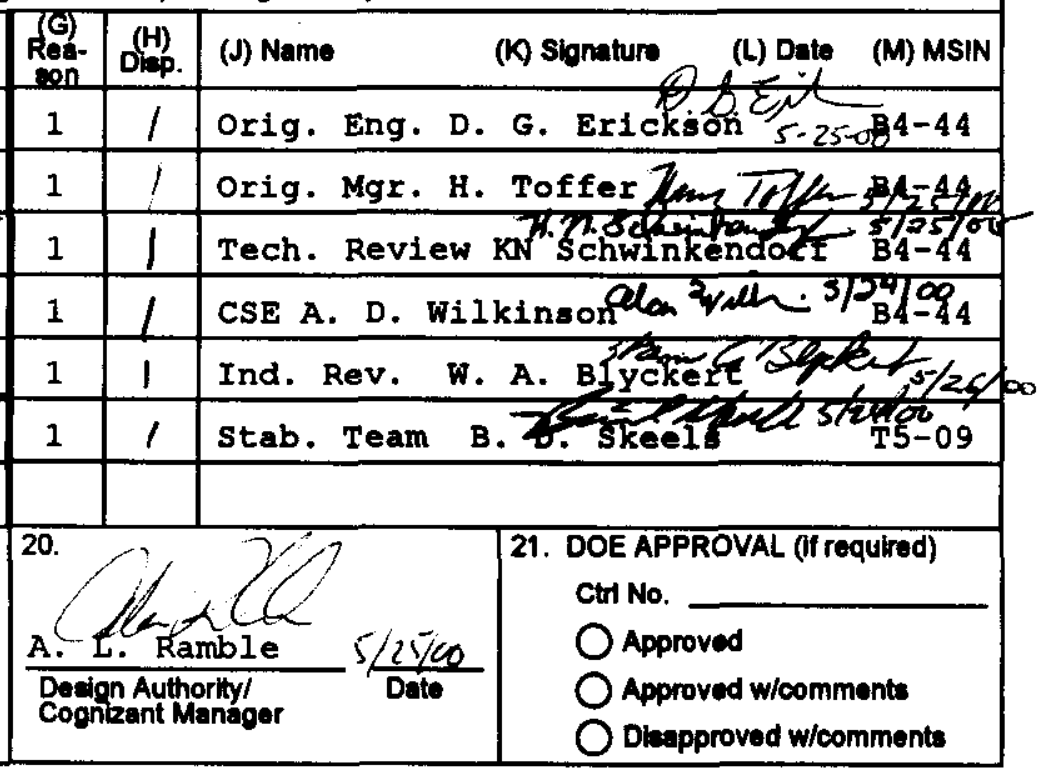




\section{DISTRIBUTION SHEET}

To

Distribution

Project TitleMNork Order

CSER 00-008: Use of PFP Glovebox HC-18BS for Storage and Transport of Fissionable Material

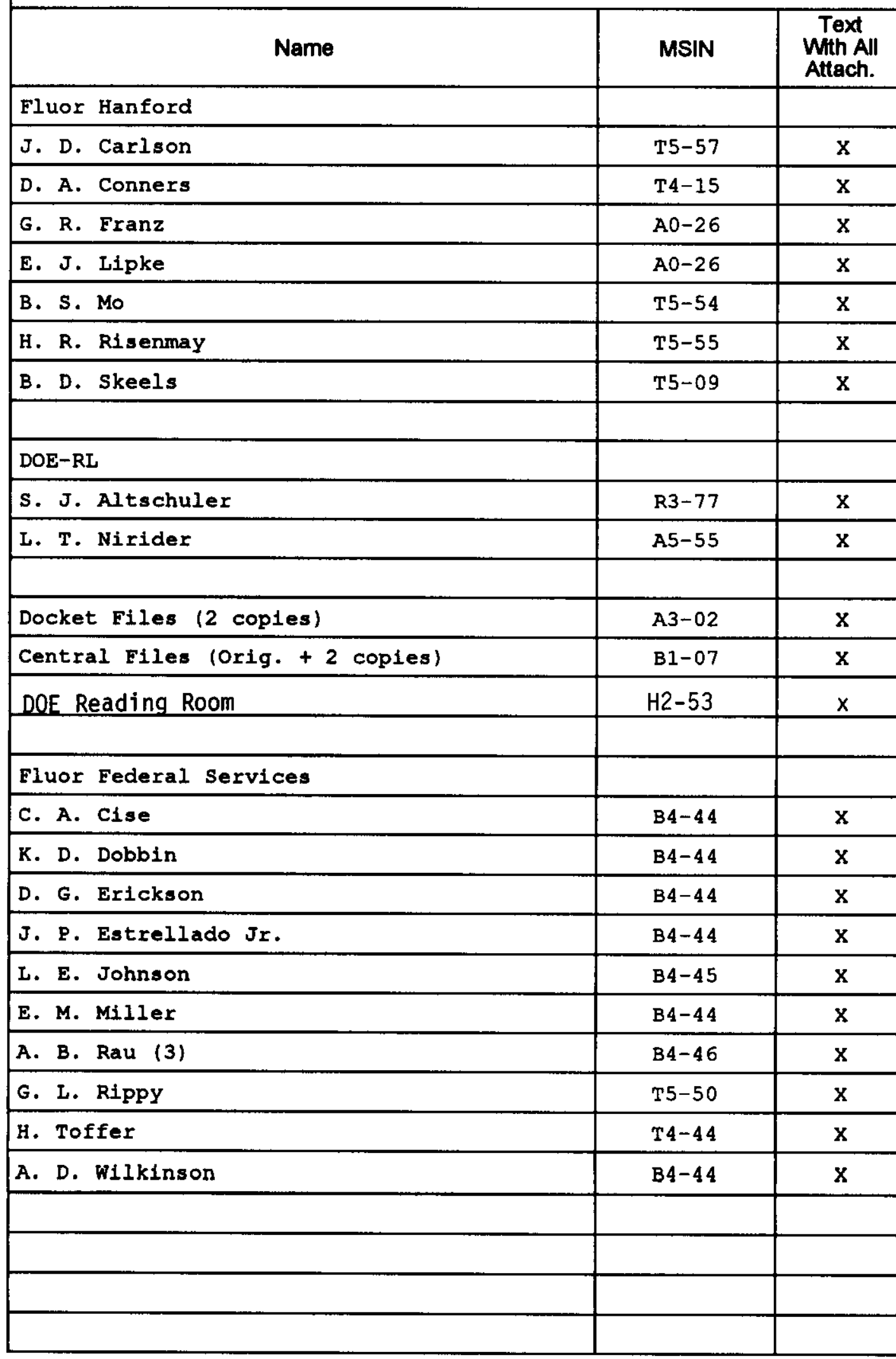

From

Criticality and shielding FFS

$\begin{array}{llll}\text { Page } & 1 & \text { of } & 1\end{array}$

Date 5/11/00

EDT No. 619960

ECN No. N/A

Attach./

Text Only Appendix

Only

EDT/ECN

Only 
$S$

\section{CSER 00-008: Use of PFP Glovebox HC-18BS for Storage and Transport of Fissionable Material}

Prepared for the U.S. Department of Energy

Assistant Secretary for Environmental Management

Project Hanford Managoment Contractor for the

U.S. Department of Energy under Contract DE-ACO6-96RL13200

Fluor Hanford

P.O. Box 1000

Richland, Washington 
HNF-6271

Revision 0

EDT 619960

\title{
CSER 00-008: Use of PFP Glovebox HC-18BS for Storage and Transport of Fissionable Material
}

\author{
D. G. Erickson \\ C, A, Cise \\ Fluor Federal Services
}

Date Published

May 2000

Prepared for the U.S. Department of Energy

Assistant Secretary for Environmental Management

Project Hanford Management Contractor for the

U.S. Department of Energy under Contract DE-AC06-96RL13200

Fluor Hanford

P.O. Box 1000

Richland, Washington
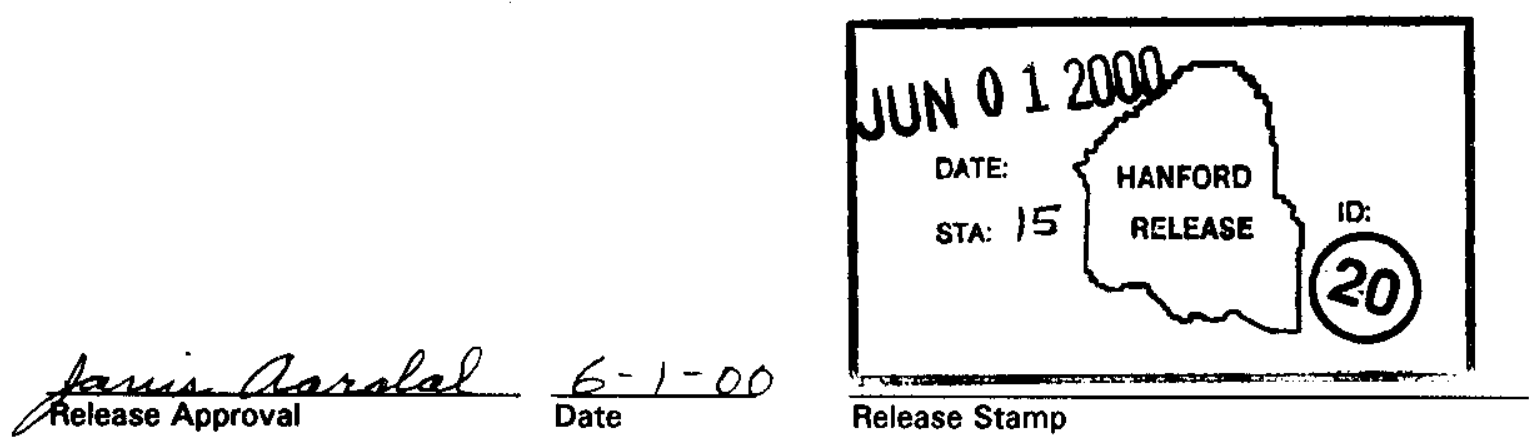
HNF-6271, Rev. 0

\section{CSER 00-008: Use of PFP Glovebox HC-18BS for Storage and Transport of Fissionable Material}

Key Words: Glovebox HC-18BS, Plutonium, PFP,

Abstract: This CSER addresses the feasibility of increasing the allowed number of open containers and permitting the transfer and storage of fissionable material in Glovebox HC-18BS without regard to form or density (metal, oxide having an $\mathrm{H} / \mathrm{X} \leq 20$, material having unrestricted moderation and plutonium hydroxide having a plutonium density of $0.2 \mathrm{~g} / \mathrm{cm}^{3}$ ). 
HNF-6271

Rev. 0

TRADEMARK DISCLAMMER

Reference herein to any specific commercial product, proceses,

or eervice by trade name, trademark, manufacturer, or

otherwise, does not necesearily constitute or Imply its

endoreement, recommendation, or favoring by the United

States Government or any agency thereof or its contractors or subcontractors.

This report has been reproduced from the best avallable copy.

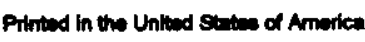

Total Pages: 105 
HNF-6271, Rev. 0

\section{CSER 00-008: Use of PFP Glovebox HC-18BS for Storage and Transport of Fissionable Material}

May 2000

Prepared by

Fluor Federal Services

Richland, Washington

For

Fluor Hanford

In Support of

Contract 5204

Prepared by:

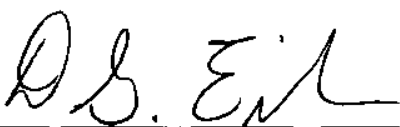

Date: $5-24 \cdot 050$
D. G. Erickson, Criticality and Shielding

Prepared by:

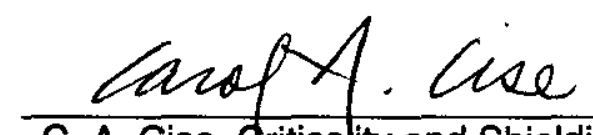

C. A. Cise, Qriticality and Shielding

Date: $5 \cdot 24-00$

Reviewed by:

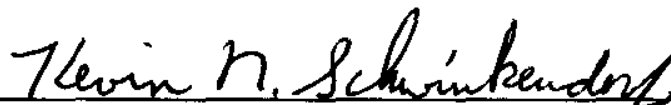

K. N. Schwinkendorf, Criticality and Shielding

Date: $5 / 25 / 00$

Approved by:

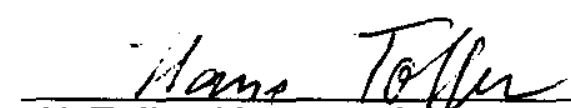

H. Toffer, Manager, Criticality and Shielding

Date: $5 / 25 / 00$

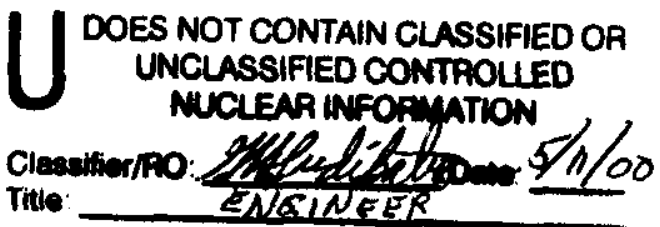


HNF-6271, Rev. 0

This page intentionally left blank 


\section{TABLE OF CONTENTS}

1.0 INTRODUCTION AND SUMMARY ................................................................... 1

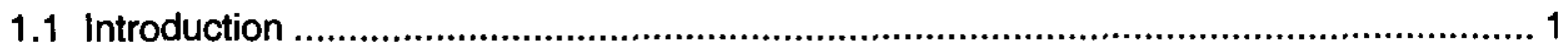

1.2 Double Contingency Documentation ................................................................ 1

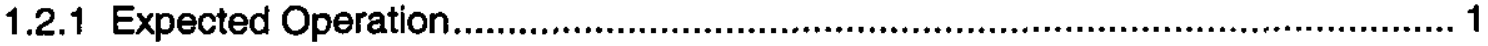

1.2.2 Expected Normal Conditions .................................................................... 1

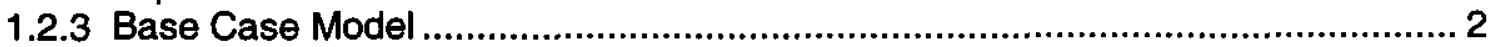

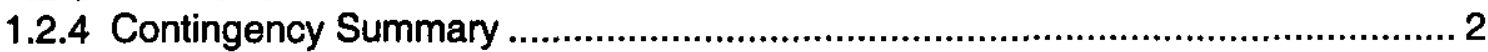

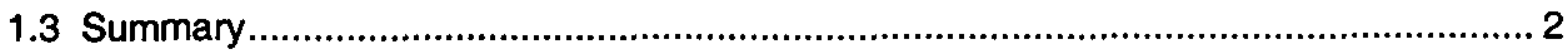

2.0 SYSTEM DESCRIPTION AND NORMAL OPERATIONS............................................. 5

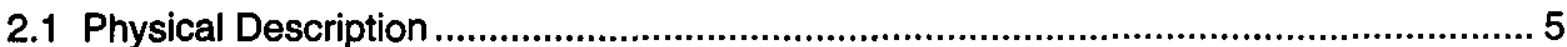

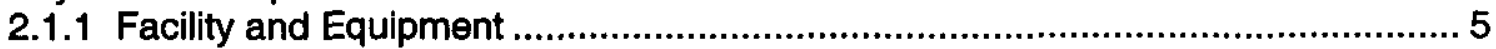

2.1.2 Fissionable Material Containers............................................................... 8

2.1.3 Can Pedestals and Furnace Boat Holders ............................................... 8

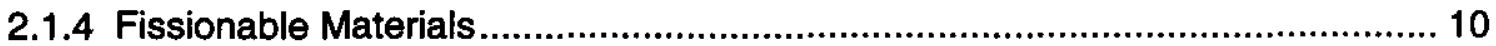

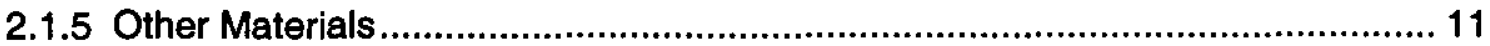

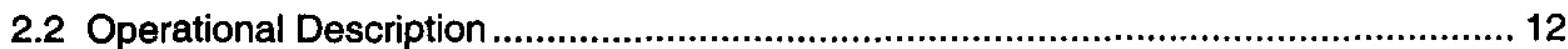

2.2.1 Preparation of Plutonium for Furnace Burning ............................................ 12

2.2.2 Transfer of Plutonium Oxide into Storage Cans .......................................... 12

2.2.3 Glovebox HC-18BS Storage of Plutonium Oxide .......................................... 13

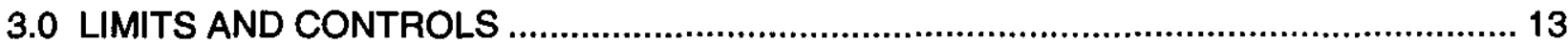

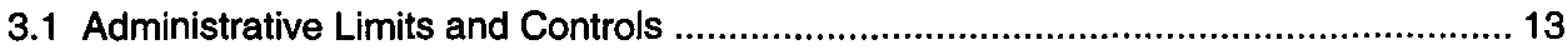

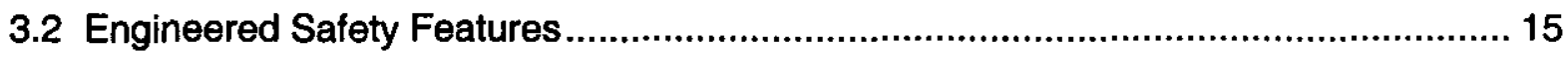

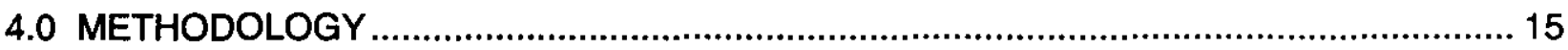

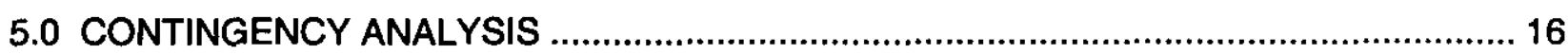

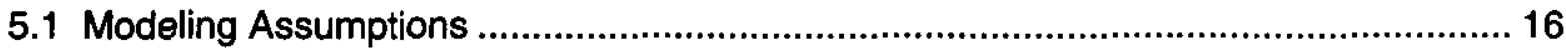

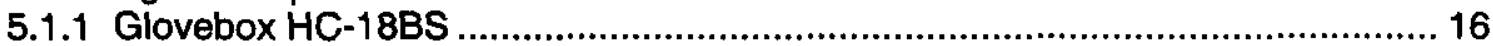

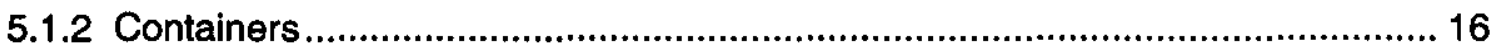

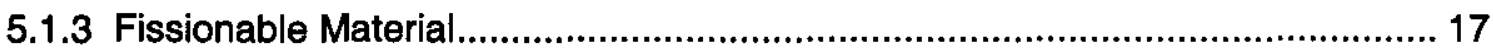

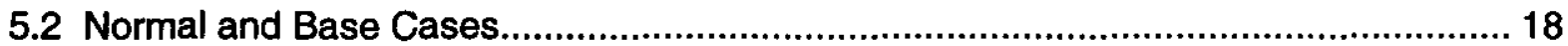

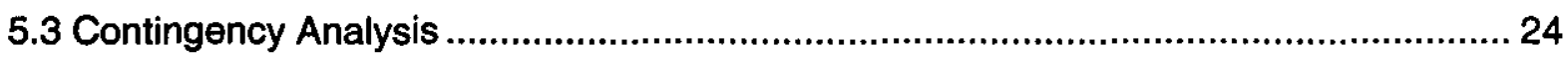

5.3.1 Hazards Assessment....................................................................... 24

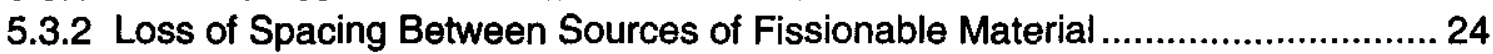

5.3.3 Additional Fissionable Material Introduced into Glovebox .............................. 27

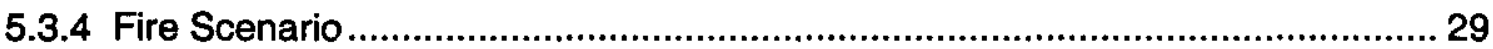

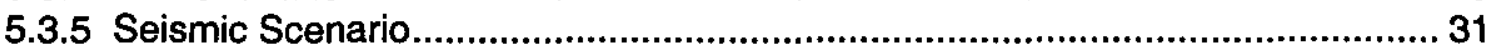

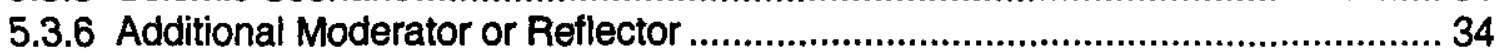

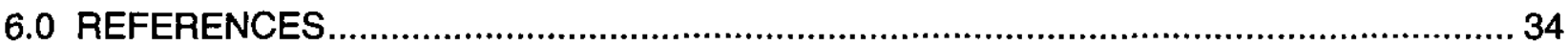


APPENDIX A - INDEPENDENT REVIEW COMMENTS AND CHECKLIST

APPENDIX B - WASTE PACKAGE DATA

APPENDIX C - MCNP COMPUTER CODE VALIDATION ................................................

APPENDIX D - PRELIMINARY HAZARDS ANALYSIS .............................................

APPENDIX E - FIRE FIGHTING WATER DENSITY ................................................ E-1

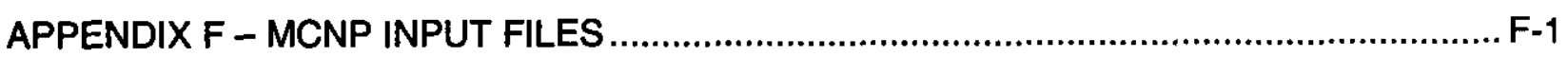

\section{LIST OF TABLES}

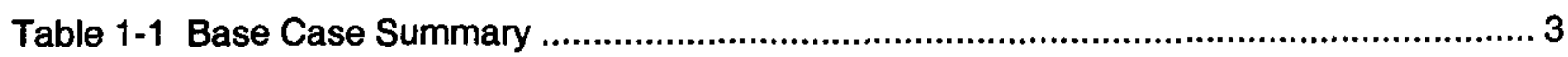

Table 1-2 Contingency Summary .............................................................................. 4

Table 2-1 Nominal Dimensions of Containers Likely to be in Glovebox HC-18BS .................. 8

Table 3-1 Parameters Controlled in Glovebox HC-18BS Operations.................................. 14

Table 5-1 Dimensions of Modeled Containers ................................................................ 17

Table 5-2 Densities Used in Modeling Plutonium Oxide .................................................... 17

Table 5-3 Results of MCNP Calculations for Normal Cases .............................................. 20

Table 5-4 Results of MCNP Calculations for Base Cases ................................................. 21

Table 5-5 Results of MCNP Calculations for Interaction Events Within Glovebox................... 26

Table 5-6 Results of MCNP Calculations for a Mass Violation............................................. 28

Table 5-7 Results of MCNP Calculations for a Fire Event with Metal Items in Containers ....... 30

Table 5-8 Results of MCNP Calculations for a Fire Event with Oxide at an $\mathrm{H} / \mathrm{X}=20 \ldots \ldots \ldots . . .31$

Table 5-9 Results of MCNP Calculations for Seismic Events .......................................... 32

\section{LIST OF FIGURES}

Figure 2-1 Sketch of the Glovebox HC-18BS Conveyor .............................................. 6

Figure 2-2 Room Configurations for Stabilization Program at PFP ..................................... 7

Figure 2-3 Vertical Cross-Sectional View of Historic Pedestal Design ..................................... 9

Figure 2-4 Plan and Elevation Views of Alternate Pedestal Design ...................................... 9

Figure 5-1 Plan View Sketch of Normal Case Model with Rectangular Geometry Containers . 19

Figure 5-2 Plan and Elevation View Sketches of Base Case Model with Cylindrical Geometry

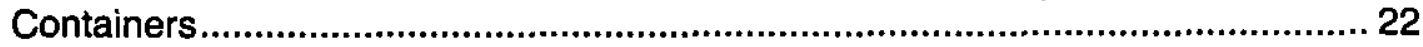

Figure 5-3 Plan View Sketch of Base Case Model with Mixed Container Array .................... 23

Figure 5-4 Sketch of Glovebox HC-18BS Conveyor Showing the Two Credible Locations Where Five Containers Can be Assembled. 
HNF-6271, Rev. 0

\subsection{INTRODUCTION AND SUMMARY}

\subsection{Introduction}

The plutonium stabilization program at the Plutonium Finishing Plant (PFP) converts plutonium-bearing material into dry powder that is chemically stable for long-term storage. Glovebox $\mathrm{HC}-18 \mathrm{BS}$ is an enclosure where operators may transfer fissionable material from the HC-2 conveyor into Glovebox HC-18M for packaging. Glovebox HC-18BS may also be used to store the packaged materials while awaiting sampling results.

Current criticality safety limits restrict operations to the transfer and storage of oxide having an $H / X \leq 20$ only. A small number of plutonium metal pieces from the incomplete oxidation of plutonium metal in the muffle furnaces are allowed to be present in the oxide. In addition, only one boat (open container) of fissionable material is permitted in the glovebox. In an effort to increase throughput and to simplify limits and controls for activities in Glovebox HC-18BS, Operations has requested an increase in the allowed number of open containers and the elimination of the form and density restrictions thus allowing most fissionable material located at PFP to be present in Glovebox HC-18BS.

This CSER addresses the feasibility of increasing the allowed number of open containers and permitting the transfer and storage of fissionable material in Glovebox HC-18BS without regard to form or density (metal, oxide having an $H / X \leq 2$, oxide having an $H / X \leq 20$, material having unrestricted moderation and plutonium hydroxide having a plutonium density of $0.2 \mathrm{~g} / \mathrm{cm}^{3}$ ).

\subsection{Double Contingency Documentation}

\subsubsection{Expected Operation}

Glovebox HC-18BS is expected to receive boats of dry oxide $(\mathrm{H} / \mathrm{X}$ typically less than or equal to 2) from the muffle furnaces for transfer into Glovebox HC-18M. After the oxide is placed in a container and a Loss On Ignition (LOI) sample is taken in Glovebox HC-18M, the canned oxide is temporarily stored in Glovebox HC-18BS. Multiple boats and containers of metal, oxide, or material having unrestricted moderation may also be stored in Glovebox HC-18BS as necessary.

\subsubsection{Expected Normal Conditions}

Glovebox HC-18BS may contain plutonium and/or uranium in metal or oxide forms. Although it is expected that the material in the glovebox will be oxide having an $\mathrm{H} / \mathrm{X}$ ratio $\leq 2$ due to the muffle furnace operations that typically produce the material, the normal condition considers both metal and oxide $(H / X \leq 2, H / X \leq 20$, and unrestricted moderation). No fissionable material solutions are allowed. The fissile mass is limited to $2.5 \mathrm{~kg}$ plutonium or plutonium fissile equivalent per container with the uranium enriched in ${ }^{235} \mathrm{U}$ to no more than $50 \%$ in each container. The fissile material may be present in containers having a maximum volume of 2.3 liters. There is no restriction on the number of open containers (typically boats) allowed in the glovebox. Each container is located in a pedestal in one of the 20 fixed storage positions on 
the conveyor. When out of the designated fixed storage position, containers must be spaced a minimum of $25.4 \mathrm{~cm}$ (10 inches) edge-to-edge from other containers. Up to $50 \mathrm{ml}$ lubricant may be present anywhere within the glovebox.

\subsubsection{Base Case Model}

The base case includes both normal and anticipated off-normal events. The anticipated off-normal events included in the base case are given in Table 1-1. The glovebox was modeled as a $4 \times 5$ array of containers spaced $34.3 \mathrm{~cm}$ (13.5 inches) center-to-center. An additional container representing the anticipated spacing violation was modeled adjacent to a container within the array. Each container representing oxide or other compound was modeled with $2.75 \mathrm{~kg}$ plutonium in a cylinder having an $\mathrm{h} / \mathrm{d}=1$ up to a maximum volume of 2.3 liters. Metal was modeled as $2.75 \mathrm{~kg}$ plutonium in a cylinder having an $\mathrm{h} / \mathrm{d}=1$. A 0.3175-cm- $(0.125$-inch-) thick layer of full density plutonium oxide at an $\mathrm{H} / \mathrm{X}=20$ was modeled $19.05 \mathrm{~cm}$ (7.5 inches) below the array of containers to conservatively account for normal accumulation and inadvertent material spills. There is full water reflection [30.0 cm (approximately 12 inches)] on all sides of the glovebox and nominal water reflection [3.0 cm (approximately 1 inch)] on the bottom and top of the glovebox. A 2.54-cm- (1-inch-) thickness of water was modeled around each container. Structural materials have been ignored. The plutonium was assumed to be $100 \%{ }^{239} \mathrm{Pu}$. Because the source of fissionable material passing through Glovebox HC-18BS is from the muffle furnaces, it is expected that the $\mathrm{H} / \mathrm{X}$ will be less than or equal to 2 (dry oxide). However, all forms of material are allowed and the analyses modeled metal, oxide having an $\mathrm{H} / \mathrm{X} \leq 2$, oxide having an $H / X \leq 20$, and material having unrestricted moderation in an effort to find the most reactive material or materials. Material was also modeled at a minimum plutonium density of $0.2 \mathrm{~g} / \mathrm{cm}^{3}$. A summary of the limits derived from this analysis of fissionable material in Glovebox HC-18BS is presented in Table 1-1.

\subsubsection{Contingency Summary}

Table 1-2 summarizes the analyses of unlikely and independent off-normal events (contingencies) possible in Glovebox HC-18BS while performing activities as described in Section 2.0. The base case, as previously described, was modified to reflect the off-normal events. The resultant computed multiplication is compared to the subcriticality target $k_{\text {eff }}$ of 0.932 for MCNP calculations of metal systems and 0.942 for MCNP calculations of non-metal systems, as explained in Section 4.0. Table 1-2 summarizes the analysis found in Section 5.0. Specific calculations were not made for contingencies in the table that were bound by other analyzed contingencies.

\subsection{Summary}

This criticality safety evaluation report (CSER) documents the criticality safety of operations involving the transfer and storage of fissionable metal and oxide compounds as well as plutonium hydroxide in Glovebox HC-18BS. The calculations presented allow the processing of up to $2.5 \mathrm{~kg}$ plutonium of any form, except solutions, in maximum 2.3-liter containers in each of the 20 storage positions in the glovebox. Glovebox HC-18BS is classified as a dry glovebox where no internal solution lines are present and no free liquids are allowed. Credit is taken for the fixed storage positions as well as for the seismic integrity of the glovebox. 
HNF-6271, Rev. 0

Table 1-1 Base Case Summary

\begin{tabular}{|c|c|c|}
\hline Controlled Parameter & Limit & $\begin{array}{l}\text { Abnormal but Anticipated Conditions } \\
\text { (Conservatism for Analysis) }\end{array}$ \\
\hline Mass & $\begin{array}{l}\text { Maximum } 2.5 \mathrm{~kg} \text { plutonium or fissile } \\
\text { equivalent per container }\end{array}$ & $\begin{array}{l}\text { All containers modeled as } 2.75 \mathrm{~kg} \\
\text { plutonium. This is a } 10 \% \text { overbatch. }\end{array}$ \\
\hline Volume & Maximum 2.3-liter container & $\begin{array}{l}\text { none } \\
\text { There is no process container having a } \\
\text { volume greater than } 2.3 \text { liters allowed } \\
\text { in the operating area. }\end{array}$ \\
\hline Moderation & $\begin{array}{l}\text { Dry glovebox } \\
\text { No solutions allowed }\end{array}$ & $\begin{array}{l}\text { none } \\
\text { All forms of solid fissionable material } \\
\text { are allowed: metal, oxide having an } \\
H / X \leq 2 \text {, oxide having an } H / X \leq 20 \text {, and } \\
\text { unrestricted moderation }\end{array}$ \\
\hline Interaction & $\begin{array}{l}\text { Minimum } 10 \text {-inch surface-to-surface } \\
\text { spacing of containers when outside of } \\
\text { storage position. } \\
\text { Maximum } 3 \text { open containers in } \\
\text { glovebox. } \\
\text { Spills must be cleaned up before } \\
\text { continuing operations. }\end{array}$ & $\begin{array}{l}\text { One spacing violation included. } \\
\text { A } 0.3175-\mathrm{cm} \text {-thickness of plutonium } \\
\text { oxide }(H / X=20) \text { modeled on the floor } \\
\text { of the glovebox. } \\
\text { Array modeled at center-to-center } \\
\text { spacing of } 13.5 \text { inches to bound } \\
\text { minimum calculated center-to-center } \\
\text { spacing of } 14.6 \text { inches at the comers. }\end{array}$ \\
\hline Reflection & $\begin{array}{l}\text { Dry glovebox } \\
\text { Maximum } 50 \mathrm{ml} \text { lubricants }\end{array}$ & none \\
\hline Geometry & none & $\begin{array}{l}\text { All closed containers modeled with an } \\
\mathrm{h} / \mathrm{d}=1 \text {. } \\
\text { Effect of open container geometry } \\
\text { examined as a normal condition }\end{array}$ \\
\hline Enrichment/sotopics & Maximum $50 \%{ }^{235} \mathrm{U}$ in $\mathrm{U}$ & $\begin{array}{l}{ }^{235} \mathrm{U} \text { treated as }{ }^{239} \mathrm{Pu} \text { fissile equivalent } \\
\text { Modeled as } 100 \%{ }^{239} \mathrm{Pu}\end{array}$ \\
\hline Homogeneity & none & none \\
\hline Density & none & $\begin{array}{l}\text { none } \\
\text { Material was analyzed at a minimum } \\
\text { plutonium density of } 0.2 \mathrm{~g} / \mathrm{cm}^{3} \text { to } \\
\text { bound the presence of plutonium } \\
\text { hydroxide. }\end{array}$ \\
\hline Concentration & none & none \\
\hline Poisons & none & none \\
\hline
\end{tabular}


HNF-6271, Rev. 0

Table 1-2 Contingency Summary

\begin{tabular}{|c|c|c|c|}
\hline Contingency Description & $\begin{array}{c}\text { Affected } \\
\text { Parameter(s) }\end{array}$ & $\begin{array}{c}\text { Barriers that Make Contingency } \\
\text { Unlikely }\end{array}$ & $\begin{array}{l}\mathrm{k}_{\text {eff }} \text { for Bounding } \\
\text { Contingency } \\
\text { (Case ID) }\end{array}$ \\
\hline $\begin{array}{l}\text { Loss of spacing occurs } \\
\text { between unit masses } \\
\text { within the glovebox }\end{array}$ & Interaction & $\begin{array}{l}\text { Operator training to procedures } \\
\text { Pre-operational inspection of glovebox } \\
\text { for obstructions in the conveyor path. } \\
\text { Operating switch requires constant } \\
\text { pressure to move conveyor } \\
\text { Can pedestal and boat holder design } \\
\text { prohibit easy removal of containers from } \\
\text { storage locations on conveyor. } \\
\text { Two operators are required to observe } \\
\text { the movement of conveyor. } \\
\text { An inadvertent assembling of more than } \\
\text { three containers is not credible. }\end{array}$ & $\begin{array}{c}0.924 \\
(18 \mathrm{bs}-\text { ou }-25)\end{array}$ \\
\hline $\begin{array}{l}\text { Additional fissionable } \\
\text { material is introduced into } \\
\text { glovebox such that } \\
\text { container in storage } \\
\text { position contains greater } \\
\text { than } 2.75 \mathrm{~kg} \text { fissionable } \\
\text { material }\end{array}$ & Mass & $\begin{array}{l}\text { Operator training to procedures } \\
\text { A container holding more than two times } \\
\text { the allowed mass of } 2.5 \mathrm{~kg} \text { is not } \\
\text { credible. }\end{array}$ & $\begin{array}{c}0.921 \\
\text { (18bs-om-22) }\end{array}$ \\
\hline $\begin{array}{l}\text { Fire with glovebox breach } \\
\text { and sprinkler activation } \\
\text { causes material in open } \\
\text { containers to become } \\
\text { saturated. }\end{array}$ & $\begin{array}{l}\text { Moderation } \\
\text { Reflection }\end{array}$ & $\begin{array}{l}\text { Fire that damages glovebox to allow } \\
\text { water ingress is unlikely } \\
\text { Full flooding due to fire is not credible as } \\
\text { HC-18BS conveyor is approximately } \\
7.5 \text { inches above the glovebox floor. The } \\
\text { floor has an approximate } 0.25 \text {-inch lip } \\
\text { before draining into the HC-1 and HC-2 } \\
\text { conveyors which have criticality safety } \\
\text { drains or drain into another glovebox } \\
\text { which has a criticality safety drain (HC-2 } \\
\text { drains into HC-5 which has a criticality } \\
\text { safety drain). } \\
\text { Sprinkler density greater than } 0.5 \mathrm{~g} / \mathrm{cm}^{3} \\
\text { is not credible. }\end{array}$ & $\begin{array}{c}0.912 \\
(18 b s-0 s-46)\end{array}$ \\
\hline $\begin{array}{l}\text { Seismic event, including } \\
\text { sprinkler activation causes } \\
\text { material in open containers } \\
\text { to become saturated. }\end{array}$ & $\begin{array}{l}\text { Moderation } \\
\text { Reflection }\end{array}$ & $\begin{array}{l}\text { Seismic event is unlikely. } \\
\text { Credit taken for the seismic qualification } \\
\text { of Glovebox HC-18BS. }\end{array}$ & $\begin{array}{c}0.921 \\
(18 b s-0 e-24)\end{array}$ \\
\hline
\end{tabular}


All normal and anticipated off-normal operations were modeled as a base case. This model was then modified to reflect the contingent conditions. A hazards analysis was conducted to assure that each credible unlikely event or set of correlated unlikely events was included in the contingency analysis. Calculations were performed with these models using the MCNP calculational code. Each contingent condition was found to have a calculated $k_{\text {eff }}$ that is less than the criticality safety limit of 0.942 for non-metal systems or 0.932 for metal systems. These limit values are based on the chosen subcritical safety limit of 0.95 modified for MCNP calculational bias and uncertainty. Each contingent condition was shown to be both unlikely and less than the allowable criticality safety limits. Therefore, operations in Glovebox HC-18BS are in compliance with the double contingency principle.

\subsection{SYSTEM DESCRIPTION AND NORMAL OPERATIONS}

Glovebox HC-18BS is located in room 228C in the main PFP Building, 234-5Z, which is located in the 200 West area. This facility was historically used to process plutonium into oxide or metal forms. The facility is now undergoing a cleanup phase to stabilize the plutonium still located there.

\subsection{Physical Description}

\subsubsection{Facility and Equipment}

Glovebox HC-18BS is a glovebox with a $914.4-\mathrm{cm}$-long (360-inch-long) conveyor loop having 20 plutonium storage locations. Glovebox HC-18BS is $208.3 \mathrm{~cm}$ ( 82 inches) in depth, $68.3 \mathrm{~cm}$ (26.875 inches) in height, and $250.8 \mathrm{~cm}$ (98.75 inches) in length. The bottom of Glovebox $\mathrm{HC}-18 \mathrm{BS}$ is $117.5 \mathrm{~cm}$ (46.25 inches) above the floor of the room. There is a $20.0-\mathrm{cm}$ (7.875-inch) spacing between the top of the conveyor where fissionable material is located and the bottom of the glovebox. The conveyor is supported within the glovebox by three levels of thick angle iron and C-channel (PFP FSAR, 1999). Four of the wheels around which the conveyor passes are located at the corners of the glovebox with their centers $47.0 \mathrm{~cm}$ (18.5 inches) from the long sides and $54.6 \mathrm{~cm}$ (21.5 inches) from the short side. A fifth wheel is located at the center of the short side and $86 \mathrm{~cm}$ (34 inches) from the center of the two wheels on one of the short sides. All five wheels have $27.9-\mathrm{cm}(11$-inch) radii (measured from the wheel axis to the conveyor centerline). The conveyor passes around the four outer wheels and loops about the inner one from the short side from which the $86-\mathrm{cm}$ (34-inch) offset is measured in such a manner as to provide maximum length, $914 \mathrm{~cm}$ (360 inches) as shown in Figure 2-1.

As shown in Figure 2-2, Glovebox HC-18BS connects to the HC-1 and HC-2 conveyors, which have floors at a lower elevation. The openings from Glovebox $\mathrm{HC}-18 \mathrm{BS}$ to the $\mathrm{HC}-1$ and $\mathrm{HC}-2$ conveyors act as criticality drains and eliminate the concern of Glovebox HC-18BS holding water and flooding. The table frame supporting Glovebox HC-18BS has horizontal members for additional structural support. Glovebox HC-18BS is seismically qualified (PFP FSAR, 1999).

There are no equipment items that could act as containers for plutonium available in Glovebox $\mathrm{HC}-18 \mathrm{BS}$. Container storage positions are defined by fixed storage positions on the conveyor. With 20 fixed storage positions specified, there is an average of $45.7-\mathrm{cm}$ (18-inch) center-to-center linear spacing along the conveyor. Storage positions are $22.9-\mathrm{cm}$ (9-inch) long, 
HNF-6271, Rev. 0

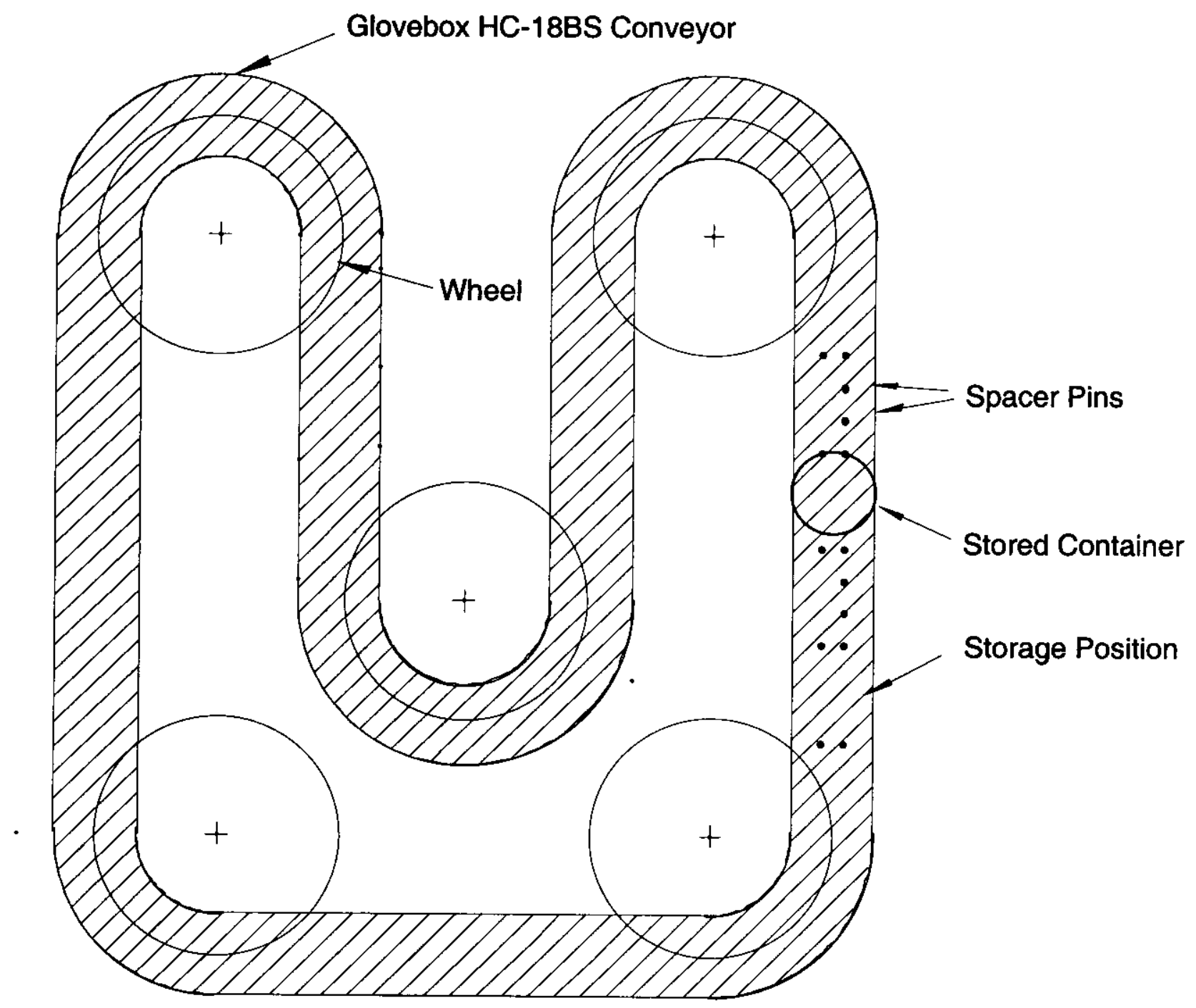

Figure 2-1 Sketch of the Glovebox HC-18BS Conveyor 
HNF-6271, Rev. 0

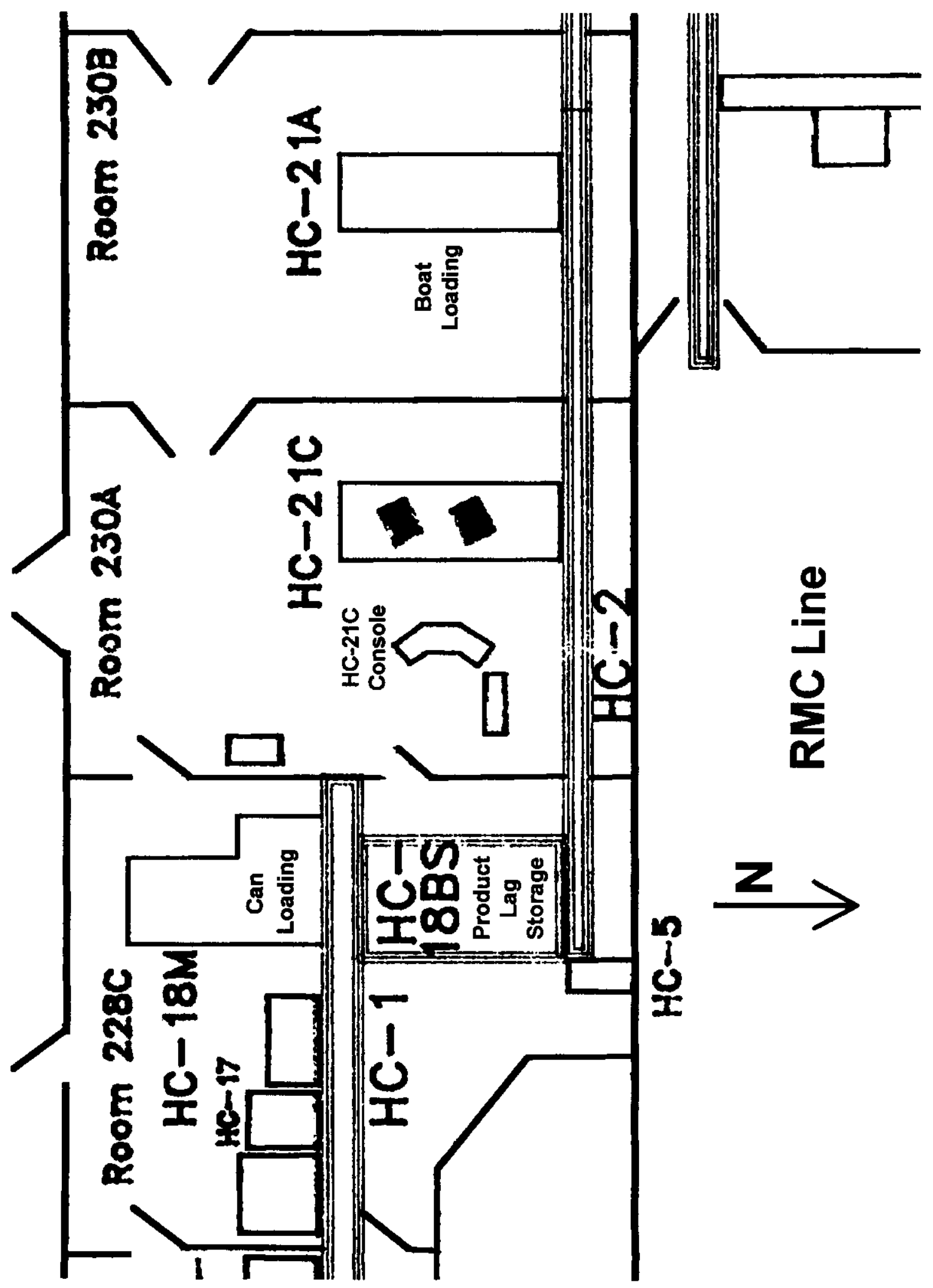

Figure 2-2 Room Configurations for Stabilization Program at PFP 
with a pair of $0.95-\mathrm{cm}(0.375$-inch) tall pins delineating each position. A pedestal is placed in each position to hold either a can or a furnace boat. The pedestals are restricted between the two pairs of pins spaced $22.8 \mathrm{~cm}$ (9.0 inches) apart on the conveyor track. There is no engineered safety feature to prevent placing containers in between storage locations, although a single row of pins make placing pedestals between positions awkward.

There are gloveports around the perimeter of the glovebox. It is not possible to reach the center of the glovebox by reaching through the gloveports. The walls and ceiling of the glovebox have clear plastic panels for easy viewing of the glovebox contents.

\subsubsection{Fissionable Material Containers}

Plutonium oxide is introduced into the glovebox for storage or transfer to Glovebox $\mathrm{HC}-18 \mathrm{M}$ in furnace boats, cans, or polyjars. The dimensions of several typical containers likely to be present in Glovebox HC-18BS are given in Table 2-1. Because limits and controls are given in terms of open and closed containers, other containers not listed in Table 2-1 are allowed in the glovebox as long as they comply with the glovebox limits. The oxide cans are typically made of commercial steel electroplated with tin and have a very thin wall thickness, $0.0229 \mathrm{~cm}$ (0.009 inches). The furnace boat is typically made from $0.3175-\mathrm{cm}$-thick $(0.125$-inch-thick) metal sheet stock shaped into a 'cake pan.' The polyjars are typically polypropylene with an approximate wall thickness of $0.16 \mathrm{~cm}$ (0.063 inches).

Table 2-1 Nominal Dimensions of Containers Likely to be in Glovebox HC-18BS

\begin{tabular}{|c|c|c|}
\hline Container & Dimensions & $\begin{array}{c}\text { Volume } \\
\text { (liter) }\end{array}$ \\
\hline polyjar & $\begin{array}{c}\text { outside diameter: } 8.26 \mathrm{~cm}(3.25 \mathrm{inch}) \\
\text { outside height: } 10.16 \mathrm{~cm}(4.0 \mathrm{inch})\end{array}$ & 0.50 \\
\hline Purex slip lid can & $\begin{array}{c}\text { outside diameter: } 8.73 \mathrm{~cm}(3.44 \mathrm{inch}) \\
\text { outside height: } 13.65 \mathrm{~cm}(5.375 \mathrm{inch})\end{array}$ & 0.80 \\
\hline 'new' slip lid can & $\begin{array}{c}\text { outside diameter: } 9.21 \mathrm{~cm}(3.63 \mathrm{inch}) \\
\text { outside height: } 13.97 \mathrm{~cm}(5.50 \mathrm{inch})\end{array}$ & 0.95 \\
\hline furnace boat & $\begin{array}{c}\text { outside width: } 13.34 \mathrm{~cm}(5.25 \mathrm{inch}) \\
\text { outside length: } 28.58 \mathrm{~cm}(11.25 \mathrm{inch}) \\
\text { outside height: } 6.50 \mathrm{~cm}(2.57 \mathrm{inch})\end{array}$ & 2.20 \\
\hline
\end{tabular}

\subsubsection{Can Pedestals and Furnace Boat Holders}

Cylindrical containers are placed directly into a pedestal located on the conveyor. Two existing pedestal designs are shown in Figures 2-3 and 2-4. Figure 2-3 is a vertical cross-sectional view of the pedestal design historically used in this glovebox. The pedestal is $18.4 \mathrm{~cm}(7.25$ inches) in diameter, barely fitting within the guardrails on the conveyor. It has a recess into which cans or the bottom of a furnace boat holder may be placed. It was designed to hold containers 
HNF-6271, Rev. 0

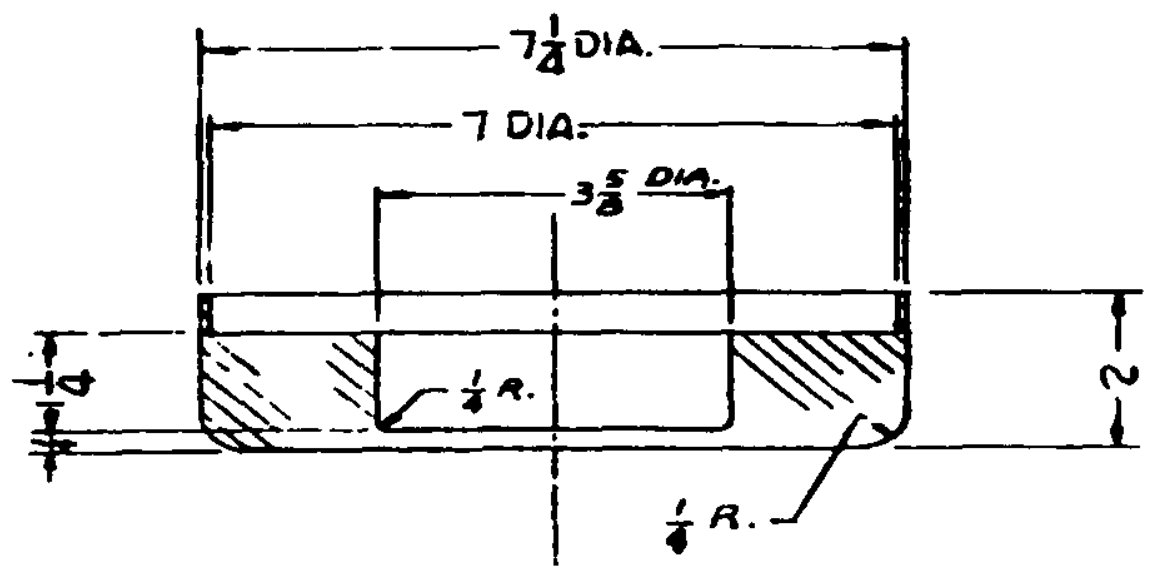

Figure 2-3 Vertical Cross-Sectional View of Historic Pedestal Design
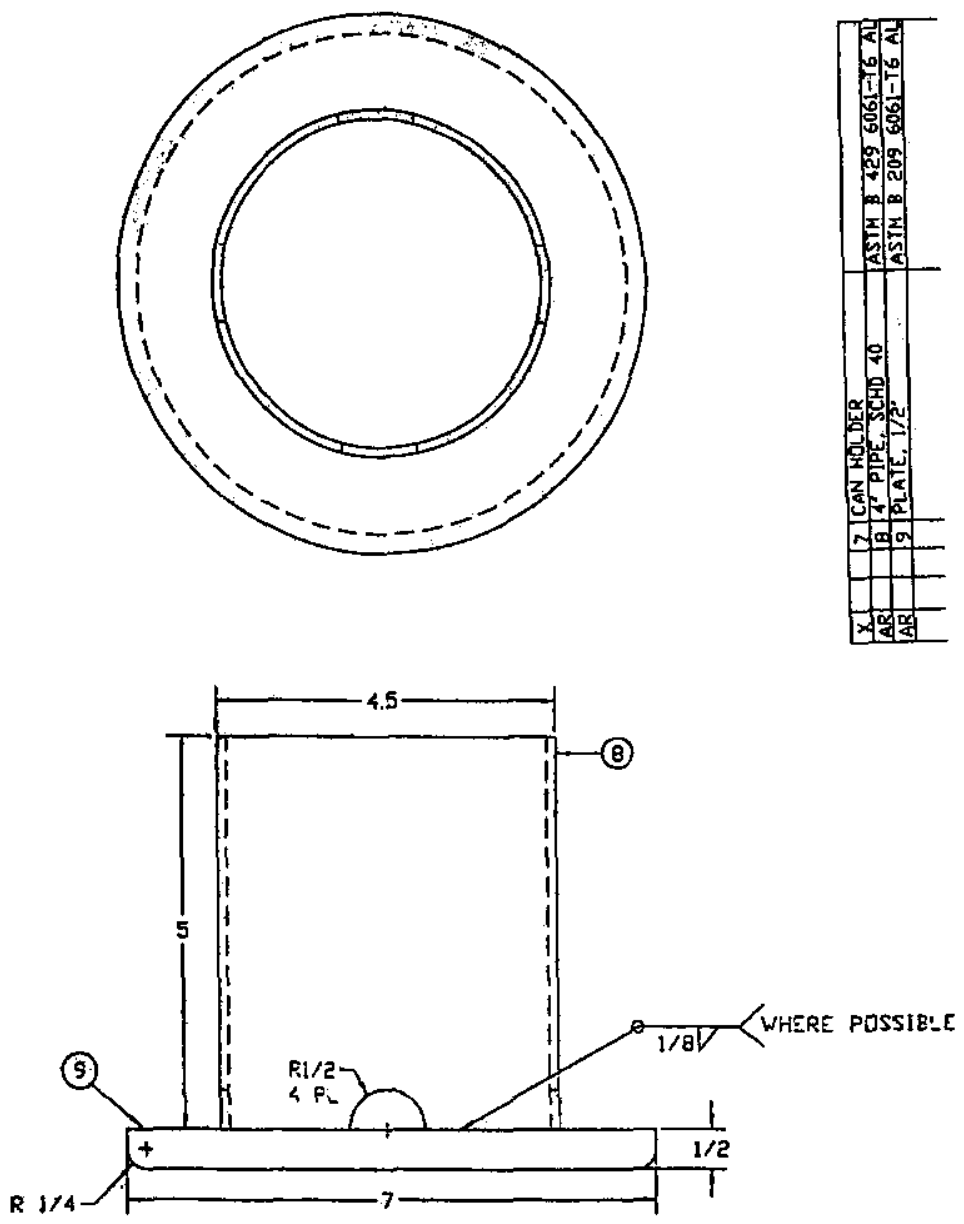

Figure 2-4 Plan and Elevation Views of Alternate Pedestal Design 
having a nominal outside diameter $\leq 8.9 \mathrm{~cm}$ ( 3.5 inches). Figure $2-4$ is a plan and elevation view of an alternate pedestal design. This pedestal is a $12.7-\mathrm{cm}-(5-\mathrm{inch}-)$ high section of Schedule 40 pipe sleeving welded onto the center of a $1.27-\mathrm{cm}-(0.5$-inch-) thick base having a diameter of $17.8 \mathrm{~cm}$ (7 inches). It was designed to hold containers having a nominal outside diameter $\leq 10.1 \mathrm{~cm}$ (4 inches). Although not physically attached to the conveyor, pedestals are restricted from sliding along the conveyor by the $0.95-\mathrm{cm}-(0.375$-inch- $)$ tall spacing pins on the conveyor surface.

The PFP Final Safety Analysis Report (FSAR) stated that it is extremely improbable that a seismic event would generate sufficient vertical forces for a can to be dislodged from its pedestal (PFP FSAR, 1999). Due to the recent development of the alternate pedestal design and the date of issue for the FSAR, it was inferred that the above conclusion was based on the historic pedestal design shown in Figure 2-3. It is not required that the two designs shown in Figures 2-3 and 2-4 are used exclusively. Other designs are allowed as long as they have a minimum 3.175-cm- (1.25-inch-) deep recess and a diameter that will adequately keep the cylindrical containers upright during conveyor movement (i.e. a design similar to that used in the FSAR conclusion). In designing other pedestals, it should be noted that the pedestals must either comply with the volume limit of 2.3 liters or be made into a non-container as specified in the General Limit CPS (CPS-Z-165-80010).

A furnace boat holder placed into a pedestal opening is used to support and restrain a muffle furnace boat in Glovebox HC-18BS as it is being transferred from the $\mathrm{HC}-2$ conveyor to Glovebox HC-18M through Glovebox HC-18BS. The boat holder is designed to maintain the rectangular containers in their designated locations during a seismic event with equal or greater probability as a can in a pedestal. It is inferred from the above discussion regarding the FSAR and cylindrical containers that the boat holder must have minimum 3.175-cm- (1.25-inch-) high sides or sidepieces. This design feature, along with the inherent lower center of gravity for a rectangular container having the dimensions given in Table 2-1 over a cylindrical container would ensure that the probability of a container being dislodged during a seismic event is no greater than presented in the FSAR. As with the pedestals, the boat holder must comply with either the volume limit of 2.3 liters or the requirements of the General Limit CPS

(CPS-Z-165-80010) for a non-container.

\subsubsection{Fissionable Materials}

The fissionable material handled in Glovebox HC-18BS is plutonium in the forms of metal, oxide and other compounds as well as mixed oxides of plutonium and uranium. The fissionable isotope content and physical forms are discussed below.

Fissionable Isotopes The plutonium used in the models in this CSER is $100 \%{ }^{239} \mathrm{Pu}$. This simplification is conservative for plutonium with more ${ }^{240} \mathrm{Pu}$ than ${ }^{241} \mathrm{Pu}$ which encompasses the reactor-produced plutonium at PFP. All fissile isotopes are assumed to be plutonium or plutonium equivalent as presented in the PFP General Limits (CPS-Z-165-80010). Natural or depleted uranium does not make a positive contribution to reactivity and may be included without adding to the plutonium mass.

Plutonium Oxide and Other Plutonium Compounds Under normal operating conditions, the plutonium in Glovebox HC-21A will be in the form of oxide. It will be present in cans, polyjars, or furnace boats. In this current document, the use of the term oxide, and more specifically, 
plutonium oxide $\left(\mathrm{PuO}_{2}\right)$, refers to compounds such as $\mathrm{PuO}_{2}$ [oxide], $\mathrm{PuF}_{\mathrm{x}}$ [fluoride], $\mathrm{PuPO}_{4}$ [phosphate], $\mathrm{Pu}\left(\mathrm{CO}_{3}\right)_{\times}$[carbonate], $\mathrm{Pu}\left(\mathrm{C}_{2} \mathrm{O}_{4}\right)_{x}$ [oxalate], $\mathrm{Pu}\left(\mathrm{SO}_{4}\right)_{x}$ [sulfate], and $\mathrm{Pu}\left(\mathrm{NO}_{3}\right)_{x}$ [nitrate] and to mixtures such as plutonium-uranium mixed oxide fuels. A plutonium oxide density of $11.46 \mathrm{~g} / \mathrm{cm}^{3}$ was used in the analysis.

The discussion in CSER 98-008 (Greenborg, 1999) concluded that the other plutonium compounds listed above are less reactive than plutonium oxide due to lower plutonium density within the compound and higher absorption cross sections of the nonfissile elements. Although PuC $_{x}$ [carbide] and $\mathrm{PuN}_{\mathrm{x}}$ [nitride] have higher theoretical densities than plutonium oxide, it is anticipated that they will occur as fractional by-products or contaminants so that their contribution to the reactivity of the compound will be negligible. For non-metal material, it was shown that $\mathrm{PuH}_{\mathbf{x}}$ [hydride] would have an insignificant effect on the reactivity of the material unless it is a major constituent. It was demonstrated the chemical makeup of corrosion products, including plutonium hydride, will have an insignificant effect on the $2.5 \mathrm{~kg}$ metal unit masses. Therefore, the limit set derived from the analyses presented in this CSER bounds credible quantities of other plutonium compounds.

It has been shown that water and plutonium mixtures are more reactive than water and uranium mixtures where the uranium is enriched up to $50 \mathrm{wt} . \%{ }^{235} \mathrm{U}$ (Marusich, 1999) whereby the mass limit set for plutonium may be used when uranium, enriched up to $50 \mathrm{wt} . \%{ }^{235} \mathrm{U}$, is mixed with or substituted for plutonium.

Plutonium Metal Plutonium metal may be present as individual items having a maximum credible mass of $2.5 \mathrm{~kg}$ or as small pieces in oxide resulting from incomplete oxidation in the muffle furnaces. A density of $19.6 \mathrm{~g} / \mathrm{cm}^{3}$ for plutonium metal was used for this evaluation.

Unrestricted Moderation Sludge (plutonium oxide having unrestricted moderation) may be introduced into Glovebox HC-18BS. Sludge is assumed to be plutonium oxide and water with an $\mathrm{H} / \mathrm{X}$ ratio $>20$.

Plutonium Hydroxide Material introduced into Glovebox HC-18BS may have plutonium densities as low as $0.2 \mathrm{~g} / \mathrm{cm}^{3}$ for the case of plutonium hydroxide, the product resulting from the magnesium hydroxide process.

\subsubsection{Other Materials}

HEPA Filters PFP gloveboxes have in-place High Efficiency Particulate Air (HEPA) filters in the exhaust lines to remove plutonium dust and other particulate. The filter is normally located in a recess in the glovebox roof and is changed using a separate control set (Altschuler, 1981) after unloading the fissile material containers from the glovebox. A glovebox would only have one significantly contaminated filter since experience has shown that even if there are two filters in sequence, only the first is contaminated with sufficient fissile material to be of any concern for criticality safety. The second filter will be contaminated but only with milligram quantities of plutonium unless the first filter has been physically broken through.

CSAR 80-014 (Altschuler, 1981) shows that over the credible range of plutonium particle densities, criticality in an optimally moderated filter is not credible at either full or nominal water reflection. In Glovebox HC-18BS with no water lines and the introduction of water prohibited, nominal reflection is considered normal. Although, the HEPA filter alone is not a threat to 
criticality safety, interaction of this filter with other fissionable material in the glovebox during removal operations needs consideration.

Waste Packages Glovebox waste is generated from PFP plutonium stabilization operations. It is placed into plastic bags, transferred to Isolated Transport Containers (ITCs), assayed, then placed into waste drums. This waste consists of gloves, bags, rags, and containers used to bag-in items. No fissile item is intentionally placed in these packages. Waste packages are allowed in Glovebox HC-18BS and result from glovebox cleaning operations. Waste packages created in this glovebox would only contain the fissile material already inventoried.

To determine a typical fissile mass in a waste package an inspection of data for recent assays of low-density items counted on the Nal counter (Appendix B) was performed. This inspection indicated that the majority of these packages contain only $1-10 \mathrm{~g}$ fissile material with all items showing a fissile content less than $\mathbf{4 0} \mathrm{g}$.

\subsection{Operational Description}

Figure 2-2 illustrates the layout of the area encompassing the $\mathrm{Pu}$ stabilization activities on the first floor of PFP. Preparation of furnace boat charges will be performed in Glovebox HC-21A in Room 230B. Loaded furnace boats may be transferred to furnace gloveboxes (e.g., Glovebox $\mathrm{HC}-21 \mathrm{C}$ in Room 230A) via the conveyor gloveboxes. Furnace gloveboxes receive only prepared furnace boats. Furnace boats of fired material from the furnace gloveboxes are sent to Glovebox $\mathrm{HC}-18 \mathrm{M}$ via Glovebox $\mathrm{HC}-18 \mathrm{BS}$ for further processing. After the $\mathrm{PuO}_{2}$ is sieved, a loss on ignition (LOI) sample is taken, the remaining $\mathrm{PuO}_{2}$ is placed into a can, and a lid is attached to this can. The can may then be temporarily stored in Glovebox HC-18BS until the LOI results are returned.

The gloveboxes involved in the processes for preparation, firing and product packaging for the furnace operations are designated so that free liquids or solutions are not allowed. There are no water or liquid lines for processes or firefighting purposes within the dry gloveboxes. Storage of plutonium from other sources within PFP is permitted within the constraints of the limits.

\subsubsection{Preparation of Plutonium for Furnace Burning}

Material that will be received in Glovebox $\mathrm{HC}-21 \mathrm{~A}$ in the near term will be either plutonium metal $(\leq 2.5 \mathrm{~kg}$ plutonium) or plutonium oxides or compounds in quantities of $\leq 2.5 \mathrm{~kg}$ plutonium per can. The charges are made up in metal furnace boats with a volume of no more than 2.3 liters. The furnace boats can be sent via conveyor to the muffle furnaces.

\subsubsection{Transfer of Plutonium Oxide into Storage Cans}

After the plutonium metal is heated in the furnace, the cooled furnace boats containing $\mathrm{PuO}_{2}$ and contaminants are sent to Glovebox HC-18M via the Glovebox HC-18BS conveyor. At this time there should not be any plutonium in the form of metal in the furnace boats, only $\mathrm{PuO}_{2}$ in Glovebox $\mathrm{HC}-18 \mathrm{M}$. The furnace boats now contain a very dry $\mathrm{PuO}_{2}$ powder. One at a time, the contents of the furnace boats are emptied into a pan sieve system and sieved, any chunks are ground as necessary until they can pass through the sieve, and the powder is typically placed into a metal can. Once a can is filled, it is weighed, sampled for LOI, a lid is attached and taped 
onto the can, and then it is transported to Glovebox HC-18BS for temporary storage until the LOI results are returned.

\subsubsection{Glovebox HC-18BS Storage of Plutonium Oxide}

There are 20 pedestals that serve as storage locations for containers in Glovebox HC-18BS. A container storage location may be used for storage of a furnace boat using a special furnace boat tray that fits into the storage pedestal. Glovebox HC-18BS will be used to transfer furnace boats filled with $\mathrm{PuO}_{2}$ from the muffle furnaces to Glovebox $\mathrm{HC}-18 \mathrm{M}$. It will also be used for lag storage of sealed containers until the LOI results are available. After LOI results are returned, the containers can be retrieved from Glovebox HC-18BS for bag out from Glovebox HC-18M and canning in nested containers before storage in a vault.

\subsection{LIMITS AND CONTROLS}

Table 3-1 lists each of the parameters of concern for criticality safety, and lists the administrative limits associated with the controls of these parameters for storage and transport of fissionable material in Glovebox HC-18BS.

\subsection{Administrative Limits and Controls}

- Maximum $2.5 \mathrm{~kg}$ plutonium or plutonium fissile equivalent per container.

- Maximum 2.3-liter container per storage position.

- Minimum 25.4-cm (10-inch) edge-to-edge spacing between fissionable material containers when outside of storage position.

- No fissionable material solutions allowed in glovebox.

- All cylindrical containers of fissionable material shall be located in a pedestal in one of the fixed storage positions during storage or during movement of the conveyor.

- All rectangular containers of fissionable material shall be located in a furnace boat holder and pedestal arrangement in one of the fixed storage positions during storage or during movement of the conveyor.

- Containers of fissionable material shall not be stacked.

- Maximum $50 \mathrm{ml}$ lubricants (non-fissionable material solutions) allowed in glovebox.

- Fissionable material spills shall be cleaned up before continuing operations.

- Conveyor movement shall be observed by a second operator to ensure that containers remain in position and are not upset.

- A pre-movement inspection is required to verify conveyor travel is free of extended gloves and other items that could interfere with stored item stability.

- Damp rags, up to a maximum of $6 \mathrm{ft}^{2}$, allowed in glovebox for cleaning.

- Maximum $50 \%{ }^{235} \mathrm{U}$ in uranium.

- During HEPA filter change out, all containers of fissionable material shall be removed from the glovebox.

- This glovebox must be category $\mathrm{C}$ for fire fighting. This designation allows mists or fogs during fire fighting. No directed solid streams of water are allowed to possibly move or upset containers of fissionable materials. 
HNF-6271, Rev. 0

Table 3-1 Parameters Controlled in Glovebox HC-18BS Operations

\begin{tabular}{|c|c|c|}
\hline Parameter & Controlled & Associated Limits \\
\hline Mass & yes & $\begin{array}{l}\text { Maximum } 2.5 \mathrm{~kg} \text { plutonium or plutonium fissile equivalent per } \\
\text { container }\end{array}$ \\
\hline Volume & yes & Maximum 2.3-liter containers \\
\hline Moderation & yes & $\begin{array}{l}\text { No fissionable solutions allowed. } \\
\text { Dry glovebox }\end{array}$ \\
\hline Interaction & yes & $\begin{array}{l}\text { Minimum 10-inch surface-to-surface spacing of containers } \\
\text { when outside of storage position. } \\
\text { Spills must be cleaned up before continuing operations. } \\
\text { Pre-operational inspection for possible obstructions in the } \\
\text { conveyor path. } \\
\text { A second operator is required to observe the movement of the } \\
\text { conveyor. }\end{array}$ \\
\hline Reflection & yes & $\begin{array}{l}\text { Dry glovebox } \\
\text { Maximum } 50 \mathrm{ml} \text { lubricants } \\
\text { Criticality drains present in Conveyors HC-1 and HC-5 }\end{array}$ \\
\hline Geometry & no & $\begin{array}{l}\text { Geometry not controlled. Process was analyzed using } \\
\text { cylinders having an } h / d=1 \text {. }\end{array}$ \\
\hline Enrichment/lsotopics & yes & Maximum $50 \%{ }^{235} \mathrm{U}$ in Uranium \\
\hline Homogeneity & no & Homogeneity not controlled. \\
\hline Density & no & $\begin{array}{l}\text { Density not controlled. A density of } 19.6 \mathrm{~g} / \mathrm{cm}^{3} \text { was used for } \\
\text { plutonium metal. For oxide, maximum }\left(11.46 \mathrm{~g} / \mathrm{cm}^{3}\right) \text { and } \\
\text { minimum }\left(0.2 \mathrm{~g} / \mathrm{cm}^{3}\right) \text { credible plutonium densities examined. }\end{array}$ \\
\hline Concentration & no & $\begin{array}{l}\text { Concentration not controlled. There are no fissionable solutions } \\
\text { allowed in this glovebox. }\end{array}$ \\
\hline Poisons & no & Poisons are not controlled. They are not used in this operation. \\
\hline
\end{tabular}




\subsection{Engineered Safety Features}

Credit has been taken for the following Engineered Safety Features as a primary means of preventing a criticality in Glovebox HC-18BS.

- Conveyor storage positions must be designated through the use of nominal 0.375 -inch-high pins.

- Conveyor storage positions shall have a nominal center-to-center spacing of 18 inches linearly along the conveyor.

- Pedestals shall have a minimum 1.25-inch-deep recess with a diameter adequate to maintain cylindrical containers in upright position in designated locations.

- Furnace boat holders shall have minimum 1.25-inch-high sides or sidepieces to maintain containers in designated locations.

- The Glovebox HC-18BS floor opens into the $\mathrm{HC}-1$ and $\mathrm{HC}-2$ conveyors such that solution will not accumulate in the glovebox but will flow out towards the conveyors.

- There are criticality drains in the $\mathrm{HC}-1$ and $\mathrm{HC}-5$ conveyors. The $\mathrm{HC}-2$ conveyor drains to the HC-5 conveyor.

- Glovebox HC-18BS is seismically qualified such that it will not collapse or allow container displacement during a seismic event.

- Structure supporting the HC-18BS conveyor is of sufficient construction to not collapse.

- The switch to activate the conveyor shall require the application of constant force for activation.

\subsection{METHODOLOGY}

Calculations supporting the development of limits and controls for oxide operations in Glovebox HC-18BS were performed using the general-purpose Monte Carlo code MCNP Version 4B. This code has been verified for use on a personal computer running DOS under the Windows-NT operating system (Lan, 1999) and validated on such machines for plutonium systems (Lan, 1999). A summary of this validation including a method for determining criticality safety limits for both metal and non-metal plutonium systems is included in Appendix C.

To determine the criticality safety limit for storage and transport operations in Glovebox HC-18BS, it is necessary to first determine the appropriate subcritical limit. The Hanford Procedure for the Criticality Safety Control of Fissionable Material (HNF-PRO-537) requires that the safety margin for calculations of complicated geometry systems be 0.05 . With a critical system having a $k_{\text {eff }}$ of 1.0 , the subcritical limit for complicated geometries is a $k_{\text {eff }} \leq 0.95$. A criticality safety limit was then calculated through modification of the chosen subcritical limit to account for calculational bias and uncertainties in the code and cross sections. As presented in Appendix C, assuming a one-sigma calculational uncertainty less than or equal to 0.002 results in criticality safety limits of 0.942 for non-metal systems and 0.932 for metal systems. 
HNF-6271, Rev. 0

\title{
5.0 CONTINGENCY ANALYSIS
}

\author{
5.1 Modeling Assumptions
}

\subsubsection{Glovebox HC-18BS}

Glovebox HC-18BS is modeled as a $4 \times 5$ array of containers spaced $34.2 \mathrm{~cm}$ (13.5 inches) center-to-center. This spacing is less than the closest separation that can occur between containers in the glovebox. The closest distance that can occur between containers is on the conveyor turn where the minimum center-to-center separation at the corners is about $37 \mathrm{~cm}$ (14.6 inches). Thus, the model of the closely spaced $4 \times 5$ array is conservative for all situations.

For all cases except for the examination of sprinkler activation, there is a $2.54-\mathrm{cm}$ (1-inch) close-fitting water reflector around each container in the array to account for the container body, plastics, worker hands, and other nearby reflective objects, such as rags and waste packages. This is a conservative modeling assumption as all containers in all storage positions will not be simultaneously moved by operators (i.e. hands will not be around all containers at once). In the interaction cases with three masses modeled together, the presence of hands around the upset is not reasonable. In the majority of these cases, a $0.635-\mathrm{cm}(0.25-\mathrm{inch})$ close fitting water reflector is modeled around the containers to account for the possibility of plastic bags surrounding the containers. No water reflector is modeled around the three-mass upset when the presence of plastic around the upset is not realistic.

Containers are modeled $19.05 \mathrm{~cm}$ (7.5 inches) above a $0.3175-\mathrm{cm}\left(0.125\right.$-inch) layer of $\mathrm{PuO}_{2}$ representing normal accumulation and inadvertent fissionable material spills on the glovebox floor. Just below this layer is a $3.0-\mathrm{cm}$ (1.2-inch), close-fitting water reflector to bound reflection from objects beneath the conveyor. Reflection from objects above the conveyor is bound by a $3.0-\mathrm{cm}$ (1.2-inch), close-fitting water reflector modeled $48.26 \mathrm{~cm}$ (19 inches) above the bottom of the container array. There is $30.48-\mathrm{cm}$-thick (12-inch-thick) water reflector, representing reflection from worker bodies at the glovebox walls, modeled $17.1 \mathrm{~cm}(6.73$ inches) from the center of the modeled containers on the outside of the array.

\subsubsection{Containers}

To eliminate container-specific controls, individual fissionable material containers (e.g. slip lid cans, polyjars) are not modeled. Alternately, the maximum unit mass, including anticjpated $10 \%$ overbatch, of $2.75 \mathrm{~kg}$ is modeled as a cylinder with an approximate $\mathrm{h} / \mathrm{d}=1$. Furnace boats were modeled in selected cases to show that the presence of rectangular geometry having the maximum allowed volume did not increase the multiplication of the system. The structure of the containers was not included. Unit masses under normal operations may be metal, oxide having an $H / X \leq 2$, oxide having an $H / X \leq 20$, or material having unrestricted moderation. Fissionable solutions are not allowed. A plutonium density of $11.46 \mathrm{~g} / \mathrm{cm}^{3}$ was used for most calculations. To account for the presence of plutonium hydroxide, material having a plutonium density of $0.2 \mathrm{~g} / \mathrm{cm}^{3}$ was also examined. The modeled dimensions of the unit masses are given in Table 5-1. 
Table 5-1 Dimensions of Modeled Containers

\begin{tabular}{|c|c|c|}
\hline \multirow{2}{*}{ Unit Mass Description ${ }^{\mathrm{a}}$} & \multicolumn{2}{|c|}{ Dimensions } \\
\cline { 2 - 3 } & $\begin{array}{c}\text { Radius } \\
(\mathrm{cm})\end{array}$ & $\begin{array}{c}\text { Height } \\
(\mathrm{cm})\end{array}$ \\
\hline $2.75 \mathrm{~kg}$ plutonium as oxide having an $\mathrm{H} / \mathrm{X}=2$ & 4.241 & 8.482 \\
\hline $2.75 \mathrm{~kg}$ plutonium as oxide having an $\mathrm{H} / \mathrm{X}=20 \mathrm{in} 2.35$ liters & 7.199 & 14.399 \\
\hline $2.75 \mathrm{~kg}$ plutonium as oxide having an $\mathrm{H} / \mathrm{X}=20$ & $\begin{array}{c}\text { Length: } 12.70 \\
\text { Width: } 27.94\end{array}$ & 6.61 \\
\hline rectangular geometry & 7.405 & 14.811 \\
\hline $2.75 \mathrm{~kg}$ plutonium as oxide having an $\mathrm{H} / \mathrm{X}=22$ in 2.55 liters & 7.154 & 14.307 \\
\hline $0.375 \mathrm{~kg}$ plutonium as oxide having an $\mathrm{H} / \mathrm{X}=160$ in 2.3 liters & 2.82 & 5.63 \\
\hline 2.75 kg plutonium $\mathrm{metal}$ & &
\end{tabular}

a. Cylindrical geometry, unless noted.

\subsubsection{Fissionable Material}

Plutonium Oxide The $H / X$ ratio of most plutonium oxide was modeled at 2 (dry), 20 (moderated), 22 (corresponding to $2.5 \mathrm{~kg}$ in 2.3 liters, the largest $\mathrm{H} / \mathrm{X}$ ratio with $2.5 \mathrm{~kg}$ plutonium), and 160 (corresponding to wet oxide having a plutonium density of $0.163 \mathrm{~g} / \mathrm{cm}^{3}$ ). Several additional calculations were performed for the normal case with oxide having an $\mathrm{H} / \mathrm{X}$ ratio between 22 and 160 to be assured that multiplication is inversely proportional to $H / X$ ratio when volume is restricted. Components of material densities in the $\mathrm{PuO}_{2}$ models are listed in Table 5-2. These were calculated using the theoretical densities of $11.46 \mathrm{~g} / \mathrm{cm}^{3}$ for $\mathrm{PuO}_{2}$ and $1.0 \mathrm{~g} / \mathrm{cm}^{3}$ for water.

Table 5-2 Densities Used in Modeling Plutonium Oxide

\begin{tabular}{|c|c|c|c|c|}
\hline \multirow{2}{*}{ Description } & \multicolumn{4}{|c|}{$\mathrm{H} / \mathrm{X}$} \\
\cline { 2 - 5 } & 2 & 20 & 22 & 160 \\
\hline $\mathrm{PuO}_{2}$ Volume Fraction & 0.568 & 0.116 & 0.107 & 0.016 \\
\hline Water Volume Fraction & 0.423 & 0.884 & 0.893 & 0.984 \\
\hline $\mathrm{PuO}_{2}$ Density $\left(\mathrm{g} / \mathrm{cm}^{3}\right)$ & 6.505 & 1.330 & 1.222 & 0.185 \\
\hline Plutonium Density $\left(\mathrm{g} / \mathrm{cm}^{3}\right)$ & 5.737 & 1.173 & 1.078 & 0.163 \\
\hline Water Density $\left(\mathrm{g} / \mathrm{cm}^{3}\right)$ & 0.432 & 0.884 & 0.893 & 0.984 \\
\hline Total Density $\left(\mathrm{g} / \mathrm{cm}^{3}\right)$ & 6.938 & 2.214 & 2.115 & 1.169 \\
\hline
\end{tabular}


Plutonium Metal Plutonium metal was modeled as $100 \mathrm{wt} . \%{ }^{239} \mathrm{Pu}$ with a density of $19.6 \mathrm{~g} / \mathrm{cm}^{3}$. Although plutonium metal may be present as individual items having a maximum credible mass of $2.5 \mathrm{~kg}$ or as small pieces in oxide resulting from incomplete oxidation in the muffle furnaces, analysis presented for the larger items will bound the presence of the small pieces in oxide.

Unrestricted Moderation Sludge (plutonium oxide having unrestricted moderation) may be present in Glovebox HC-18BS. Sludge was assumed to be plutonium oxide and water with an $H / X$ ratio $>20$. At the limits of $2.5 \mathrm{~kg}$ and 2.3 liters, the $H / X$ ratio is 22 . The $H / X$ ratio and mass will be inversely proportional at $H / X$ ratios greater than 22 as volume remains at 2.3 liters. Due to the volume restriction in Glovebox $\mathrm{HC}-18 \mathrm{BS}$, oxide having an $\mathrm{H} / \mathrm{X}=22$ is considered bounding for material having unrestricted moderation.

Plutonium Hydroxide Material introduced into Glovebox HC-18BS may have plutonium densities as low as $0.2 \mathrm{~g} / \mathrm{cm}^{3}$ for the case of plutonium hydroxide, the product resulting from the magnesium hydroxide process. At that density, the largest possible fissionable mass per container will be $\mathbf{4 6 0}$ grams and the largest possible $\mathrm{H} / \mathrm{X}$ ratio in the material under water ingress will be approximately 130. Calculations using oxide at an $H / X=160$ (plutonium density of $0.163 \mathrm{~g} / \mathrm{cm}^{3}$ ) bound credible densities of plutonium hydroxide.

\subsection{Normal and Base Cases}

The normal case for storage and transport of fissionable material in Glovebox HC-18BS was chosen to be a $4 \times 5$ array of containers spaced on $34.29-\mathrm{cm}$ (13.5-inch) centers. $A$ 0.3175 -cm-thick (0.125-inch-thick) layer of oxide having an $\mathrm{H} / \mathrm{X}=20$ was modeled $19.05 \mathrm{~cm}$ ( 7.5 inches) below the array. Containers were modeled in either a cylindrical geometry having an $\mathrm{h} / \mathrm{d}=1$ or in rectangular geometry similar to a furnace boat. Each container (unit mass) was modeled with a mass of $2.5 \mathrm{~kg}$ plutonium in metal or oxide with 2.54-cm-thick (1-inch-thick) water reflector around each container. The $\mathrm{H} / \mathrm{X}$ ratio for $2.5 \mathrm{~kg}$ oxide was 2,20 or 22 . Above an $\mathrm{H} / \mathrm{X}=22$, modeling $2.5 \mathrm{~kg}$ fissionable material would exceed the volume limit of 2.3 liters. Calculations were performed for $H / X$ ratios of $40,80,120,140$, and 160 at a volume of 2.3 liters to ascertain the intuitive assumption that multiplication and $H / X$ ratios are inversely proportional when volume is held constant. Oxide at an $\mathrm{H} / \mathrm{X}$ ratio of 20 was modeled in rectangular geometry to determine the effect of container geometry on the system multiplication. Rectangular geometry results in closer interaction and decreased height of unit masses in comparison with cylindrical geometry. A sketch of the rectangular geometry normal case is shown in Figure 5-1. The results of the normal cases are presented in Table 5-3. The largest multiplication ( $k_{\text {eff }}$ of $0.790 \pm 0.001$ ) occurs in case $18 \mathrm{bs}-n-51$, oxide having the maximum oxide mass $(2.5 \mathrm{~kg})$ and volume (2.3 liters) resulting in an $\mathrm{H} / \mathrm{X}=22$. 
HNF-6271, Rev. 0

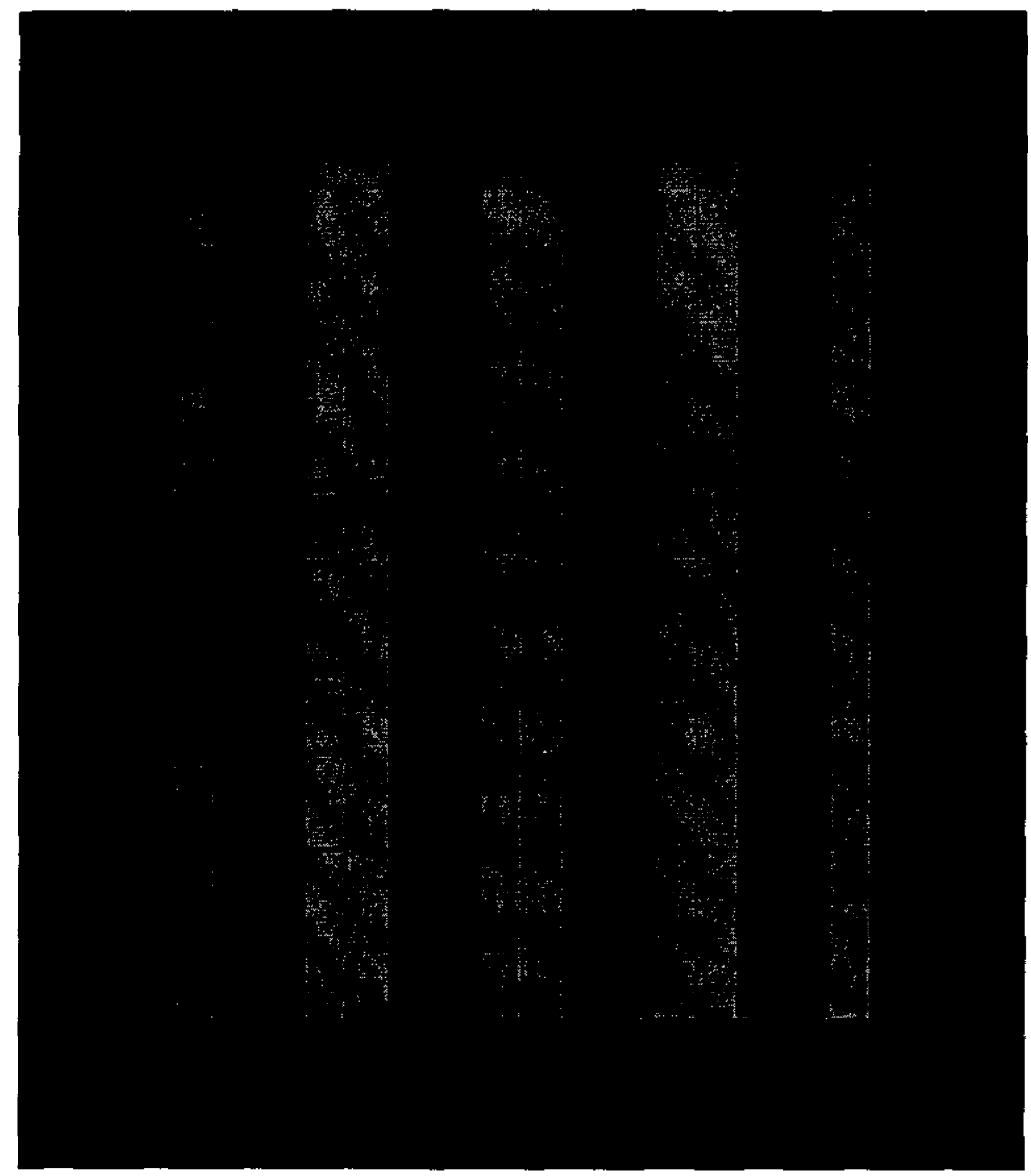

Figure 5-1 Plan View Sketch of Normal Case Model with Rectangular Geometry Containers 
Table 5-3 Results of MCNP Calculations for Normal Cases

\begin{tabular}{|c|c|c|c|}
\hline Case & Description & $k_{\text {eff }}$ & $1 \sigma$ \\
\hline $18 b s-n-11$ & $\begin{array}{l}4 \times 5 \text { array of rectangular unit masses }(2.5 \mathrm{~kg} \\
\text { plutonium as oxide having an } \mathrm{H} / \mathrm{X}=20) \text { modeled } \\
13.5 \text { inches center-to-center such that a minimal } \\
\text { amount of space exists between containers. } 12 \text {-inch } \\
\text { water reflection around sides of glovebox and } 1 \text {-inch } \\
\text { water reflection on top and bottom of glovebox as well } \\
\text { as around unit masses. } 0.3175-\mathrm{cm} \text {-thick layer of } \\
\text { plutonium oxide having an } \mathrm{H} / \mathrm{X}=20 \text { modeled } 19.05 \mathrm{~cm} \\
\text { below the container array. }\end{array}$ & 0.659 & 0.001 \\
\hline $18 b s-n-21$ & $\begin{array}{l}18 \mathrm{bs}-n-11 \text { with cylindrical unit masses of } 2.5 \mathrm{~kg} \\
\text { plutonium metal instead of rectangular unit masses. }\end{array}$ & 0.730 & 0.001 \\
\hline $18 b s-n-31$ & $\begin{array}{l}18 \mathrm{bs}-n-11 \text { with cylindrical unit masses of } 2.5 \mathrm{~kg} \\
\text { plutonium as oxide having an } \mathrm{H} / \mathrm{X}=2 \text { instead of } \\
\text { rectangular unit masses. }\end{array}$ & 0.552 & 0.001 \\
\hline $18 b s-n-41$ & $\begin{array}{l}18 \mathrm{bs}-n-11 \text { with cylindrical unit masses of } 2.5 \mathrm{~kg} \\
\text { plutonium as oxide having an } \mathrm{H} / \mathrm{X}=20 \text { instead of } \\
\text { rectangular unit masses. }\end{array}$ & 0.775 & 0.001 \\
\hline $18 b s-n-51$ & $\begin{array}{l}18 \mathrm{bs}-n-11 \text { with cylindrical unit masses of } 2.5 \mathrm{~kg} \\
\text { plutonium as oxide in } 2.3 \text { liters (resulting in an } \\
\mathrm{H} / \mathrm{X}=22 \text { ) instead of rectangular unit masses. }\end{array}$ & 0.790 & 0.001 \\
\hline $18 b s-n-52$ & $\begin{array}{l}18 b s-n-51 \text { with } 2.3 \text {-liter cylindrical unit masses of } \\
\text { plutonium as oxide having an } H / X=40 \text { (resulting in a } \\
\text { plutonium mass of } 1432 \mathrm{~g} \text { ) instead of } H / X=22 \text {. }\end{array}$ & 0.765 & 0.001 \\
\hline $18 b s-n-53$ & $\begin{array}{l}18 b s-n-51 \text { with } 2.3 \text {-liter cylindrical unit masses of } \\
\text { plutonium as oxide having an } H / X=80 \text { (resulting in a } \\
\text { plutonium mass of } 739 \mathrm{~g} \text { ) instead of } H / X=22 \text {. }\end{array}$ & 0.745 & 0.001 \\
\hline $18 b s-n-54$ & $\begin{array}{l}18 b s-n-51 \text { with } 2.3-\text { liter cylindrical unit masses of } \\
\text { plutonium as oxide having an } H / X=120 \text { (resulting in a } \\
\text { plutonium mass of } 498 \mathrm{~g} \text { ) instead of } H / X=22 \text {. }\end{array}$ & 0.733 & 0.001 \\
\hline $18 b s-n-55$ & $\begin{array}{l}\text { 18bs-n-51 with 2.3-liter cylindrical unit masses of } \\
\text { plutonium as oxide having an } H / X=140 \text { (resulting in a } \\
\text { plutonium mass of } 428 \mathrm{~g} \text { ) instead of } H / X=22 \text {. }\end{array}$ & 0.725 & 0.001 \\
\hline $18 b s-n-56$ & $\begin{array}{l}\text { 18bs-n-51 with 2.3-liter cylindrical unit masses of } \\
\text { plutonium as oxide having an } H / X=160 \text { (resulting in a } \\
\text { plutonium mass of } 375 \mathrm{~g} \text { ) instead of } H / X=22 \text {. }\end{array}$ & 0.723 & 0.001 \\
\hline $18 b s-n-57$ & $\begin{array}{l}18 b s-n-51 \text { with } 0.25 \text {-inch-thick water reflection around } \\
\text { containers. }\end{array}$ & 0.698 & 0.001 \\
\hline $18 b s-n-58$ & $18 b s-n-51$ with no water reflection around containers. & 0.665 & 0.001 \\
\hline
\end{tabular}


The base case for storage and transport of fissionable material in Glovebox HC-18BS included anticipated upsets in the normal model described above: the $4 \times 5$ modeled array of the normal case, the water-reflector around all containers, and the thin oxide layer. All containers were modeled with $2.75 \mathrm{~kg}$ fissionable material to represent the anticipated mass upset. An additional container was modeled between two and adjacent to one of the containers in the array to represent the anticipated spacing violation. To maximize multiplication, the spacing violation was modeled between two containers near the $30.48-\mathrm{cm}$-thick (12-inch-thick) water reflector at the glovebox walls. A sketch of a cylindrical geometry base case is given in Figure 5-2. Table 5-4 lists the results of MCNP calculations of the above-described base cases. The results of these base cases indicate a maximum $k_{\text {eff }}$ of $0.845 \pm 0.001$ for oxide having an $H / X=22$ which is less than the criticality safety limit of 0.942 for MCNP calculations of non-metal systems. Note that the volume per container is 2.55 liters for this model. The calculated $k_{\text {eff }}$ for metal unit masses is $0.836 \pm 0.001$ which is less than the criticality safety limit of 0.932 for MCNP calculations of metal systems.

Table 5-4 Results of MCNP Calculations for Base Cases

\begin{tabular}{|c|c|c|c|}
\hline Case & Description & $k_{\text {eff }}$ & $1 \sigma$ \\
\hline $18 b s-b-11$ & $\begin{array}{l}4 \times 5 \text { array of rectangular unit masses }(2.75 \mathrm{~kg} \\
\text { plutonium as oxide having an } \mathrm{H} / \mathrm{X}=20) \text { modeled } \\
13.5 \text { inches center-to-center such that a minimal } \\
\text { amount of space exists between containers. Additional } \\
\text { rectangular container modeled between two containers } \\
\text { in array (anticipated spacing violation). } 12 \text {-inch water } \\
\text { reflection around sides of glovebox and } 1 \text {-inch water } \\
\text { reflection on top and bottom of glovebox as well as } \\
\text { around unit masses. } 0.3175-\mathrm{cm} \text {-thick layer of } \\
\text { plutonium oxide having an } \mathrm{H} / \mathrm{X}=20 \text { modeled } 19.05 \mathrm{~cm} \\
\text { below the container array. }\end{array}$ & 0.705 & 0.001 \\
\hline $18 b s-b-21$ & $\begin{array}{l}18 b s-b-11 \text { with cylindrical unit masses of } 2.75 \mathrm{~kg} \\
\text { plutonium metal. }\end{array}$ & 0.836 & 0.001 \\
\hline $18 b s-b-31$ & $\begin{array}{l}18 \mathrm{bs}-\mathrm{b}-11 \text { with cylindrical unit masses of } 2.75 \mathrm{~kg} \\
\text { plutonium as oxide having an } \mathrm{H} / \mathrm{X}=2 \text {. }\end{array}$ & 0.600 & 0.001 \\
\hline $18 b s-b-41$ & $\begin{array}{l}18 b s-b-11 \text { with cylindrical unit masses of } 2.75 \mathrm{~kg} \\
\text { plutonium as oxide having an } \mathrm{H} / \mathrm{X}=20 \text {. }\end{array}$ & 0.826 & 0.001 \\
\hline $18 b s-b-51$ & $\begin{array}{l}\text { 18bs-b-11 with cylindrical unit masses of } 2.75 \mathrm{~kg} \\
\text { plutonium as oxide having an } \mathrm{H} / \mathrm{X}=22 \text {. Note that this } \\
\text { case is modeled with } 2.55 \text { liters. }\end{array}$ & 0.845 & 0.001 \\
\hline $18 b s-b-61$ & $\begin{array}{l}18 \mathrm{bs}-\mathrm{b}-11 \text { with random placement of rectangular and } \\
\text { cylindrical containers with } 2.75 \mathrm{~kg} \text { plutonium metal or } \\
\text { oxide of previously specified } \mathrm{H} / \mathrm{X} \text { ratios instead of } \\
\text { rectangular unit masses only. Anticipated spacing } \\
\text { violation included for all types of containers and } \\
\text { fissionable material. }\end{array}$ & 0.838 & 0.001 \\
\hline
\end{tabular}


HNF-6271, Rev. 0
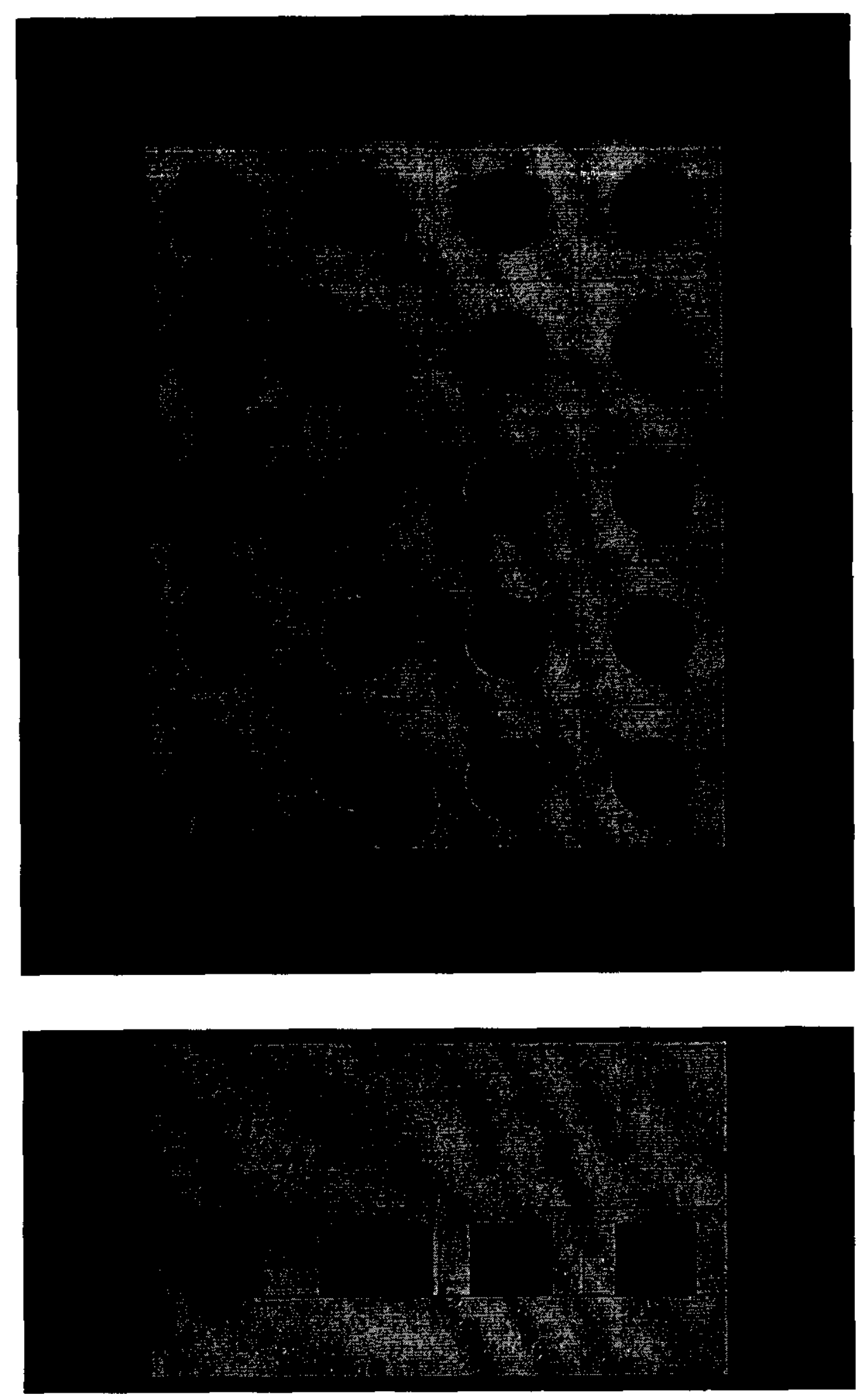

Figure 5-2 Plan and Elevation View Sketches of Base Case Model with Cylindrical Geometry Containers 
It is anticipated that metal and oxides will be present in the glovebox simultaneously. One calculation was performed to show that the random, mixed placement of metals and oxides in fixed storage locations in Glovebox HC-18BS would not have a multiplication greater than that for an array of one type material. For added conservatism, the spacing violation for each type material was included in the model. A sketch of this random, mixed placement model

$(18 b s-b-61)$ is shown in Figure 5-3. The $k_{\text {eff }}$ for case 18bs-b-61 $(0.838 \pm 0.001)$, given in Table 5-4, is less than the criticality safety limit of 0.932 for MCNP calculations of metal or mixed systems. It is also statistically the same as the result of base case $18 b \mathbf{b}-\mathbf{b}-21$ such that calculations modeling metal or credible volumes of oxide ( $2.75 \mathrm{~kg}$ in 2.3 liters) with an $\mathrm{H} / \mathrm{X}=20$ will bound the mixed array of metals and oxides at any $\mathrm{H} / \mathrm{X}$ ratio.

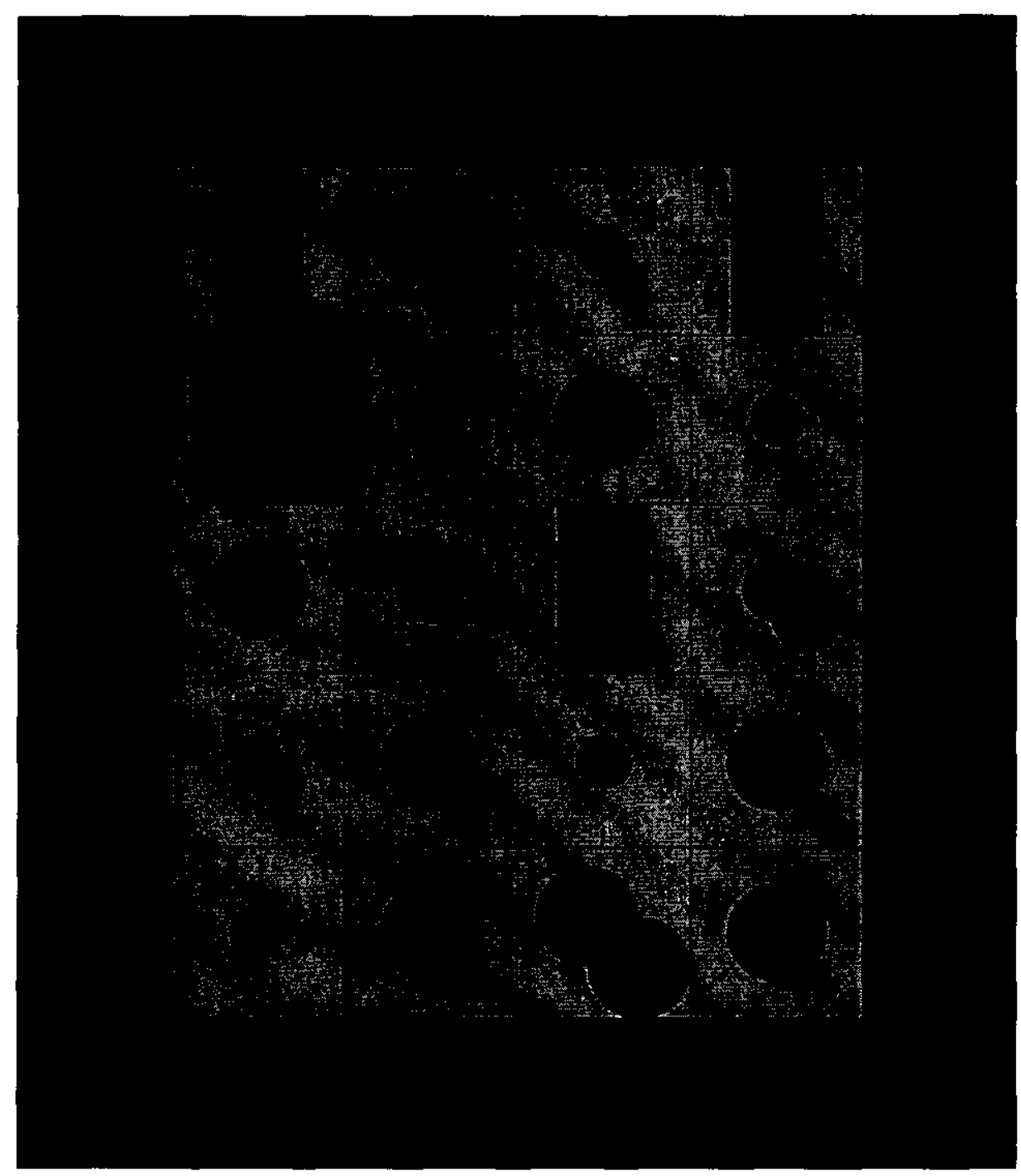

Figure 5-3 Plan View Sketch of Base Case Model with Mixed Container Array 
HNF-6271, Rev. 0

\subsection{Contingency Analysis}

\subsubsection{Hazards Assessment}

Identification of the contingencies for the operation described in Section 2 used a hazards assessment technique called a Preliminary Hazard Assessment (PHA). The goal of this effort is to identify deviations from the planned operation that may pose a challenge to criticality safety. Analysis is done as necessary to demonstrate that each identified condition satisfies the criticality safety criteria.

In a PHA, an interdisciplinary team uses a disciplined, systematic approach to identify hazards and deviations that could lead to undesirable consequences. Because the criticality safety concerns usually arise from deviations from the process design, an experienced team leader systematically guides the team through the planned operation. Off-normal events are identified and separated into likely and unlikely to happen during the duration of the operation. The likely events become part of the base case and the unlikely events are the contingencies. The detailed results of this assessment are presented in Appendix D.

\subsubsection{Loss of Spacing Between Sources of Fissionable Material}

Within Glovebox The normal situation for storage and transport of fissionable materials in Glovebox HC-18BS is to have up to 20 containers of fissionable material in fixed storage spaces on the conveyor. Each container is restricted to a maximum fissionable mass of $2.5 \mathrm{~kg}$ and a maximum volume of 2.3 liters. Fissionable material of any form except solution is allowed in any designated storage location. During operations in Glovebox HC-18BS, situations could arise that result in a spacing violation between containers. The most common spacing violation occurs when containers, not in fixed storage locations, are closer than 10 inches apart in the plane of the conveyor (horizontal) as when placing containers on or removing containers from the conveyor. A horizontal spacing violation could also occur if a container is placed on the conveyor between spacing pins. Although it is possible for containers to be situated on that section of conveyor, a row of spacing pins between storage locations helps preclude this action. A stacking violation would occur when containers are closer than 10 inches apart in the vertical direction. This could occur if an operator passed a container of fissionable material over another container of fissionable material located in a fixed storage location contrary to training and normal conduct of operations. A vertical spacing violation could also occur if a container of fissionable material is dropped onto the floor of the glovebox and rolls under other containers in fixed storage locations. It is not credible to have a stacking violation of greater than two containers.

A single spacing violation is considered likely; a spacing violation involving greater than three containers is not credible. This determination is based on the following independent, required controls with anticipated frequency shown in parentheses as developed during the PHA: inspection of glovebox for possible obstructions in conveyor pathway $(0.1)$, requirement for a second operator to observe conveyor movement (0.1), operational switch requiring constant force to initiate conveyor movement $(0.01)$, and pedestal and boat holder designs that adequately maintain containers in designated locations during conveyor movement $(0.01)$. A 
HNF-6271, Rev. 0

horizontal spacing violation of 2-3 containers is unlikely. This could occur through the placement of more than one container in a storage location or between storage locations, the dropping of more than one container onto the glovebox floor, or a displacement of containers due to an obstruction (e.g. glovebox glove inadvertently left on conveyor) while the conveyor is moving.

From Table 5-4, it can be seen that the highest results for $2.75 \mathrm{~kg}$ fissionable material in a maximum 2.3 liters were for metal and oxide having an $\mathrm{H} / \mathrm{X}=20$. The result for the calculation involving oxide having an $\mathrm{H} / \mathrm{X}=22$ modeled $2.75 \mathrm{~kg}$ fissionable material in 2.55 liters. Because no container is available with a volume greater than 2.3 liters, $2.75 \mathrm{~kg}$ oxide with an $\mathrm{H} / \mathrm{X}=22$ cannot be physically attained in this glovebox. Calculations involving anticipated spacing violations were performed with metal and oxide having an $\mathrm{H} / \mathrm{X}=20$.

Horizontal spacing violations can be considered as two adjacent unit masses. One horizontal spacing violation has been included in the base cases as an anticipated event. Three bounding calculations were performed to assess the effect of a horizontal spacing violation involving: multiple metal items, oxide at an $\mathrm{H} / \mathrm{X}=20$ modeled as multiple cylinders, and oxide at an $H / X=20$ modeled as one large cylinder having an $h / d=0.75$. The large cylinder was modeled with the largest practical $\mathrm{h} / \mathrm{d}$ ratio that physically would fit below the conveyor. The result of the one large cylinder will bound the scenario where the contents of three displaced open containers are collected in one large mound on the bottom of the glovebox. Each grouping was modeled in a single plane (no stacking) on the floor of the glovebox below another container on the conveyor. A $0.635-\mathrm{cm}(0.25$-inch) thickness of water was modeled around the metal and the oxide cylinders to account for any plastic that may be present around the fissionable material inside or outside of the container. No water reflection was modeled around the one large cylinder as it is not credible to have a mound of oxide that has the mass of three containers in plastic. The results of these three calculations are given in Table 5-5. The results of these cases indicate that the metal and single large oxide cylinder cases have the largest calculated $k_{\text {eff }}$ for the contingency of multiple, credible spacing violations. Both results are less than the criticality safety limits of 0.932 for MCNP calculations of metal systems or 0.942 for MCNP calculations of non-metal systems.

Vertical spacing violations are bound by the calculations for the above horizontal spacing violation (oxide) and for the contingency of additional fissionable material introduced into the glovebox (metal) as presented in Section 5.3.3. The calculational model for the horizontal spacing violation modeled the volume of three oxide containers directly below another container of oxide. This calculation is bounding for vertical spacing violations involving oxides (18bs-ou-44). The calculational model for the contingency of additional fissionable material modeled $5.5 \mathrm{~kg}$ metal in a cylinder having an $\mathrm{h} / \mathrm{d}=1$. This is a more conservative geometry than modeling a $2.75 \mathrm{~kg}$ metal cylinder directly above another similar metal cylinder and is bounding for the vertical spacing violation involving metal (18bs-om-22).

Outside Glovebox The normal situation for storage and transport of fissionable materials in Glovebox HC-18BS is to have up to 20 containers of fissionable material in fixed storage spaces on the conveyor. Each container is restricted to a maximum fissionable mass of $2.5 \mathrm{~kg}$ and a maximum volume of 2.3 liters. Fissionable material of any form except solution is allowed in any storage space. 
During operations in Glovebox HC-18BS, situations could arise that result in a spacing violation between unit masses in the glovebox and fissionable material outside the glovebox.

Transportation activities are governed by PFP limits for transportation of fissile material (CPS-Z-165-80110) which give the minimum spacing between items in transition and a glovebox or between a transportation array (e.g. hand carry) and glovebox as 18 inches. Vertical spacing violations are considered unlikely due to the height of the glovebox floor above the floor of the room (approximately 46 inches) and the height of the conveyor above the

Table 5-5 Results of MCNP Calculations for Interaction Events Within Glovebox

\begin{tabular}{|c|c|c|c|}
\hline Case & Description & $k_{\text {eff }}$ & $1 \sigma$ \\
\hline $18 b s-o u-25$ & $\begin{array}{l}\text { Same as base case } 18 \mathrm{bs}-b-21 \text { except that three } \\
\text { additional metal cylinders are modeled on the glovebox } \\
\text { floor } 19.05 \mathrm{~cm} \text { below the modeled array. The metal } \\
\text { cylinders are modeled adjacent to each other in a } \\
\text { single plane directly below another container (metal } \\
\text { cylinder) in a storage location. A } 0.625 \mathrm{~cm} \text { thickness of } \\
\text { water is modeled around the grouping of three } \\
\text { containers. }\end{array}$ & 0.924 & 0.001 \\
\hline $18 b s-o u-43$ & $\begin{array}{l}\text { Same as base case } 18 \mathrm{bs}-b-41 \text { except that three } \\
\text { additional oxide }(\mathrm{H} / \mathrm{X}=20) \text { cylinders are modeled on } \\
\text { the glovebox floor } 19.05 \mathrm{~cm} \text { below the modeled array. } \\
\text { The oxide cylinders are modeled adjacent to each } \\
\text { other in a single plane directly below another container } \\
\text { (oxide cylinder having an } \mathrm{H} / \mathrm{X}=20 \text { ) in a storage } \\
\text { location. A } 0.625 \mathrm{~cm} \text { thickness of water is modeled } \\
\text { around the grouping of three containers. }\end{array}$ & 0.902 & 0.002 \\
\hline $18 b s-o u-44$ & $\begin{array}{l}\text { Same as base case } 18 \text { bs-ou- } 43 \text { except that three } \\
\text { additional oxide }(H / X=20) \text { cylinders are modeled as } \\
\text { one large cylinder having an } h / d=0.75 \text {. The cylinder } \\
\text { does not have a surrounding thickness of water. }\end{array}$ & 0.921 & 0.002 \\
\hline
\end{tabular}

glovebox floor (approximately 8 inches). The effective height of the conveyor from the floor (approximately 54 inches) precludes a vertical spacing violation with material in wagons or material set on the floor. It also precludes a spacing violation with fissionable material rolling under the glovebox. There are no criticality concerns with the retrieval of such material due to the $0.3175-\mathrm{cm}$-thick (0.125-inch-thick) layer of fissionable material modeled on the glovebox floor, the 3.0-cm-thick (1.2-inch-thick) water reflector, and the $19.05 \mathrm{~cm}(7.5 \mathrm{~cm})$ distance of the glovebox floor from the conveyor.

Fissionable material in transition, as defined by the PFP limits for transportation for fissile material, may inadvertently be brought closer to the glovebox than the allowed 18 inches. Bringing fissionable material less than or equal to a container mass of $2.5 \mathrm{~kg}$ next to the glovebox window would be similar to a horizontal spacing violation within the glovebox and thus will be bound by the contingency of fissionable material interaction within the glovebox (multiple containers on the bottom of the glovebox). 
HNF-6271, Rev. 0

Interaction with material on the $\mathrm{HC}-1$ and $\mathrm{HC}-2$ conveyors will be bound by the contingency of additional fissionable material brought into the glovebox (Section 5.3.3). The calculational models for that contingency included an additional container of material next to the two containers modeled as an anticipated spacing violation. The additional container was modeled directly above the container in the storage location and adjacent to the container representing the anticipated spacing violation in all cases except the oxide. The two containers of oxide were modeled in a cylinder having a mass of $5.5 \mathrm{~kg}$ and an $\mathrm{h} / \mathrm{d}=1$ adjacent to the container representing the anticipated spacing violation. Base case 18bs-b-61 indicates that the distribution of material (metal, oxide at $\mathrm{H} / \mathrm{X}=20$, or unrestricted moderation) in Glovebox HC-18BS does not affect criticality safety as the array models random containers of material with several spacing violations. Information from these calculations indicates that material on the HC-1 and HC-2 conveyors does not adversely affect the criticality safety of operations in Glovebox HC-18BS.

HEPA Filters Another source of interaction between fissionable material within the glovebox could occur during the removal of the glovebox HEPA filter. The $8 \times 8 \times 6$ inches filter has an effective filter media of $6.5 \times 6.5 \times 5.375$ inches ( 3.72 liters) with no restriction on plutonium mass (CPS-Z-165-80250). Under normal operating conditions, plutonium will deposit on a nominally-reflected filter within the glovebox. Due to the filter media and voids, it has been determined that only $40 \%$ of the filter will contain fissionable material (Altschuler, 1981). A deposition of $5 \mathrm{~g} \mathrm{Pu} / \mathrm{cm}^{3}$ (the density of plutonium oxide at an $\mathrm{H} / \mathrm{X}=2$ ) in $40 \%$ of the filter is equivalent to a deposition of $2 \mathrm{~g} \mathrm{Pu} / \mathrm{cm}^{3}$ in $100 \%$ of the filter and results in $7440 \mathrm{~g}$ plutonium. The highest density of plutonium in oxide available at PFP is $5.5 \mathrm{~g} \mathrm{Pu} / \mathrm{cm}^{3}$. The minimum critical mass of a nominally-reflected plutonium oxide system at $2 \mathrm{~g} \mathrm{Pu} / \mathrm{cm}^{3}$ is $14.5 \mathrm{~kg}$; the minimum critical mass of a fully-reflected system at the same density is $9.6 \mathrm{~kg}$ (Carter, 1968). The deposition of $7440 \mathrm{~g}$ plutonium is therefore $51 \%$ of the nominally-reflected critical mass and $78 \%$ of the fully-reflected minimum critical mass. The above discussion describes an under-moderated system. The concentration for an optimally moderated plutonium-water system is $30 \mathrm{~g} \mathrm{Pu} / \mathrm{l}$. At this concentration, the filter holds approximately $112 \mathrm{~g}$ fissionable material. The minimum critical mass for a fully-reflected system at $30 \mathrm{~g} \mathrm{Pu} / \mathrm{l}$ is approximately $530 \mathrm{~g}$ (Carter, 1968) resulting in the filter containing $21 \%$ of a minimum critical mass at optimal moderation. The discussion for the filter at $5 \mathrm{~g} \mathrm{Pu} / \mathrm{cm}^{3}$ is bounding for all credible moderation in the filter.

Noting the above discussion, the remaining plutonium in a glovebox must be restricted to less than $22 \%$ of a minimum critical mass during HEPA filter change out. Under normal operations in Glovebox HC-18BS, it is likely that there will be greater than $22 \%$ of a minimum critical mass in the glovebox. Therefore, all containers of accountable fissionable material (tracked through inventory) must be removed from the glovebox during filter removal. Glovebox holdup is not considered accountable (although must be counted towards the total glovebox limit) and is not in a geometry conducive to providing a significant interaction effect (e.g. spread across the glovebox floor).

\subsubsection{Additional Fissionable Material Introduced into Glovebox}

The normal situation for storage and transport of fissionable materials in Glovebox HC-18BS is to have up to 20 containers of fissionable material in fixed storage spaces on the conveyor. Each container is restricted to a maximum fissionable mass of $2.5 \mathrm{~kg}$ and a maximum volume of 
2.3 liters. Fissionable material of any form except solution is allowed in any designated storage location. Additional fissionable material could be introduced into Glovebox HC-18BS if the mass of material entering the glovebox was incorrectly determined at the source glovebox or, in the case of metal, two items were inadvertently placed in the same container. Although considered unlikely due to the limits and controls implemented in the source gloveboxes, additional fissionable material could be introduced into the glovebox whereby the container mass limit will be violated.

All models were the same as the associated base case with $5.5 \mathrm{~kg}$ fissionable material modeled as one container. The anticipated spacing violation is modeled adjacent to this container having additional mass. The metal unit having an increased mass was modeled as a $5.5 \mathrm{~kg}$ cylinder having an $h / d=1$. The oxide units (both rectangular and cylindrical geometry) were modeled as $5.5 \mathrm{~kg}$ in 2.3 liters. To accommodate $5.5 \mathrm{~kg}$ in 2.3 liters, the $\mathrm{H} / \mathrm{X}$ ratio of the oxide was reduced. The results of the MCNP calculations for the inadvertent introduction of additional fissionable material into Glovebox HC-18BS are given in Table 5-6. The results of these cases indicate that the additional metal mass has the greatest effect on the system multiplication with an approximate $10 \%$ increase in $\mathrm{K}_{\text {eff }}$ over the metal base case, 18bs-b-21. The oxide cases both show minimal increases over their associated base case. All results are less than the criticality safety limits of 0.932 for MCNP calculations of metal systems or 0.942 for MCNP calculations of non-metal systems.

Table 5-6 Results of MCNP Calculations for a Mass Violation

\begin{tabular}{|c|c|c|c|}
\hline Case & Description & $k_{\text {eff }}$ & $1 \sigma$ \\
\hline $18 b s-o m-12$ & $\begin{array}{l}\text { Same as base case } 18 \mathrm{bs}-\mathrm{b}-11 \text { except that one } \\
\text { rectangular container is modeled with } 5.5 \mathrm{~kg} \text { fissionable } \\
\text { material. The } \mathrm{H} / \mathrm{X} \text { ratio has been reduced to } \\
\text { accommodate the additional mass in the fixed volume. } \\
\text { The anticipated spacing violation is modeled adjacent } \\
\text { to the container having additional mass. }\end{array}$ & 0.737 & 0.001 \\
\hline 18bs-om-22 & $\begin{array}{l}\text { Same as base case } 18 \mathrm{bs}-\mathrm{b}-21 \text { except that a metal } \\
\text { cylinder is modeled as a } 5.5 \mathrm{~kg} \text { cylinder having an } \\
\mathrm{h} / \mathrm{d}=1 \text {. The anticipated spacing violation is modeled } \\
\text { adjacent to the } 5.5 \mathrm{~kg} \text { metal cylinder. }\end{array}$ & 0.921 & 0.001 \\
\hline $18 b s-0 m-42$ & $\begin{array}{l}\text { Same as base case } 18 \mathrm{bs}-\mathrm{b}-41 \text { except that one } \\
\text { cylindrical container is modeled with } 5.5 \mathrm{~kg} \text { fissionable } \\
\text { material. The } \mathrm{H} / \mathrm{X} \text { ratio has been reduced to } \\
\text { accommodate the additional mass in the fixed volume. } \\
\text { The anticipated spacing violation is modeled adjacent } \\
\text { to the container having additional mass. }\end{array}$ & 0.839 & 0.001 \\
\hline
\end{tabular}


HNF-6271, Rev. 0

\subsubsection{Fire Scenario}

The normal situation for storage and transport of fissionable materials in Glovebox HC-18BS is to have up to 20 containers of fissionable material in fixed storage spaces on the conveyor. Each container is restricted to a maximum fissionable mass of $2.5 \mathrm{~kg}$ and a maximum volume of 2.3 liters. Fissionable material of any form except solution is allowed in any designated storage location. Glovebox HC-18BS is designated as a dry glovebox. There are no liquid lines running into or through the glovebox and no free liquids or solutions are allowed except for a maximum $50 \mathrm{ml}$ of lubricant. Damp rags are also allowed for cleanup. For there to be a possibility of water ingress into the glovebox, an event would need to occur that would break or melt the glovebox windows. It is unlikely that there will be a fire of such magnitude as to breach the glovebox containment.

Glovebox HC-18BS is open to both the HC-1 and HC-2 conveyors. The floor of the glovebox leading to these two conveyors has a minimal 0.25-inch lip. Solution on the Glovebox HC-18BS floor will drain into the $\mathrm{HC}-1$ and $\mathrm{HC}-2$ conveyors precluding the accumulation of liquid in the glovebox. The $\mathrm{HC}-1$ conveyor glovebox has a criticality safety drain and $\mathrm{HC}-2$ conveyor glovebox drains into the $\mathrm{HC}-5$ conveyor which has a criticality safety drain. Full flooding of Glovebox HC-18BS is not credible due to these engineered safety features. In the event of a fire main break elsewhere in the building, it is not credible for Room $228 \mathrm{C}$ and adjacent rooms to fill to a water depth greater than 54 inches and provide more than nominal reflection on the bottom of the glovebox.

In the event of a fire, sources of water would include that used by the fire department and overhead sprinklers in the room. This glovebox has been designated as Fire Fighting Category $\mathrm{C}$ that prohibits the use of streams of water that could rearrange containers of fissionable material within the glovebox. Therefore, this contingency will examine only water ingress into the glovebox and not the concurrent accumulation of all fissionable material in one location. The method of determining water density in a room due to sprinkler activation presented in Appendix $E$ can very conservatively be applied to Glovebox HC-18BS. There are two sprinkler heads above Glovebox HC-18BS. If it is assumed that all water from these two sprinkler heads enters Glovebox HC-18BS (having an internal volume of approximately $125 \mathrm{ft}^{3}$ ), a maximum water density of $0.0022 \mathrm{~g} / \mathrm{cm}^{3}$ results. If it is assumed that the entire volume of water from the fire hoses also enter the glovebox, a maximum water density in the glovebox of $0.0093 \mathrm{~g} / \mathrm{cm}^{3}$ results. It is therefore not considered credible for the water density with Glovebox HC-18BS to be greater than $0.1 \mathrm{~g} / \mathrm{cm}^{3}$ from sprinkler activation or the use of fogs or mists.

The MCNP model of this contingency was the same as the base cases with the void internal to the glovebox modeled as water with varying densities to simulate the introduction of sprinklers or mists. Unlike the base case, these fire/flooding contingency cases did not model the nominal reflection around each container. Calculations were performed with the limiting base cases of metal and oxide having an $\mathrm{H} / \mathrm{X}=20$.

Under water ingress, the $\mathrm{H} / \mathrm{X}$ ratio of dry oxide will increase until water molecules occupy all interstices in the oxide. At a plutonium density of $1 \mathrm{~g} / \mathrm{cm}^{3}$, this $\mathrm{H} / \mathrm{X}$ ratio is approximately 24 while at a plutonium density of $0.2 \mathrm{~g} / \mathrm{cm}^{3}$ (plutonium hydroxide), the resulting $H / X$ ratio is approximately 130 . Alternately, if water ingress exceeds the fixed volume of the container, that 
is the limiting $\mathrm{H} / \mathrm{X}$ ratio for the container. It was seen in Table 5-3 for the normal cases that, as expected, $2.5 \mathrm{~kg}$ fissionable material in oxide having an $\mathrm{H} / \mathrm{X}=22$ has a higher multiplication than oxide having an $H / X=20$. It was also seen that as the $H / X$ ratio increased beyond 22 , the constraint of the fixed volume lowered the effective mass per container and likewise the system multiplication. The analyzed mass was increased to $2.75 \mathrm{~kg}$ in the base cases of Table 5-4. At this mass, oxide having the more effective moderation of 22 occupied 2.55 liters and oxide at an $H / X$ ratio of 20 occupied a little over 2.3 liters (2.35 liters). Under water ingress to open containers in Glovebox HC-18BS, the bounding oxide has an $\mathrm{H} / \mathrm{X}$ ratio of 20 .

The results of the MCNP calculations for interstitial moderation and flooding cases are given in Tables 5-7 (metal) and 5-8 (oxide). The multiplication of the system increases with increasing water density in the glovebox. The limiting water density in the glovebox is approximately $0.75 \mathrm{~g} / \mathrm{cm}^{3}$ which is a factor of 7 greater than the highest credible sprinkler density in the glovebox. The calculated $k_{\text {eff }}$ for the models having a water density of $0.75 \mathrm{~g} / \mathrm{cm}^{3}$ is $0.906 \pm 0.001$ for the metal containers and $0.912 \pm 0.001$ for the oxide containers. These results are less than the criticality safety limits of 0.932 for MCNP calculations of metal systems and 0.942 for MCNP calculations of non-metal systems. As stated previously, full-flooding of the glovebox is not credible due to existing engineered safety features which prevent the accumulation of liquids in the glovebox.

Table 5-7 Results of MCNP Calculations for a Fire Event with Metal Items in Containers

\begin{tabular}{|c|c|c|c|}
\hline Case & Description & $k_{\text {eff }}$ & $1 \sigma$ \\
\hline $18 b s-a s-23$ & $\begin{array}{l}\text { Same configuration as base case } 18 \mathrm{bs}-\mathrm{b}-21 \text { except } \\
\text { that inside of glovebox is modeled with interstitial water } \\
\text { at } 0.1 \mathrm{~g} / \mathrm{cm}^{3}\end{array}$ & 0.770 & 0.001 \\
\hline $18 b s-0 s-24$ & $\begin{array}{l}\text { Same as 18bs-0s-23 except that interstitial water is at } \\
0.3 \mathrm{~g} / \mathrm{cm}^{3}\end{array}$ & 0.816 & 0.001 \\
\hline $18 b s-0 s-25$ & $\begin{array}{l}\text { Same as } 18 \mathrm{bs}-0 \mathrm{~s}-23 \text { except that interstitial water is at } \\
0.5 \mathrm{~g} / \mathrm{cm}^{3}\end{array}$ & 0.861 & 0.001 \\
\hline $18 b s-o s-26$ & $\begin{array}{l}\text { Same as } 18 b s-0 s-23 \text { except that interstitial water is at } \\
0.75 \mathrm{~g} / \mathrm{cm}^{3}\end{array}$ & 0.906 & 0.001 \\
\hline $18 b s-0 s-27$ & $\begin{array}{l}\text { Same as } 18 \mathrm{bs}-0 \mathrm{~s}-23 \text { except that interstitial water is at } \\
1.0 \mathrm{~g} / \mathrm{cm}^{3} \text { (full flooding) }\end{array}$ & 0.949 & 0.001 \\
\hline
\end{tabular}


HNF-6271, Rev. 0

Table 5-8 Results of MCNP Calculations for a Fire Event with Oxide at an $H / X=20$

\begin{tabular}{|c|l|c|c|}
\hline Case & \multicolumn{1}{|c|}{ Description } & Keff & $1 \sigma$ \\
\hline $18 b s-0 s-43$ & $\begin{array}{l}\text { Same configuration as base case 18bs-b-41 except } \\
\text { that inside of glovebox is modeled with interstitial water } \\
\text { at } 0.1 \mathrm{~g} / \mathrm{cm}^{3}\end{array}$ & 0.791 & 0.001 \\
\hline $18 b s-0 s-44$ & $\begin{array}{l}\text { Same as 18bs-0s-43 except that interstitial water is at } \\
0.3 \mathrm{~g} / \mathrm{cm}^{3}\end{array}$ & 0.840 & 0.001 \\
\hline $18 b s-0 s-45$ & $\begin{array}{l}\text { Same as 18bs-0s-43 except that interstitial water is at } \\
0.5 \mathrm{~g} / \mathrm{cm}^{3}\end{array}$ & 0.865 & 0.001 \\
\hline $18 b s-0 s-46$ & $\begin{array}{l}\text { Same as 18bs-0s-43 except that interstitial water is at } \\
0.75 \mathrm{~g} / \mathrm{cm}^{3}\end{array}$ & 0.912 & 0.001 \\
\hline $18 b s-0 s-47$ & $\begin{array}{l}\text { Same as 18bs-0s-43 except that interstitial water is at } \\
1.0 \mathrm{~g} / \mathrm{cm}^{3} \text { (full flooding) }\end{array}$ & 0.948 & 0.001 \\
\hline
\end{tabular}

\subsubsection{Seismic Scenario}

The normal situation for storage and transport of fissionable materials in Glovebox HC-18BS is to have up to 20 containers of fissionable material in fixed storage spaces on the conveyor.

Each container is restricted to a maximum fissionable mass of $2.5 \mathrm{~kg}$ and a maximum volume of 2.3 liters. Fissionable material of any form except solution is allowed in any designated storage location. The Plutonium Finishing Plant Final Safety Analysis Report (PFP FSAR, 1999) states that Glovebox HC-18BS is seismically qualified and the structure of the conveyor is of sufficient construction to not collapse in the event of a Design Basis Earthquake (DBE).

Although the glovebox and conveyor will not collapse under a DBE, the top of the glovebox may be breached. In addition, the fire suppression piping overhead will not remain intact and water ingress to the damaged glovebox is likely. The conveyor is assumed to be stationary (not being used to transport fissionable material) under the conditions of a DBE. As discussed in Section 5.3.4 for the fire scenario, under water ingress to open containers in Glovebox $\mathrm{HC}-18 \mathrm{BS}$, the bounding oxide has an $\mathrm{H} / \mathrm{X}$ ratio of 20 .

Separate calculations were performed with four closely-spaced metal or oxide containers modeled on the floor of the glovebox directly below another similar container on the conveyor. A water sprinkler density of $0.1 \mathrm{~g} / \mathrm{cm}^{3}$ (highest credible sprinkler water density as discussed in Section 5.3.4) was modeled in the glovebox. The results of these calculations are presented in Table 5-9. As expected, these results are very close to the appropriate criticality safety limits of 0.932 for MCNP calculations of metal systems (18bs-oe-24) and 0.942 for MCNP calculations of non-metal systems(18bs-oe-44). 
HNF-6271, Rev. 0

Table 5-9 Results of MCNP Calculations for Seismic Events

\begin{tabular}{|c|c|c|c|}
\hline Case & Description & $k_{\text {eff }}$ & $1 \sigma$ \\
\hline $18 b s-00-24$ & $\begin{array}{l}\text { Same as base case } 18 \mathrm{bs}-\mathrm{b}-21 \text { except that four metal } \\
\text { cylinders are modeled on the glovebox floor } 19.05 \mathrm{~cm} \\
\text { below the modeled array. The metal cylinders are } \\
\text { modeled adjacent to each other in a single plane } \\
\text { directly below another container (metal cylinder) in a } \\
\text { storage location. The mass of the metal cylinder was } \\
\text { reduced to } 2.5 \mathrm{~kg} \text { for this calculation. It is extremely } \\
\text { unlikely that a plutonium metal piece having a mass in } \\
\text { excess of } 2.5 \mathrm{~kg} \text { will be found at PFP. A sprinkler } \\
\text { density of } 0.1 \mathrm{~g} / \mathrm{cm}^{3} \text { was modeled in the glovebox. A } \\
\text { reflector was not modeled around the containers. }\end{array}$ & 0.921 & 0.001 \\
\hline $18 b s-0 e-44$ & $\begin{array}{l}\text { Same as base case 18bs-b-41 except that four } \\
\text { additional oxide }(H / X=20) \text { cylinders are modeled on } \\
\text { the glovebox floor } 19.05 \mathrm{~cm} \text { below the modeled array. } \\
\text { The oxide cylinders are modeled adjacent to each } \\
\text { other in a single plane directly below another container } \\
\text { (oxide cylinder having an } \mathrm{H} / \mathrm{X}=20) \text { in a storage } \\
\text { location. A sprinkler density of } 0.1 \mathrm{~g} / \mathrm{cm}^{3} \text { was modeled } \\
\text { in the glovebox. A reflector was not modeled around } \\
\text { the containers. }\end{array}$ & 0.918 & 0.001 \\
\hline
\end{tabular}

The results of the calculations presented above imply that the assembling of five containers under credible sprinkler densities may result in an unsafe condition. It is therefore necessary to show that the assembling of five containers during a seismic event is not credible.

Due to the physical structure supporting the conveyor, there are only two credible locations where five containers could be assembled. These are shown on Figure 5-4. As shown on this sketch, it is possible for six containers to accumulate in each location. With two credible locations, each having six containers, a total of twelve possible groupings of five containers results. It is assumed that each container will be dislodged from its pedestal at a frequency of 0.5 (A). To be assembled in one of the two locations, the container must fall in that direction. It is assumed that each container will fall directly to the floor of the glovebox at a frequency of 0.25 (B) to the right and 0.25 (B) to the left and will fall onto the conveyor at a frequency of 0.5 (C). The container will not stay on the conveyor. It is assumed that it will roll to the right at a frequency of 0.4 (D), to the left at a frequency of 0.4 (D) and remain on the conveyor at a frequency of 0.2 . Noting the above assumptions, it is determined that a container in a pedestal will be dislodged and fall to a location where it is credible to assemble five containers at a frequency of $0.225\left\{\left[\left(D^{*} C\right)+B\right]{ }^{*} A\right\}$. The frequency of five containers falling to that location is $0.225^{5}$. The frequency of assembling five containers in one of the credible locations in Glovebox HC-18BS is $\left(12^{-0.225^{5}}\right)$ or 0.007 . Noting that the FSAR states that it is extremely improbable (frequency of $10^{-4}$ ) of having a DBE sufficiently strong to dislodge a container from the pedestal, it is not credible to assemble greater than four containers in Glovebox HC-18BS during a seismic event. 
HNF-6271, Rev. 0

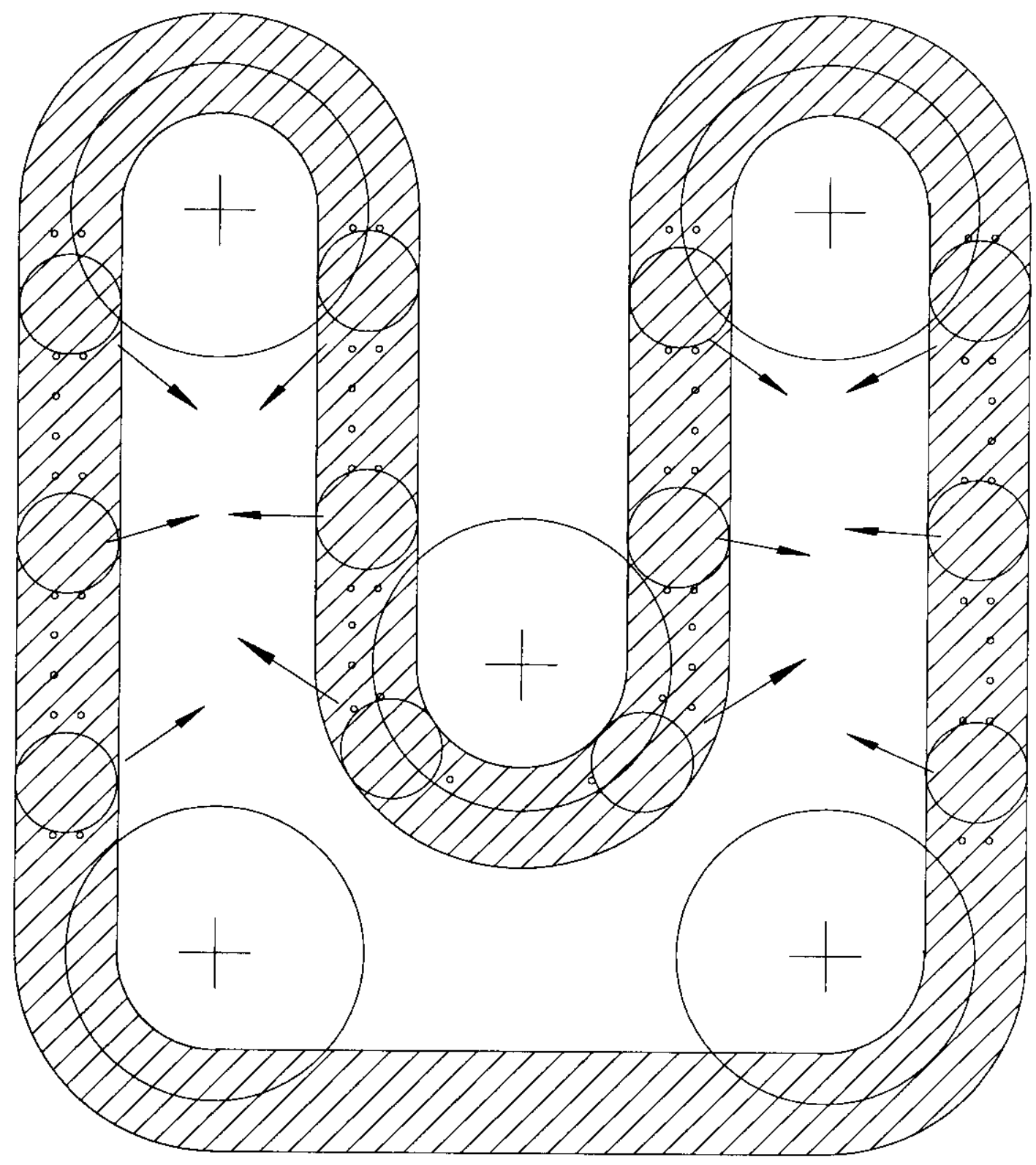

Figure 5-4 Sketch of Glovebox HC-18BS Conveyor Showing the Two Credible Locations Where Five Containers Can be Assembled 


\subsubsection{Additional Moderator or Reflector}

The normal situation for storage and transport allows damp rags for cleaning, a lubricant container with lubricant not to exceed $50 \mathrm{ml}$, and waste packages that may contain gloves, rags, and containers used to bag-in items. The above limitations on the introduction of moderator or reflector (damp rags and $50 \mathrm{ml}$ lubricant) appear in many limit sets for operations at PFP. The operators have been trained to these requirements in the performance of many different activities making a violation unlikely. In addition, a total of $6 \mathrm{ft}^{2}$ damp rags is a large volume for cleaning purposes in this glovebox whereby the introduction of greater than $6 \mathrm{ft}^{2}$ is considered unlikely. The lubricant is used for day-to-day upkeep of the conveyor. Major overhauls of the conveyor, those that potentially require greater than $50 \mathrm{ml}$ of lubricant, would necessitate that all fissionable material be removed. Therefore, the introduction of greater than $50 \mathrm{ml}$ lubricant into Glovebox HC-18BS while fissionable material is being transported or stored is unlikely. Not removing waste packages such that there is an accumulation of excess plastic in the glovebox is considered unlikely due to the lack of stationary surfaces on which to place a waste package. The introduction of additional waste packages into Glovebox HC-18BS is also considered unlikely as this glovebox is not a destination glovebox for waste packages.

Inherent in the operations that produce waste packages is the accumulation of a finite amount of fissile material within the packages. Inspection of recent assay data of low density items counted on the Nal counter shows that the majority of these packages contain only $1-10 \mathrm{~g}$ fissile material with all items showing a fissile content less than $40 \mathrm{~g}$. Appendix B documents this inspection and supports the conclusion that it is unlikely for the packages to contain greater than $50 \mathrm{~g}$ fissile material and not credible for the waste packages to contain greater than $100 \mathrm{~g}$ fissile material except in the event of a fissile item within the package.

This scenario of additional moderator or reflector present in the glovebox is bound by cases 18bs-0s-26 (metal) and 18bs-0s-46 (oxide) for a sprinkler water density (interstitial moderation) of 0.75 . It is not credible for the moderator from damp rags or waste packages to exceed this density. Full density water around the containers bounds the presence of any additional moderating or reflecting material brought into the glovebox such as the lubricant. The presence of the 0.3175 -cm-thick (0.125-inch-thick) layer of plutonium oxide at an $\mathrm{H} / \mathrm{X}=20$ on the bottom of the glovebox in the calculational model will bound any credible fissile mass present in the waste packages.

\subsection{REFERENCES}

Altschuler, S. J., 1981, CSAR 80-014: In-place Filters, WHC-SD-SQA-CSA-20231, Revision 0 Westinghouse Hanford Company, Richland, Washington.

Carter, R. D., G. R. Kiel, and K. R. Ridgway, 1968, Criticality Handbook, ARH-600, 1980 Revision, Atlantic Richfield Hanford Company, Richland, Washington, pages III.A.9(100)-4, III.A.9(100)-5.

CPS-Z-165-80010, 1999, General Limits, Revision D, Change 2, December 15, 1999, Criticality Prevention Specification, Plutonium Finishing Plant.

CPS-Z-165-80110, 1999, Transportation of Fissionable Materials, Revision D, Change 1, September 15, 1999, Criticality Prevention Specification, Plutonium Finishing Plant. 
HNF-6271, Rev. 0

CPS-Z-165-80250, 1999, In-Place Filters, Revision A, Change 2, November 17, 1999, Criticality Prevention Specification, Plutonium Finishing Plant.

Greenborg, J., 1999, CSER 98-008: Analysis of Plutonium Compounds as Applied to PFP Criticality Limits for Oxide and Metal Systems, HNF-3572, Revision 0, Fluor Daniel Hanford, Richland, Washington.

HNF-PRO-537, 1997, Criticality Safety Control of Fissionable Material, Revision 0, Fluor Daniel Hanford, Richland, Washington.

Lan , J. S., 1999, MCNP Version 4B Approval for Use Documentation and Authorized User List, FDNW-DSL-99-004, January 12, 1999, Fluor Daniel Northwest, Inc., Richland, Washington.

Marusich, R. M., 1999, CSER 99-003: Criticality Mass of Uranium as Compared to Plutonium Implications for PFP Processing Uranium, HNF-4436, Revision 0, Fluor Daniel Hanford, Richland, Washington.

PFP FSAR, 1999, Plutonium Finishing Plant Final Safety Analysis Report, HNF-SD-CP-SAR-021, Revision 1, January, 1999, Fluor Daniel Northwest, Inc., Richland, Washington,. 
HNF-6271, Rev. 0

This page intentionally left blank 
HNF-6271, Rev. 0

APPENDIX A

INDEPENDENT REVIEW COMMENTS AND CHECKLIST

A-1 
HNF-6271, Rev. 0

This page intentionally left blank 
HNF-6271, Rev. 0

Practice 1342901112

Publication Date 22Nov99

Attachment 02 - Sheet 1 of 1

FLUOR DANIGL NORTHWEST

\section{TECENICAL PEER REVIEWS}

\section{CHECKLIST FOR TECHNICAL PEER REVIEW}

Document Reviewed: HNF-6271, Rev. 0

Title:

CSER 00-008: Use of PFP Glovebox HC-18BS for Storage and Transport of

Fissionable Material

Author: $\quad$ D. G. Erickson \& C. A. Cise

Date: $\quad$ May 25, 2000

Scope of Review: · Full Document

Yes No* NA

[4] [ ] [ ]** Previous reviews complete and cover analysis, up to scope of this review, with no gaps.

[4 [ ] [ ] Problem completely defined.

[4 [ ] [ ] Accident scenarios developed in a clear and logical manner.

[4] [ ] [ ] Necessary assumptions explicitly stated and supported.

[4] [ [ ] Computer codes and data files documented.

[ [ [ ] [ ] Data used in calculations explicitly stated in document.

[ ] [ ] [4 Data checked for consistency with original source information as applicable.

[ 나 [ ] [ ] Mathematical derivations checked including dimensional consistency of results.

[ [ [ ] [ ] Models appropriate and used within range of validity or use outside range of established validity justified.

[ ] [ ] [4 Hand calculations checked for errors. Spreadsheet results should be treated exactly the same as hand calculations.

[4 [ ] [ ] Software input correct and consistent with document reviewed.

[4 [ ] [ ] Software output consistent with input and with results reported in document reviewed.

[4 [ ] [ ] Limits/criteria/guidelines applied to analysis results are appropriate and referenced. Limits/criteria/guidelines checked against references.

[ 5 [ ] [ ] Safety margins consistent with good engineering practices.

[4 [ ] [ ] Conclusions consistent with analytical results and applicable limits.

[ $[$ [ ] [ ] Results and conclusions address all points required in the problem statement.

[ [ [ ] [ ] Format consistent with applicable guides or other standards.

$[$ [ [ ]** Review calculations, comments, and/or notes are attached.

[ 4 [ ] [ ] Document approved (for example., the reviewer affirms the technical accuracy of the document).

K. N. Schwinkenderf Keulu N. Schwinkendor f Reviewer: (Ptinted and Signed) T. h. Schivin hand/2

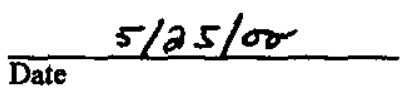

* All "NO" responses must be explained below or on an additional page.

** Any calculations, comments, or notes geacrated as part of this review should be signed, dated and attached to this checklist. The material should be labeled and recorded in such a manner as to be intelligible to a technically qualified third party.

NUCLEAR ENGINETRING 
Independent Reviewer Comments: K. N. Schwinkendorf, 05/25/2000

This CSER was independently peer reviewed by K. N. Schwinkendorf, a qualified Criticality Safety Specialist in the Criticality and Shielding group of Fluor Federal Services. This technical review covered all aspects of this CSER. As shown in the Independent Review Checklist, this CSER has been reviewed with no gaps.

The construction of base case models using bounding, abnormal but credible conditions was well documented and is conservative. No single contingency violated the criticality safety criterion. The only exception was full-density interspersed water moderation, and this was shown to be incredible.

This reviewer concurs with the conclusion of this CSER, that operation of glovebox HC-18BS satisfies double contingency.

MCNP4B inputs and outputs were checked for consistency and reasonableness. Input files were checked for material specifications and geometry. The $k_{\text {eff }}$ values given in the report were verified against output files. Output files were reviewed for adequate convergence.

Finally, minor editorial comments were suggested, and were incorporated into the final version of the CSER. 
HNF-6271, Rev. 0

\title{
MoHr and Associates ENGINEERING - ANALYSIS - CONSULTING
}

\author{
1440 AGNES STREET \\ RICHIAND, WA 99352 \\ s09-940-0941 \\ $509-946-2240$ \\ FAX 509-946-4395
}

May 23, 2000

To:

Hans Toffer, David G. Erickson and Carol A. Cise, Fluor Federal Services, Inc.

From: $\quad$ Warner A. Blyckert

Subject: Review of CSER 00-008: Use of PFP Glovebox HC-18BS for Storage and Transport of Fissionable Material (HNF-6271, Rev. 0)

Document HNF-6271, Rev. 0, CSER 00-008: Use of Glovebox HC-18BS for Storage and Transport of Fissionable Material, was given an independent technical review. The approach to analyzing the proposed operations and the technique used were checked for suitability, accuracy and completeness.

The material which was reviewed consisted of the draft of the final report. The input and output files of the computer calculations were not reviewed during the review and the results were accepted as recorded in the report. The correctness and results of the validation effort were not reviewed so that the limits used in the CSER were not checked for accuracy nor applicability other than the narrative account of the approach which is reported in an appendix. The referenced CSERs and CSARs were not reviewed and the statements concerning their results were accepted without verification.

Responses to the reviewer's comments have been incorporated into the final report and adequately address the comments.

The reviewer agrees with the conclusion of the report that the proposed storage and transport operations in Glovebox HC-18BS may be safely conducted with the postulated material under the limiting conditions of operation.

Very truly yours,

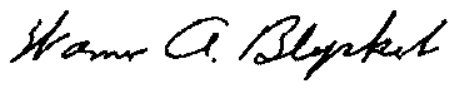

Warner A. Blyckert 
HNF-6271, Rev. 0

This page intentionally left blank 
HNF-6271, Rev. 0

\section{APPENDIX B}

WASTE PACKAGE DATA

B-1 
HNF-6271, Rev. 0

This page intentionally left blank

B-2 
HNF-6271, Rev. 0

Dobbin, Kenneth D

$\begin{array}{ll}\text { From: } & \text { Ramble, Alan L } \\ \text { Sent: } & \text { Friday, November 19, 1999 3:09 PM } \\ \text { To: } & \text { Dobbin, Kenneth D } \\ \text { Cc: } & \text { Shaw, Maria E; Ramble, Alan L } \\ \text { Subject: } & \text { FW. G Pu in Waste Packages }\end{array}$

Ken, some data. More to follow. Al

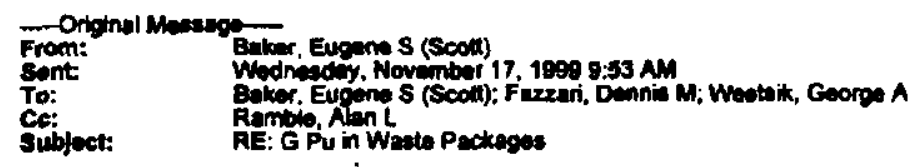

Al has asked for a littie more information on what I have mentioned below in my earlier message.

There are two calibration curves that everything in ITC's are counted on.

- $\quad 25$ lbs., low density, both combustible and non-combustible (\#1)

- dense items or ITC's > 25 Ibs. (*2)

Looking at the data below, and classifying the 100 analyses (down from $102 \mathrm{~d}$ ie to some confusion in classification), the information can be grouped as follows:

\begin{tabular}{|c|c|c|}
\hline $\begin{array}{l}\text { Pu Content } \\
0-2 \text { grams } \\
2-10 \text { grams } \\
10-20 \text { grams } \\
20-30 \text { grams } \\
30-40 \text { grams } \\
40+\text { grams } \\
\text { Average value } \\
\text { High value }\end{array}$ & $\begin{array}{c}\text { \# ofitams counted by } 11 \\
53 \\
15 \\
1 \\
0 \\
1 \\
0 \\
2.16 \\
35.43\end{array}$ & $\begin{array}{l}\text { \# of tems counted by } \$ 2 \\
15 \\
9 \\
2 \\
1 \\
9 \\
3 \\
9.82 \\
68.53\end{array}$ \\
\hline
\end{tabular}

Based on this information, if you make the assumption that all of the items that would be considered "waste packages" are less than 25 lbs. and do not contain any dense metal items, your CSER evaluation of a waste package containing 2 grams as the "normal and base case condition" would be valid. You would also be correct in pointing out the 30 gram item identffied as a contingency. I would feel a hittle uncomfortable in stating that item to be the "Only contingency identified ....in assay data history. " however.

Scott

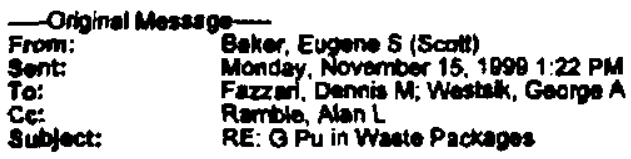

I agree with the comments Dennis makes. I have also looked at the ITC results from the Nal counter for $6 / 1 / 99$ to the present, and can make the following observations:

$\begin{array}{ll}\text { Pucontent } & \text { Ofitams } \\ 0-2 \text { grams } & 69 \\ 2-10 \text { grams } & 24 \\ 10-20 \text { grams } & 3 \\ 20-30 \text { grams } & 1 \\ 30-40 \text { grams } & 2 \\ 40+\text { grams } & 3 \\ \text { Total } & 102\end{array}$

Average gram Pu value, all items - 4.5 grams

Average gram value, $0-10$ gram items (93 items) - 1.7 grams

Highest value for a single item - 68.53 grams

If you look only at items counted 9/1/99 to the present, the numbers change to: 
HNF.6271, Rev. 0

$\begin{array}{ll}\text { Pucontent } & \text { Hofitems } \\ \text { O-2 grams } & 21 \\ 2-10 \text { grams } & 15 \\ 10-20 \text { grams } & 1 \\ 20-30 \text { grams } & 1 \\ 30-40 \text { grams } & 2 \\ 40+\text { grams } & 1 \\ \text { Total } & 41\end{array}$

Average gram Pu vatue, all items - 6.0 grams

Average gram value, 0 - 10 gram items ( 36 items) - 2.4 grams

Highest value for a single item - 45.29 grams

Scott

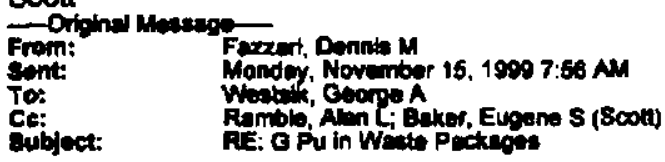

There is no way I can determine what items were waste, scrap, sludge, etc... and, for that matter, what the average or maximum gram quantity might be. Operations does not identify items well and, as a result, the information you requested cannot be easily identifed. Most waste items are assayed on the Nal counter - which is Scott's (Baker) responsibility

I'm not sure where the $\mathbf{3 0}$ gram maximum came from. Based upon the measurement results l've reviawed, I doubt any reasonable statement can be made regarding average or maximum quantities.

Similar comments below.

Dennis

\begin{tabular}{|c|c|}
\hline 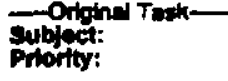 & $\begin{array}{l}\text { GPu in Whate Packeone } \\
\text { Normal }\end{array}$ \\
\hline Dourt datar: & $\begin{array}{l}\text { Mon 11/15/1999 } \\
\text { Mon 11/151999 }\end{array}$ \\
\hline Shatua: & Not Stanted \\
\hline $\begin{array}{l}\text { Total work: } \\
\text { Aetud work: }\end{array}$ & $\begin{array}{l}\text { O hours } \\
\text { O hours }\end{array}$ \\
\hline
\end{tabular}

Plesese look in your vast memories or backlog of papers and let AI Ramble (with a copy to me) know by COB 11/15 if the average package quantity and the upper limit quantity are reasonable. Thank you.

\section{George}

George coukd you confirm the $\mathbf{3 0}$ gram number. Mike this is the process upset for waste packages we are considering in glovebox 211.

\section{Al Ramble}

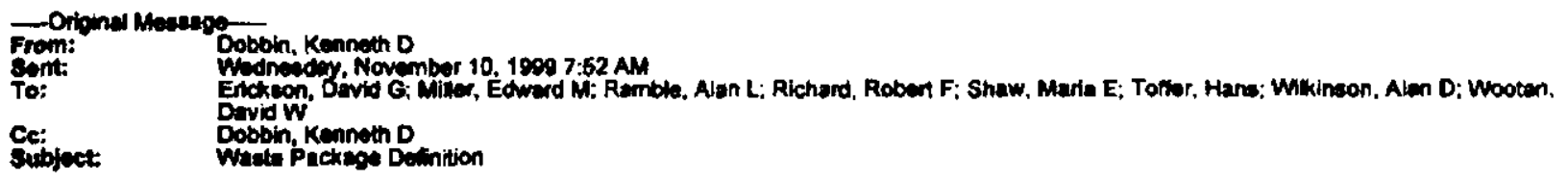

Yesterday atemoon, we agreed upon the definition of a waste package to be used for CSERs associated with plutonium stabilization. The purpose of this message is to put that definition in writing and allow meeting participants a chance to comment. Unless i hear back today, the following definition will be used in these CSERs.

Glovebox waste is generated from PFP phutonium stabilization operations. It ts placed into plastic bags, transferred to Isolated Transport Containers, assayed, then placed into waste drums. This waste consists of gloves, rags, containers used to port-in items, etc. Prior to bagging, al noticable fissile material is brushed from these items [Fazzeri, Dennis M] I doubt this is true. I suspect the items are bagged and removed without brushing. and no fissile item is intentionally placed 
HNF-6271, Rev. 0

In these packages. Inspection of historical assay data show that normally these packeges contain only 1 or 2 grams of fissile material. IFazzan, Dennis MI No. I don't belleve there is any technical basis for this statement The greatest quantity found was one package that contained 30 grams of plutonium. [Fazzarl, Dennls MI Where did this value come from?

This CSER evaluation includes a waste package containing 2 grams as the normal and base case conditions. For this fissile loading, the package acts as a reflector and possibly adds interspersed moderation between containers, however, no mons so than already modelad in the base case. The only contingency identified is the excess fissile mass condition of 30 grams that was found once in the assay data history. (Fezzeri, Dennis M) ??? Errors asspciated with loading fissile objects into the waste package are not inchuded because if loaded in this glovebox they would be already covered by ovaluation, and if the loeding error occurs in other gloveboxes and transferred to this glovebox, then two errors would be required. Waste packages are not normally brought from other gloveboxes to this one. 
HNF-6271, Rev. 0

This page intentionally left blank 
HNF-6271, Rev. 0

APPENDIX C

MCNP COMPUTER CODE VALIDATION

C-1 
HNF-6271, Rev. 0

This page intentionally left blank 


\section{C.1 VALIDATION PROCEDURE}

Validation of the computer code methods in this analysis consisted of testing the code and neutron cross sections on calculations of known critical configurations. These benchmark experiments have fissile isotopes in systems similar to that evaluated by this CSER. The computed and measured $k_{\text {etr }}$ for the benchmark configurations were compared to establish a bias that includes the uncertainty in the calculational methods. A bias-adjusted $k_{\text {eff }}\left(k_{\text {eff }}{ }^{\dagger}\right)$ for the benchmark systems was defined to include both the deviations of the calculated from the measured $k_{\text {eft }} s$, and experimental and calculational uncertainties along with the spread in the ability of the computer code to calculate similar systems. In addition, criticality safety criteria require that the $\mathrm{k}_{\text {eff }}{ }^{\dagger}$ not exceed the established $\mathrm{k}_{\text {eff }}$ safety limit at the $95 \%$ confidence level.

This method is illustrated in Figure C.1. Critical is defined as a $k_{\text {eff }}$ of unity, adjusted by the bias established from the comparison of calculations with benchmarks. This bias includes the mean difference between the calculated and measured benchmark $k_{\text {efft }}$ and a 1.645 multiplier on the standard deviation of the calculated $k_{\text {eff }}$ to have $95 \%$ confidence that $95 \%$ of the population is below this value. The bias is combined with the safety margin of 0.05 (a safety limit that $k_{\text {eff }}{ }^{\dagger}$ must be less than or equal to 0.95 ) to compare with the calculated value and statistical uncertainty of the computer calculated $k_{\text {eff }} S$ of this CSER analysis. The calculated target $k_{\text {eff }}$ is established by adding the bias, 0.05 , and 1.645 times the one-sigma uncertainty of the calculated $k_{\text {eff }}$ for the particular CSER analysis and subtracting that value from 1.0. For the analyses in this CSER, all the computer statistical uncertainties were less than \pm 0.002 , so this value was used to set the target $k_{\text {effS }}$ as described in Section C.2.

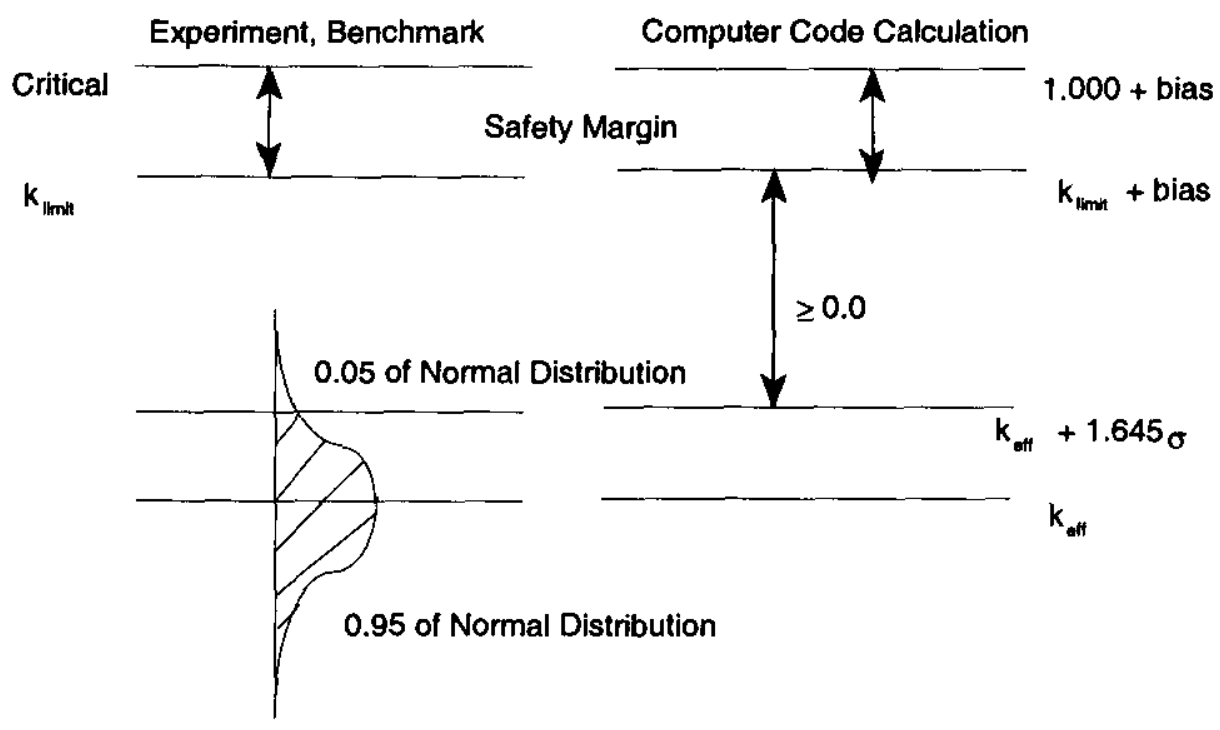

Figure C.1. Logic of Validation Procedure 


\section{C.2 GENERIC VALIDATION FOR PLUTONIUM SYSTEMS}

A report by J. S. Lan, MCNP Version 4B Approval For Use Documentation \& Authorized User List (Lan 1999), presents the results of calculations used to determine a generic bias for plutonium configurations, as encountered in the Plutonium Finishing Plant. One hundred and forty three benchmark experiments were calculated. There were different material types that were considered in the plutonium validation calculations:

- Plutonium metal,

- Plutonium oxide,

- Plutonium solutions,

- Plutonium solutions with cadmium (a neutron poison),

- Water and polystyrene moderators, and

- Water, plexiglass, paraffin, polyethylene, and steel and concrete reflectors

The safety criteria for future calculations on undetermined systems requires that the lower tolerance limit $b_{L}$ is calculated such that there is $95 \%$ confidence that $95 \%$ of the population is below that limit. This is expressed by the following formula:

$$
b_{L}=k_{a v g}-k_{b} \cdot \sigma_{a v g}
$$

where:

$b_{\mathrm{L}} \quad=$ lower tolerance limit for $95 \%$ confidence that $95 \%$ of population is below this limit,

$k_{\text {avg }}=$ the average of the $k_{\text {eff }}$ 's calculated by MCNP 4B,

$\mathrm{k}_{\mathrm{b}}=$ a multiplier found from statistical tables for non-central t-distribution, and depends on number of degrees of freedom, and

$\sigma_{\text {avg }}=$ standard deviation of the MCNP $k_{\text {eff }}$ 's.

Bias is calculated by the following formula:

$$
\text { bias }=b_{L}-k_{\text {crit }}
$$

where:

$k_{\text {crit }}=$ the average of the $k_{\text {eff }}$ 's for the critical experiments; for the plutonium experiments $k_{\text {crit }}=1.000$.

The bias for the plutonium metal group was significantly different than for all other groups. For this reason, it was concluded that separate bias values for metal and non-metal groupings would be appropriate. The lower tolerance limit for the metal group (17 benchmark critical experiments) was calculated at 0.9884 . The lower tolerance limit for the non-metal group (126 benchmark critical experiments) was calculated to be 0.9991 . These lower tolerance limits yielded the bias appropriate for each material category:

- Plutonium metal

- Plutonium non-metal bias is -0.0116 ,

bias is -0.0009 . 
For conservatism, these calculated biases were recommended to be increased to:

- Plutonium metal recommended bias is -0.0150 ,

- Plutonium non-metal recommended bias is -0.0050 .

The safety criteria for future calculations on undetermined systems requires that $k_{\text {eff }}{ }^{\dagger}$ (bias-adjusted $k_{\text {eff }}$ ) does not exceed 0.95 at the $95 \%$ confidence level. This is expressed by the following:

and

$$
\mathrm{k}_{\text {eff }}^{\dagger}=\mathrm{k}_{\text {eff }}-\text { bias }+1.645^{\star} \sigma
$$

$$
k_{\text {eff }}^{\dagger} \leq k_{\text {limit }}
$$

Therfore,

or

$$
k_{\text {eff }}-\text { bias }+1.645^{\bullet} \sigma \leq k_{\text {limit }}
$$

$$
k_{\text {eff }} \leq k_{\text {limit }}+\text { bias }-1.645^{\bullet} \sigma
$$

where:

$$
\begin{aligned}
& k_{\text {eff }}=k_{\text {eff }} \text { value given by MCNP 4B calculation for system in question, } \\
& \text { bias }=-0.015 \text { for Pu metal, and }-0.005 \text { for Pu non-metal systems, } \\
& 1.645=a \text { constant number of standard deviations for } .95 \text { of the distribution for a } \\
& \text { one-sided standard normal distribution } \\
& \sigma \quad=\text { standard deviation given by MCNP 4B calculation for system in question, and } \\
& \mathrm{k}_{\text {limit }}=0.95 \text { for plutonium systems, generally. }
\end{aligned}
$$

$k_{\text {limit }}$ is generally taken to be 0.95 for plutonium systems.

For a standard deviation $(\sigma)$ of 0.002 or less, the $k_{\text {eff }}$ for plutonium metal systems must be:

$$
\begin{gathered}
k_{\text {eff }}-(-0.015)+1.645 \cdot 0.002 \leq 0.95 \\
k_{\text {eff }} \leq 0.932
\end{gathered}
$$

On this basis, it is determined that the true $\mathrm{k}_{\mathrm{eff}}\left(\mathrm{k}_{\mathrm{eff}}^{\dagger}\right)$ of an analyzed configuration with plutonium will not exceed 0.95 with a $95 \%$ confidence level for plutonium metal systems if the calculated value ( $k_{\text {eft, }}$ and $\left.\sigma \leq 0.002\right)$ is limited to a maximum value of 0.932 . 
HNF-6271, Rev. 0

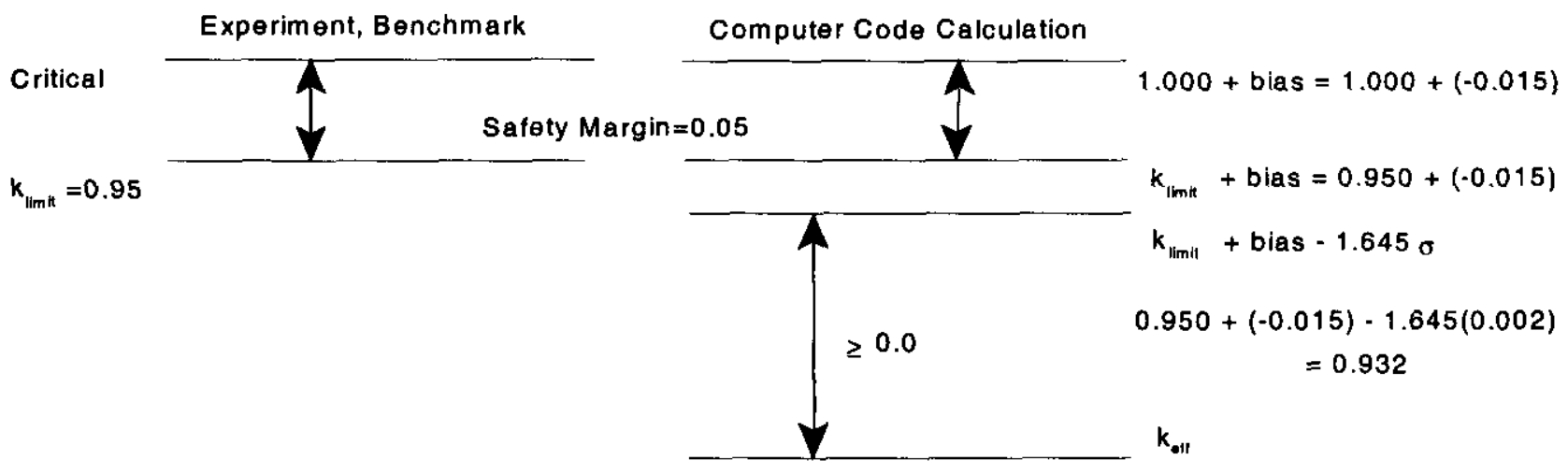

Figure C.2. Implementation of Validation Procedure for Plutonium Metal Systems

For a standard deviation $(\sigma)$ of 0.002 or less, the $k_{\text {eff }}$ for non-metal systems must be:

$$
\begin{gathered}
k_{\text {eff }}-(-0.005)+1.645 \cdot 0.002 \leq 0.95 \\
k_{\text {eff }} \leq 0.942
\end{gathered}
$$

On this basis, it is determined that the true $k_{\text {eff }}\left(k_{\text {eff }}{ }^{\dagger}\right)$ of an analyzed configuration with plutonium will not exceed 0.95 with a $95 \%$ confidence level for plutonium non-metal systems if the calculated value ( $k_{\text {eff, }}$ and $\sigma \leq 0.002$ ) is limited to a maximum value of 0.942 .

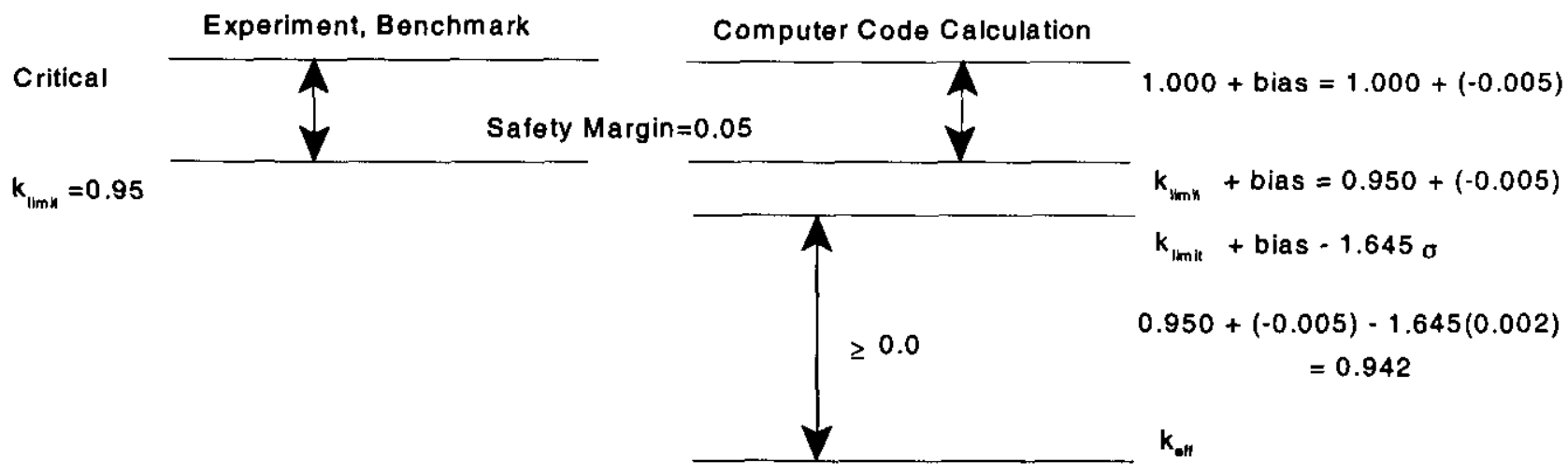

Figure C.3 Implementation of Validation Procedure for Non-Metal Plutonium Systems 
HNF-6271, Rev. 0

\section{C.3 VALIDATION OF MCNP 4B}

The valigation of the MCNP4B code on the new computing system, Intergraph ${ }^{T M}{ }^{\top}, 400 / 450 \mathrm{MHz}$ Pentiumfli, personal computers was documented in Lan, 1999. The essence of the validation was cross-correlation of calculational results obtained with this code version and results of critical experiments, as reported in MCNP Version 4B Approval for Use Documentation \& Authorized User List (Lan 1999).

Intergraph is a trademark of the Intergraph corp.

${ }^{2}$ Pentium is a trademark of the Intel corporation. 
HNF-6271, Rev. 0

This page intentionally left blank

C-8 
HNF-6271, Rev. 0

\section{APPENDIX D}

PRELIMINARY HAZARDS ANALYSIS

D-1 
HNF-6271, Rev. 0

This page intentionally left blank 


\section{HNF-6271, Rev. 0}

\section{List of Terms}

$\begin{array}{ll}\text { AlChE } & \text { American Institute of Chemical Engineers } \\ \text { CSER } & \text { Criticality Safety Evaluation Report } \\ \text { GB } & \text { glovebox } \\ \text { ID } & \text { Identification Number } \\ \text { PHA } & \text { Preliminary Hazards Analysis } \\ \text { Pu } & \text { Plutonium }\end{array}$

\section{List of Definitions}

Container - Any vessel that could be used to store and transfer material. Includes boats and different types and models of cans.

Contingency - A possible but unlikely change in a condition/control important to the nuclear criticality safety of a fissionable material operation that would, if it occurred, reduce the number of barriers (either administrative or physical) that are intended to prevent an accidental nuclear criticality. 
HNF-6271, Rev. 0

\title{
PFP GLOVEBOX HC-18BS CRITICALITY PRELIMINARY HAZARD ANALYSIS
}

\author{
Purpose
}

The purpose of this Preliminary Hazard Analysis (PHA) is to identify potential events and conditions that could lead to a nuclear criticality during fissile material handling and storage activities in Glovebox HC-18BS. The results of this PHA will be used to document the development of facility specific key assumptions and technical inputs into the Plutonium Finishing Plant (PFP) Glovebox HC-18BS Criticality Safety Evaluation Report (CSER).

\section{HAZARDS EVALUATION}

A PHA is a hazard identification/evaluation technique derived from the U.S. Military Standard System Safety Program Requirements (MIL-STD-882). A PHA is a structured discovery process involving a multi-disciplinary team and focuses on the hazardous materials and major process areas of a facility. The results of the PHA are recorded using a tabular format. Because of its military heritage, the PHA technique is well suited for reviewing process areas where energy can be released in an uncontrolled manner. In general, the PHA process develops a list of hazards and hazardous conditions by considering the following process characteristics:

- Raw materials, intermediate and final products, and their reactivity

- Plant equipment

- Facility layout

- Operating environment

- Operational activities (testing, maintenance, etc.)

- Interfaces among system components.

The American Institute of Chemical Engineers (AIChE) recognizes the PHA process as a creditable method of hazard evaluation. AIChE describes this process in their publication titled "Guidelines for Hazard Evaluation Procedures" (AIChE 1992).

The depth of a PHA is directly related to the experience and knowledge of the participants. A short resume of each team member is included to document the experience and knowledge of the PHA team. 


\section{PHA Evaluation Structure and Process Description}

This PHA only addresses the hazardous condition of unplanned nuclear criticality. Unplanned criticalities are of concern whenever significant quantities of fissile material are handled or stored. Criticality events are prevented by ensuring that limits for specific parameters are not violated. These parameters are referred to as controlled parameters. This PHA was structured to address the following controlled parameters:

$\begin{array}{ll}- & \text { Mass } \\ - & \text { Volume } \\ - & \text { Geometry } \\ - & \text { Moderation } \\ - & \text { Reflection } \\ - & \text { Interaction } \\ - & \text { Enrichment } \\ - & \text { Density } \\ - & \text { Concentration } \\ - & \text { Poisons }\end{array}$

This PHA evaluated the process of storing and transferring of fissile material through Glovebox HC-18BS. Potential failures and conditions were postulated that could result in an unplanned criticality. Any unplanned criticality is considered to be an unacceptable event. The process occurring in Glovebox $\mathrm{HC}-18 \mathrm{BS}$ involves loading and unloading containers of fissile material onto the HC-18BS conveyor from either HC-1 or HC-2 conveyor Gloveboxes. The PHA was structured to evaluate the controlled parameters associated with the following process steps and conditions:

1. Fissile material loading onto the HC-18BS Glovebox conveyor from either HC-1 or HC-2 conveyor Glovebox.

2. Moving fissile material while placed on the $\mathrm{HC}-18 \mathrm{BS}$ conveyor.

3. Possible interim storage of fissile material on HC-18BS Glovebox conveyor.

4. Fissile material unloading from the $\mathrm{HC}-18 \mathrm{BS}$ Glovebox conveyor onto either $\mathrm{HC}-1$ or $\mathrm{HC}-2$ conveyor Glovebox.

5. Evaluation of external events that impact fissile material movement and storage:

- Fire

- Seismic

- Flood 


\section{PHA Table description}

The PHA table (Table D1) was structured to ensure a systematic and thorough evaluation of the potential events that could affect the controlled parameters in such a way that a criticality was possible. No column for the recording of potential consequences or hazardous condition is provided since unplanned criticality is the accident of concern for each item in this PHA. The PHA table captures the following information:

$\underline{\text { ID: }}$

Item Identification; used to record a unique identifier for the potential cause of a criticality

Location/Activity:

The location and process step or condition being evaluated for potential situations which can result in changes in the controlled parameters that could cause a criticality in Glovebox HC-18BS.

\section{Candidate Causes:}

Description of specific events and causes that have the potential to result in a criticality. This column captures event details that may be important in the analysis that will define the controls to prevent a criticality.

\section{Controlled Parameter:}

Parameters that are effected by the candidate causes. One or more of the following parameters may be specified: mass, volume, moderation, interaction, reflection, geometry, enrichment, density, concentration, or poisons.

\section{Existing Engineering Safety:}

Hardware items identified by the PHA team that have the potential to mitigate or prevent the potential criticality

\section{Existing Administrative Safety:}

Administrative controls such as facility worker training and safety procedures identified by the PHA team that have the potential to mitigate or prevent the postulated criticality

\section{Frequency Category:}

Frequency Category - The frequency ranking is a qualitative estimate of whether the hazardous condition is considered credible or not. Conditions considered not credible will not be evaluated further.

\section{Remarks:}

Miscellaneous observations or clarifying comments for a given item. This column is also used to capture criticality analysis requirement decisions of the PHA team. 
HNF-6271, Rev. 0

\section{PHA Results}

The results of this PHA are in the form of information to be considered as part of the Criticality Safety Evaluation Report (CSER). The raw data is presented in Table D1. The information contained in the PHA table is used to ensure that the CSER analysis addresses the appropriate potential conditions that may contribute to a criticality during loading, unloading and storage of fissile materials in Glovebox HC-18BS. The following assumptions that are important to the CSER analysis were extracted from Table D1 and discussions that occurred during the PHA.

\section{PFP Glovebox HC-18BS Criticality PHA Assumptions and Dispositions:}

\section{Assumptions and Information Regarding Physical Configuration of Glovebox HC-18BS:}

1. There are 20 pedestal positions on the HC-18BS conveyor. Currently, only one boat is allowed in the glovebox. The analysis will consider unlimited open containers in the glovebox.

2. The boats have covers but the covers are not considered safety class.

3. Glovebox HC-18BS is seismically qualified. Conveyors on either side (HC- 1 and $\mathrm{HC}-2)$ are also seismically qualified.

4. There are no water sources inside the 18BS glovebox such as fire sprinklers or fire piping.

5. Water in the glovebox would come from the fire sprinklers outside the glovebox actuated as a result of a fire or seismic event.

6. The adjoining conveyor glovebox $\mathrm{HC}-1$ has a criticality safety drain. Conveyor glovebox $\mathrm{HC}-2$ drains into conveyor glovebox $\mathrm{HC}-5$ which has a criticality drain. The conveyor gloveboxes serve as criticality drains for Glovebox HC-18BS.

7. It is possible to place multiple containers between two pedestals

8. It is possible to place multiple containers on a pedestal if they are placed improperly.

9. There are two existing pedestal designs, one historically used in this glovebox and an alternate design being considered for fabrication. The analysis will address both pedestals.

10. The boat holder will need to be modified to ensure that the boat cannot be dislodged from the pedestal in an event that disrupts the boats. Currently the boat pedestal does not prevent the boat from being dislodged.

11. The $3 / 8$ inch conveyor pins locate the pedestals on conveyor and hold the pedestals in place during a seismic event.

12. There is high certainty that the can pedestal will prevent the can from being dislodged. 
Assumptions and Information Regarding the Unloading, Loading, and Storage Operations:

1. Material entering the glovebox is assumed to have an $h / x \leq 2$ or $h / x \leq 20$.

2. The analysis will consider unrestricted moderation material $(h / x>20)$ to determine if this is allowed as a normal condition. However, this is not a required condition in Glovebox HC-18BS and could be dropped from the criticality analysis if necessary.

3. This analysis will consider metal pieces up to $2.5 \mathrm{~kg}$.

4. The maximum volume container will be $2.3 \mathrm{~L}$.

5. The analysis assumes that all the fissile material is $100 \%$ pure $\mathrm{Pu}-239$.

6. Dropping one boat in Glovebox HC-18BS is considered an anticipated event.

7. Dropping a boat bounds a dropped can because the can is assumed to remain sealed while the boat cover is not a sealed lid and material can escape the boat.

8. The anticipated over-batch will be $2.75 \mathrm{~kg}(2.5 \mathrm{~kg}+10 \%)$.

9. Movement of containers of volume greater than 2.3 liters in the Glovebox HC-18BS is considered not credible. (Not used in this operation)

10. It is assumed that moving $50 \mathrm{~g}$ waste packages through Glovebox $\mathrm{HC}-18 \mathrm{BS}$ is a normal condition.

11. The waste packages are small and historically have been low in fissile material content and can be placed on the conveyor in any location.

12. The presence of $5 \mathrm{~kg}$ of metal will be analyzed as a contingency.

13. The analysis will evaluate three dislodged boats to determine the level of concern. 


\section{PHA Team Member Biographies}

Carol A. Cise - Fluor Federal Services, Inc. Criticality Safety Engineer. Ms. Cise has a BS in General Engineering and an MS in Nuclear Science and Engineering. She has recently joined Fluor Federal Services as a Criticality Safety Engineer. Previously, she has worked in criticality safety for eleven years at both the Idaho National Engineering Laboratory and at the Rocky Flats Environmental Technology Site. At Rocky Flats, she had responsibility for criticality safety in the Deactivation and Decommissioning (D\&D) of the Plutonium Recovery Building (Building 771) as Building Engineer. Prior to working in criticality safety, she worked in the Boron Neutron Capture Therapy program at the INEL and in the Reactor Physics Division at Argonne National Laboratory - West.

David G. Erickson - Fluor Federal Services, Criticality Safety Engineer. Mr. Erickson has a B.S. in Physics, and has been at the Hanford Site for 16 years performing analysis in the fields of reactor physics and 13 years in criticality safety. He is familiar with the codes used in criticality analysis and has performed analysis and reviews of other PFP operations. He is a qualified Criticality Safety Specialist with FFS.

Tomoko V. Jensen-Otsu - Fluor Federal Services, PHA Facilitator - B.S., Physics. Assisted in facilitation of multiple PHAs and Hazops. Hanford Site experience in updating, performing consistency checks, and managing TWRS FSAR Hazards Database.

Blaise S. Mo, Fluor Hanford, Inc., Criticality Safety Representative for PFP. - B.S. Physics and M.S. Environmental Science and Engineering. Over seventeen years experience in various assignments at the Rocky Flats Environmental Technology Site, including eleven years as a criticality safety engineer and six years in managing analytical laboratories, training programs, and facility operations. Recently assigned as a CSR at PFP.

H. Rees Risenmay - B\&W Hanford Company, Engineer, PFP Process Engineering, Solids Stabilization Cognizant Engineer - Mr. Risenmay has 16 years experience at the Hanford site. His experience has been in the Chemical Engineering Laboratory, the PUREX plant, the UO3 plant, and the PFP plant. His experience is mostly in process engineering with detailed knowledge of the processes and safety aspects for each plant. Mr. Risenmay has a Bachelor of Science Degree in Chemistry from Brigham Young University and a Bachelor of Science Degree in Engineering with chemical engineering emphasis from the University of Washington.

Kevin N. Schwinkendorf - Fluor Federal Services, Inc., Criticality and Shielding B.S., M.S. Nuclear Engineering from Oregon State University, Ph.D. Nuclear Engineering from University of Washington, Registered Professional Engineer (PE) in Nuclear Engineering, Washington State. Criticality Safety Engineer for N Fuels CSER. Sixteen years experience at the Hanford Site working in N Reactor physics and criticality support, including the Spent Nuclear Fuel Project, tank farms, FFTF, and the Plutonium Finishing Plant. Off-site work has included kinetics simulation for the Savannah River Site. 
Milton V. Shultz, Jr. - Fluor Federal Services Inc. Safety Analysis and Risk Assessment. B.S. Nuclear Engineering Technology. Scribe for Glovebox HC-18BS PHA. More than twenty-six years experience in a broad range of engineering and technical assignments at the Hanford Site. Experience includes leading PHAs and HAZOPs for a variety of TWRS and PFP projects, including several for the TWRS FSAR and BIO efforts, contributor to the hazards analysis work for the TWRS BIO. Has performed independent Nuclear Safety evaluations of reactor plant design and operation at Hanford $=\mathbf{s} \mathrm{N}$ Reactor.

Brian D. Skeels - Flour Hanford Company, PFP Stabilization Operations, Thermal Stabilization Support Team Leader. Mr. Skeels has 15 years experience at the Hanford Site. His experience has been at 100-KE/KW basins, $100 \mathrm{~N}$ and PFP. Mr. Skeels has been at PFP for 12 years with 9 years as a First Line Supervisor/Manager. Mr. Skeels is currently the Team Leader for the Thermal Stabilization Support Team (TSST). Prior to being assigned as the TSST Team Leader, Mr. Skeels was a Shift Manager in charge of both the Cementation and Thermal Stabilization Processes during their operating campaigns.

Hans Toffer, Fluor Federal Services, Inc. - Criticality and Shielding. Managed technical organizations and projects with emphasis on criticality safety, reactor physics and nuclear engineering. Background includes: Criticality safety of plutonium, high enriched uranium, low enriched uranium processing, storage and handling, thermal reactor core analysis and measurements, neutronic, ultrasonic and vibration measurement technology development, isotope production, reactor design analysis, computer code software quality assurance, organizing national technical meetings and participating in American National Standards development. Responsibilities included: Technical management and direction technical team leadership, coordination of multi-discretionary teams, served as classification officer, chairman of American National Standards working group ANS 8.21, chaired and organized national/international technical meetings, and served on special assessment teams at different Department of Energy contractor sites.

Alan D. Wilkinson, Fluor Federal Services, Inc, Criticality Safety Engineer - Mr. Wilkinson has a B.S. Nuclear Engineering and M.S. Nuclear Engineering with an emphasis on Nuclear Criticality Safety. He has five years experience at Rocky Flats performing nuclear criticality safety analysis, and is now supporting PFP as a nuclear criticality safety engineer.

\section{References}

AIChE, 1992, Guidelines for Hazard Evaluation Procedures, American Institute of Chemical Engineers, New York, New York.

MIL-STD-882B, 1977, System Safety Program Requirements, Department of Defense, Washington, DC 
HNF-6271, Rev. 0

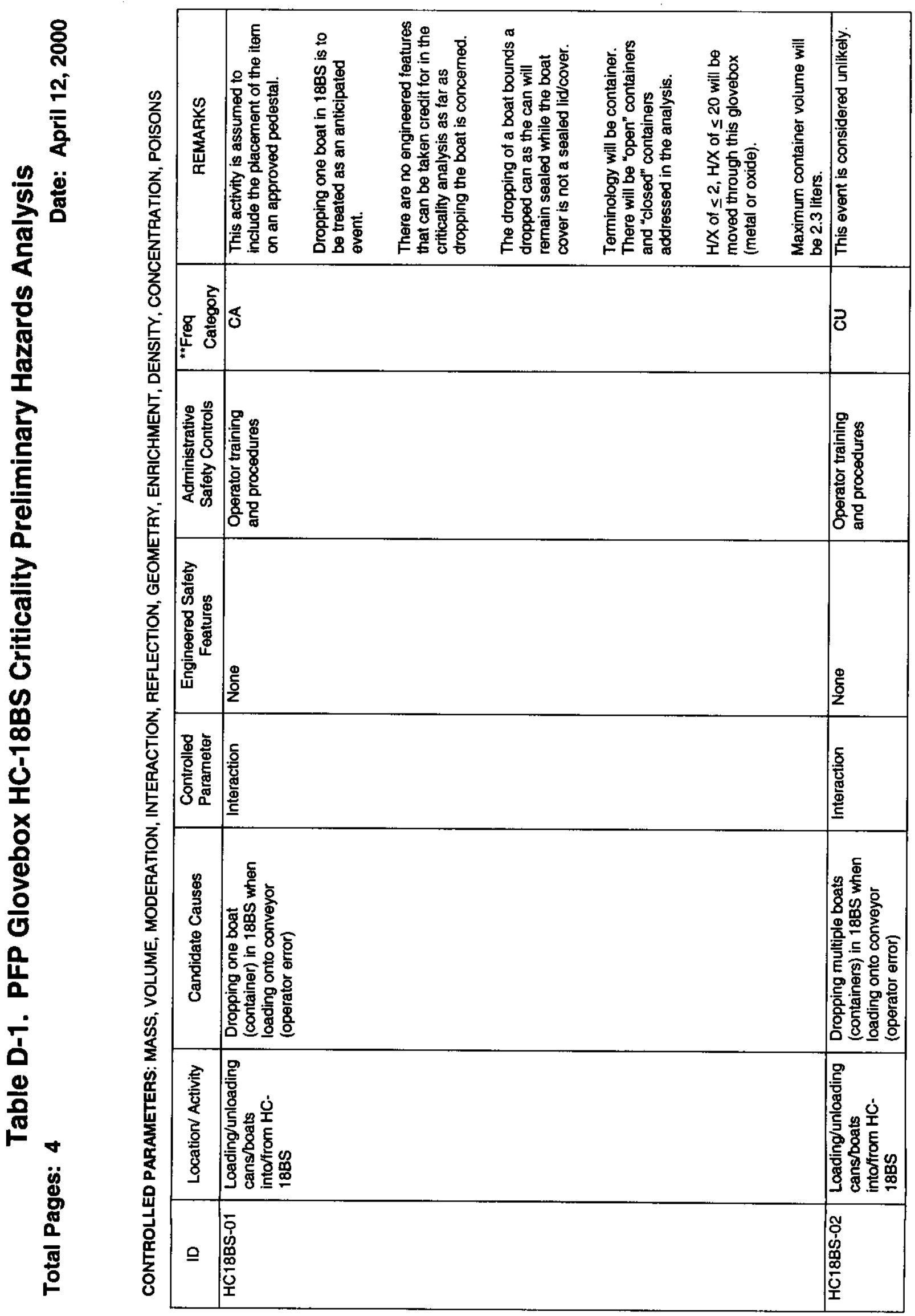


HNF-6271, Rev. 0

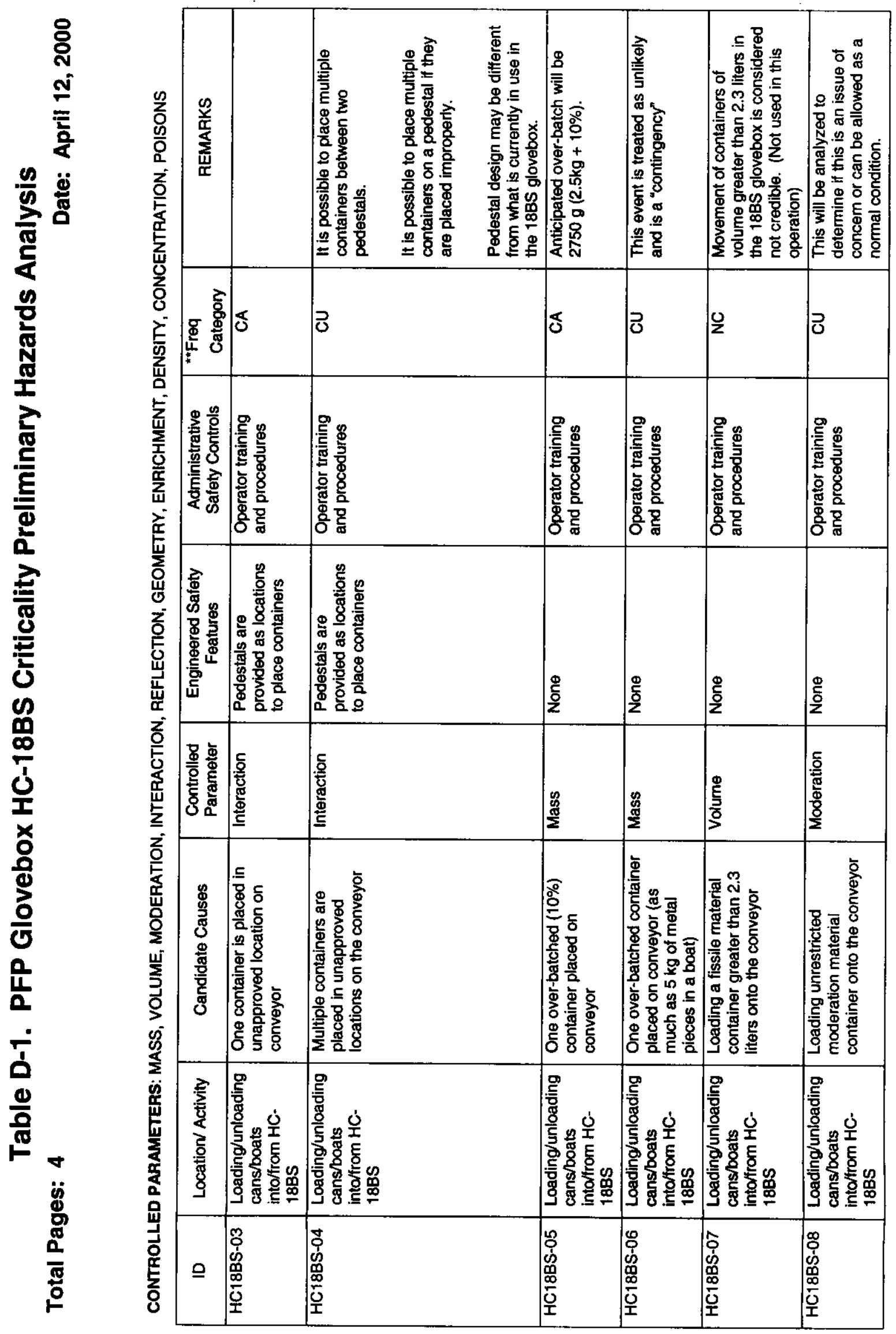


HNF-6271, Rev. 0

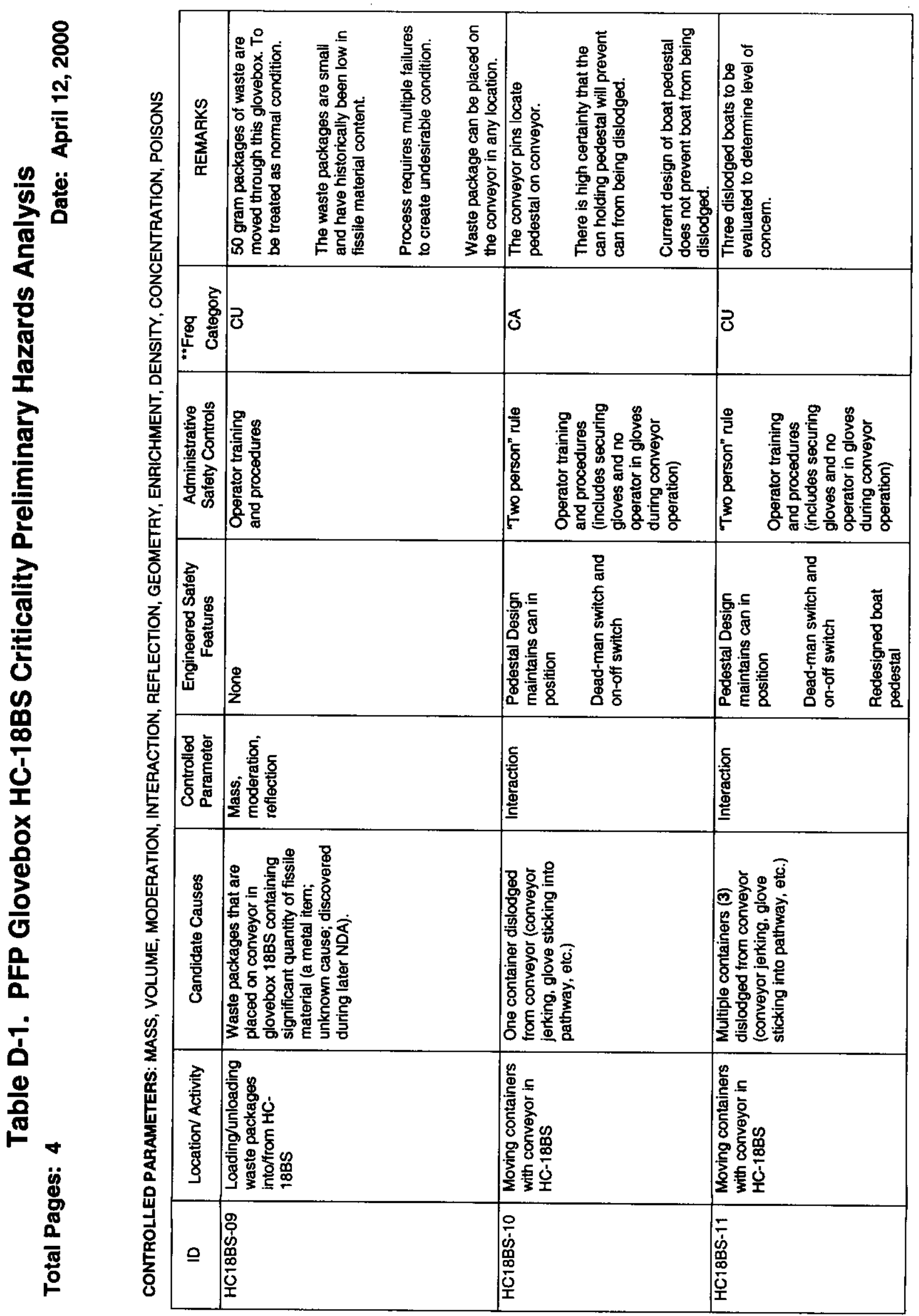


HNF-6271, Rev. o

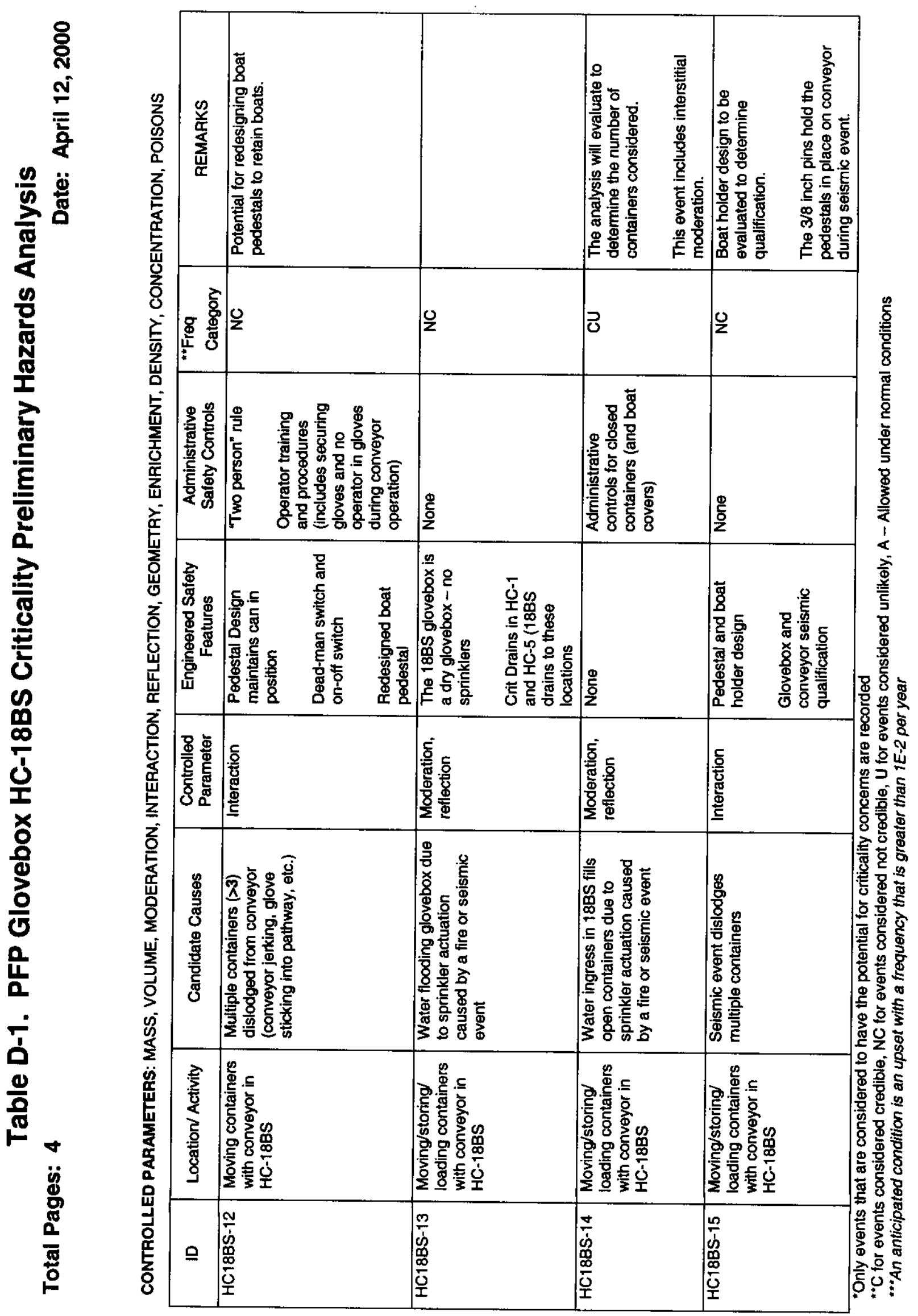


HNF-6271, Rev. 0

APPENDIX E

\section{FIRE FIGHTING WATER DENSITY}

E-1 
HNF-6271, Rev. 0

This page intentionally left blank

E-2 


\section{B \& W Hanford Co.}

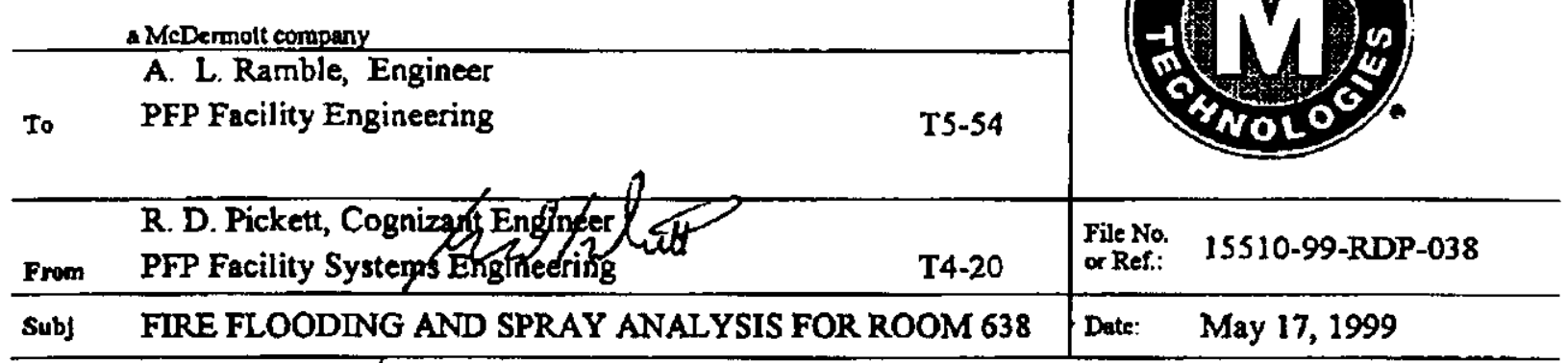

Reference: Telephone Request for Fire Water Flooding and Spray Analysis, dated May 7, 1999.

\section{ASSUMPTIONS}

- Fire department on scene withir 40 minutes (see FSAR section 9.2.2A).

- $120 \mathrm{psi}$ at each sprinkler head (this is very conservative since line losses and operation of other sprinkler heads would decrease this pressure).

- Fight a fire with two hoses for a total of $400 \mathrm{gpm}$ (one hose at $100 \mathrm{gpm}$ and second hose at $300 \mathrm{gpm}$ per information provided by the fire department). Note: these hoses are variable stream types so the pattern and flows are adjustable.

- For flooding, assume all sprinkler heads operate (this is worse than a shear of a $11 / 2$ " water line).

- 1 second of flow from a sprinkler head or hose will suspend the amount of water to achieve the maximum density.

- Assume 3 sprinkler heads worth of flow into the cage area.

- No leakage out of the room.

- There is $8 \mathrm{lb}$. Water in 1 gallon.

- Exclude floor space and volume of room 639 and 640.

\section{BACKGROUND}

- Area of the room floor $=130 \mathrm{At} 2$.

- 14 sprinkler heads in the room (see CVI 21097)

- Sprinklers have a $1 / 2$ " orifice with a $5.62 \mathrm{~K}$-factor.

- There are 7.481 gallons per ft3.

- Occupational Classification is Ordinary Hazard (see CVI 21097).

- Caged area has two sprinkler heads.

- Ceiling height is $9^{\prime} 6^{\prime \prime}$.

- Floor dimensions of caged area 7' $\times 18^{\prime} 3^{\prime \prime}$

- Probability of fire not being noticed and the fire department being delayed 30 minutes is discussed in section 9.2.2A of the FSAR.

- Flooding cannot occur when a fire hose is used since the doors to the room have to be open along the hose route all the way to the outside of the building. There are no hose connections inside $2736-\mathrm{ZB}$ or $2736-\mathrm{Z}$. 
A. L. Ramble, et. al.

Page 2

May 17, 1999

\section{CaLCÚlations}

Flow per sprinkler head $=Q=K \sqrt{\mathrm{P}}=5.62 \cdot \sqrt{120}=61.56 \mathrm{gpm}$

Sprinkler flow into cage area $=3 * 61.56=185 \mathrm{gpm}$

Sprinkler flow into the whole room $=14 \bullet 61.56=862 \mathrm{gpm}$

Volume of cage area $=7^{\prime} \bullet 18^{*} * 9.5^{\prime}=1200 \mathrm{cu} . \mathrm{ft}$.

\section{CAGE DENSITY CALCULATIONS}

Cage Density during fire fighting in cage area $=185 \mathrm{gpm}$ from sprinklers $+400 \mathrm{gpm}$ from fire hoses $=585 \mathrm{gpm}$ total flow.

Water released in 1 second of sprinklers and hoses $=585 \mathrm{gpm} *(1 \mathrm{~min} / 60 \mathrm{sec}) \cdot 1 \mathrm{sec}=9.75$ gal.

Water density in cage area $=9.75 \mathrm{gal} / 1200 \mathrm{cu} . \mathrm{ft} .=0.0081225 \mathrm{gal} / \mathrm{cu}: \mathrm{ft}$.

\section{FLOODING CALCULATIONS}

Volume of water release in 40 minutes $=40 \mathrm{~min} \bullet 862 \mathrm{gpm} *(1 \mathrm{cu} . \mathrm{ft} . / 7.481 \mathrm{gal})=4609 \mathrm{cu} . \mathrm{ft}$.

Water level after $40 \mathrm{~min} .=4609 \mathrm{cu} . \mathrm{ft} .1340$ sq. ft. floor area $=3.44 \mathrm{ft}$.

\section{CONCLUSTONS}

After 40 minutes of sprinkler flow, the water level in room 638 will be 3.44 feet. The maximum density of water suspended in the cage area is $0.008-\mathrm{gaV} / \mathrm{cu}$. $\mathrm{ft}$.

klm

Distribution

Fluor Daniel Northwest

K. D. Dobbin 
HNF-6271, Rev. 0

APPENDIX F

MCNP INPUT FILES

F-1 
HNF-6271, Rev. 0

This page intentionally left blank 
Case 18bs-n-11; Table 5-3

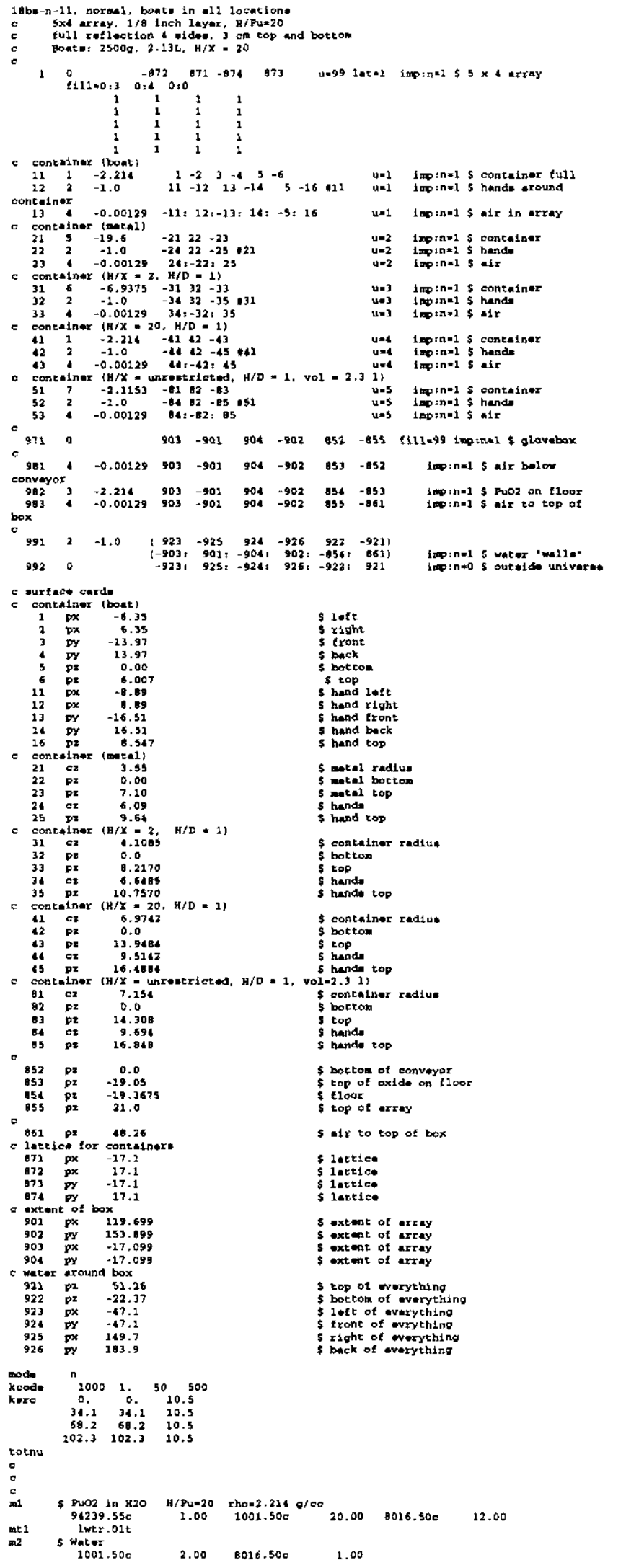

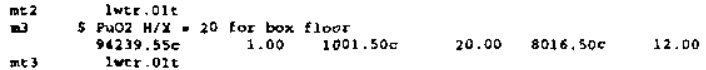

$$
\begin{aligned}
& \begin{array}{ll}
\text { met } 3 & \text { iver.01t } \\
\text { c } & \text { Air } 10.00129 \mathrm{~g} / \mathrm{cel}
\end{array}
\end{aligned}
$$

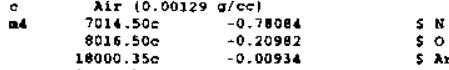

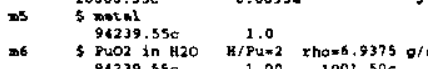

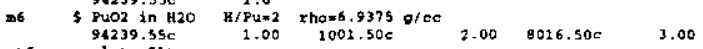

$$
\begin{aligned}
& \begin{array}{l}
\text { nt6 } \\
\text { a } 7 \text { PuO2 in } 01
\end{array}
\end{aligned}
$$

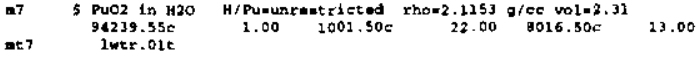

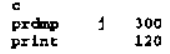

\section{Case 18bs-n-21; Table 5-3}

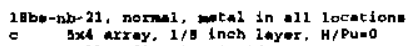

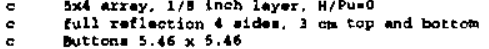

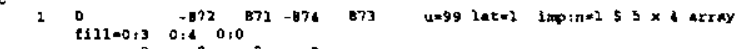

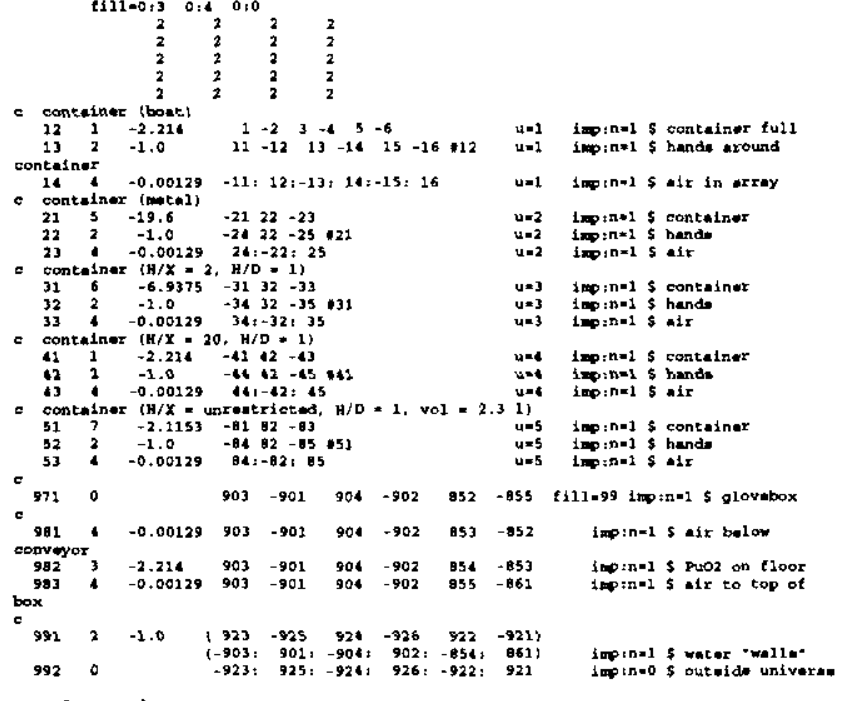

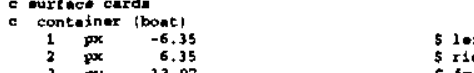

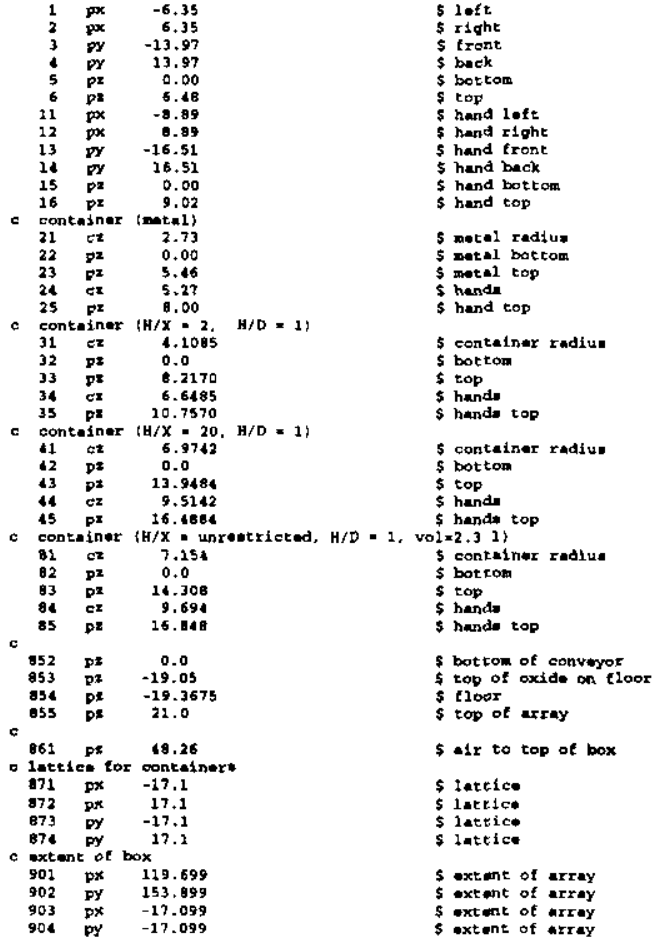


HNF-6271, Rev. 0

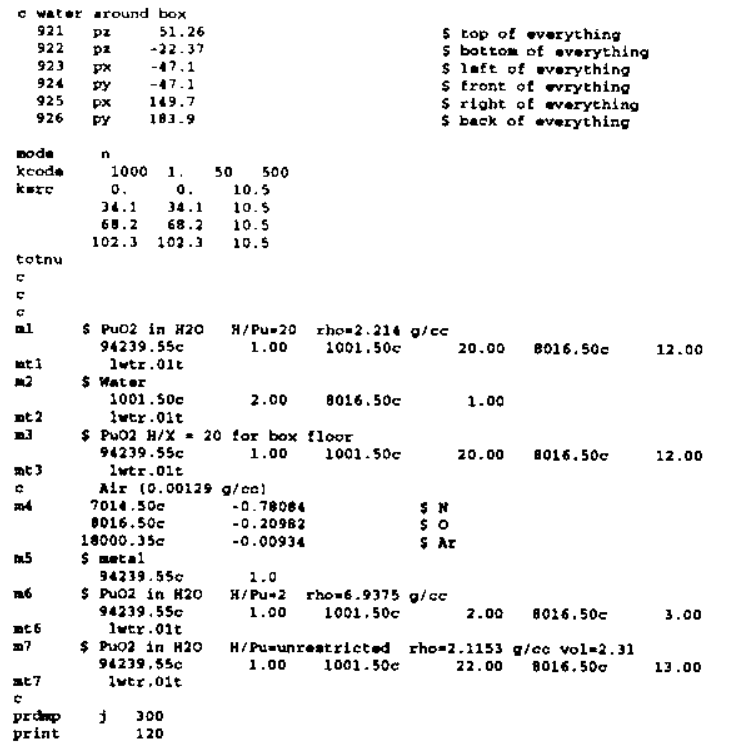

Case 18bs-n-31; Table 5-3

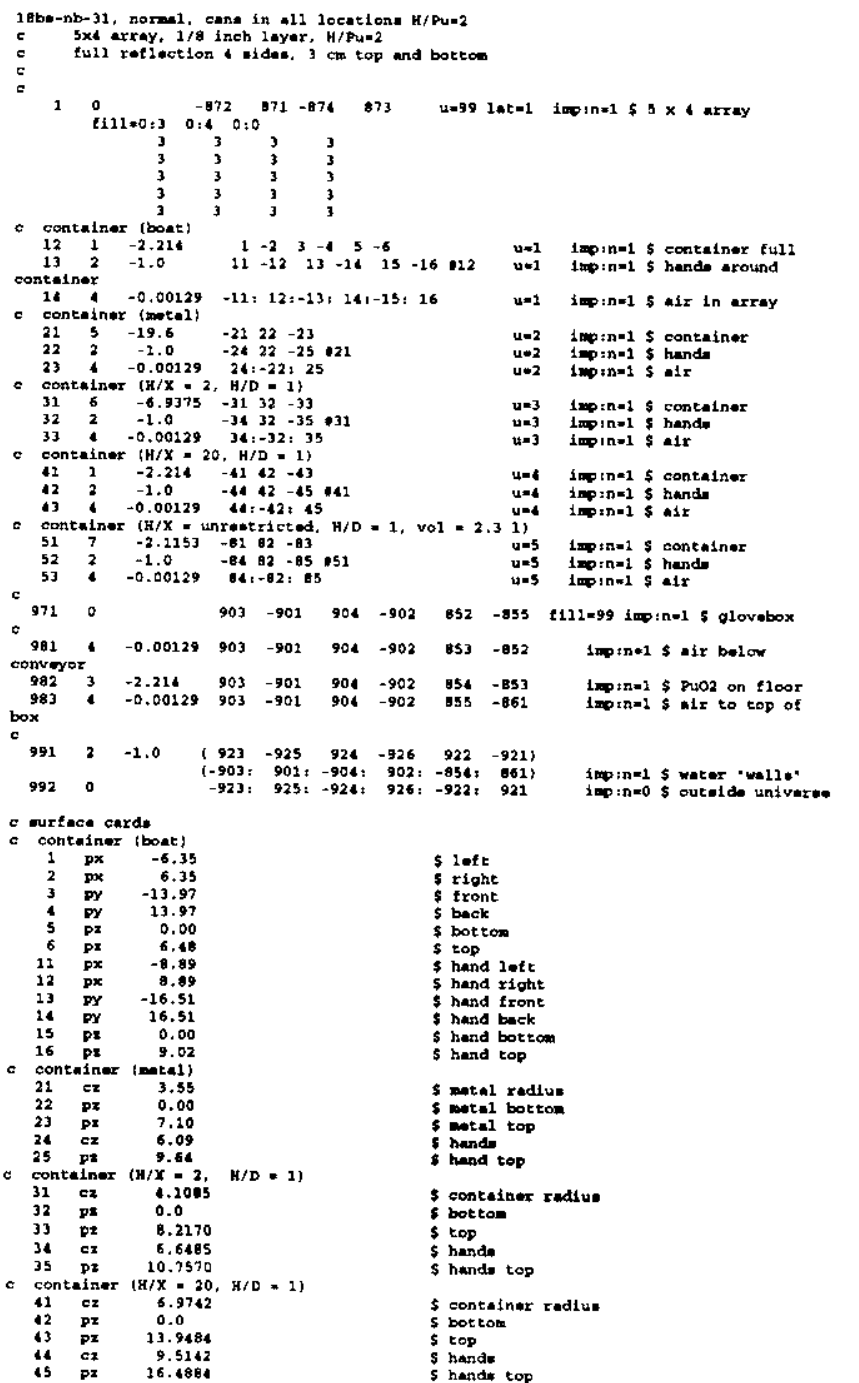

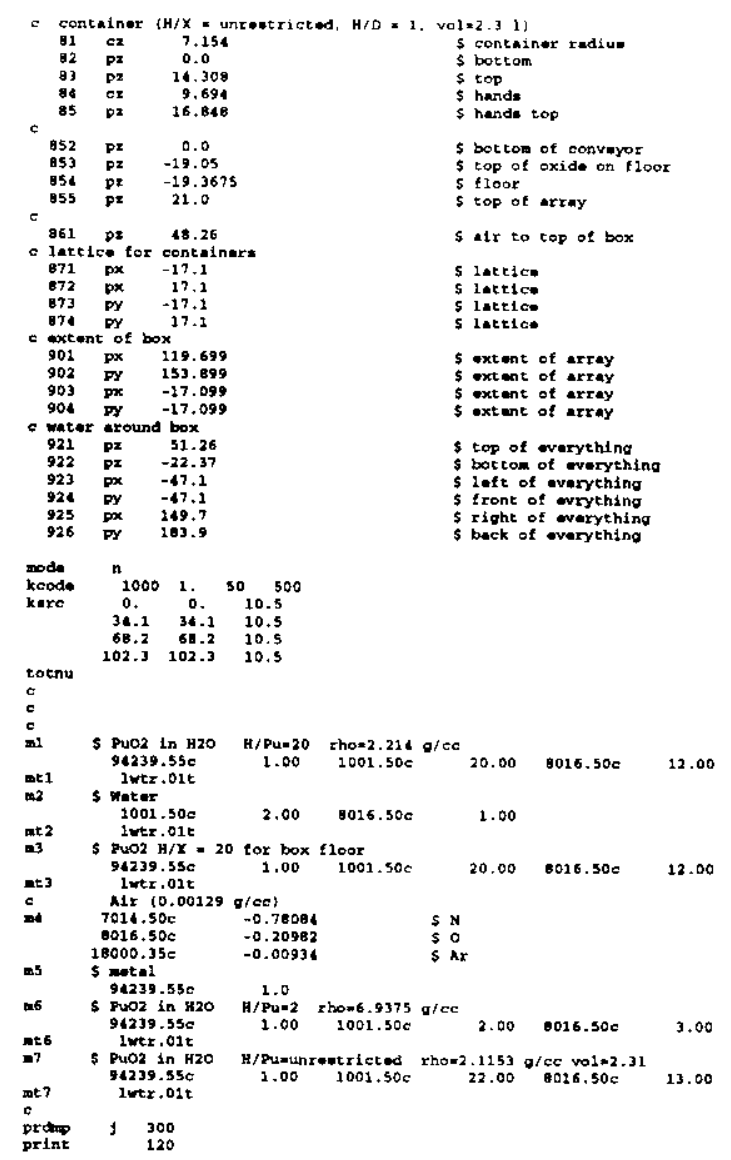

Case 18bs-n-41; Table 5-3

1tbo-nb-41, normal, cens in all tocatione H/pu=20

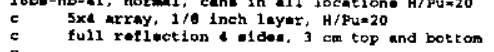

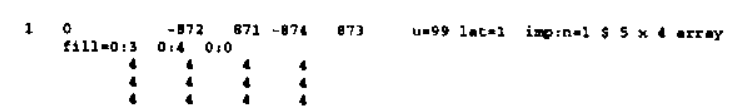

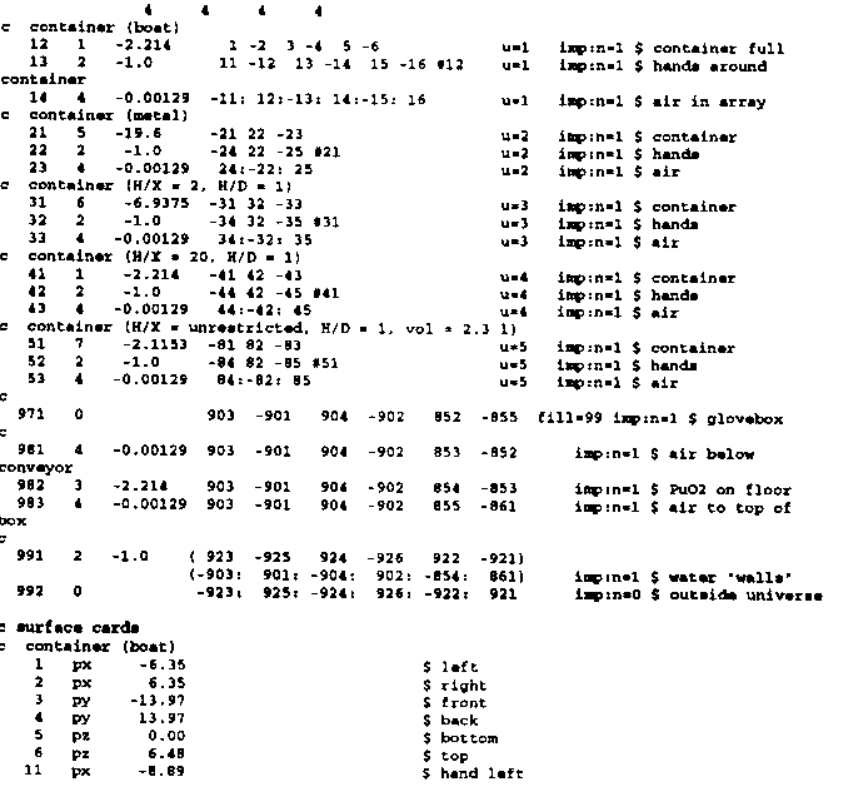


HNF-6271, Rev. 0

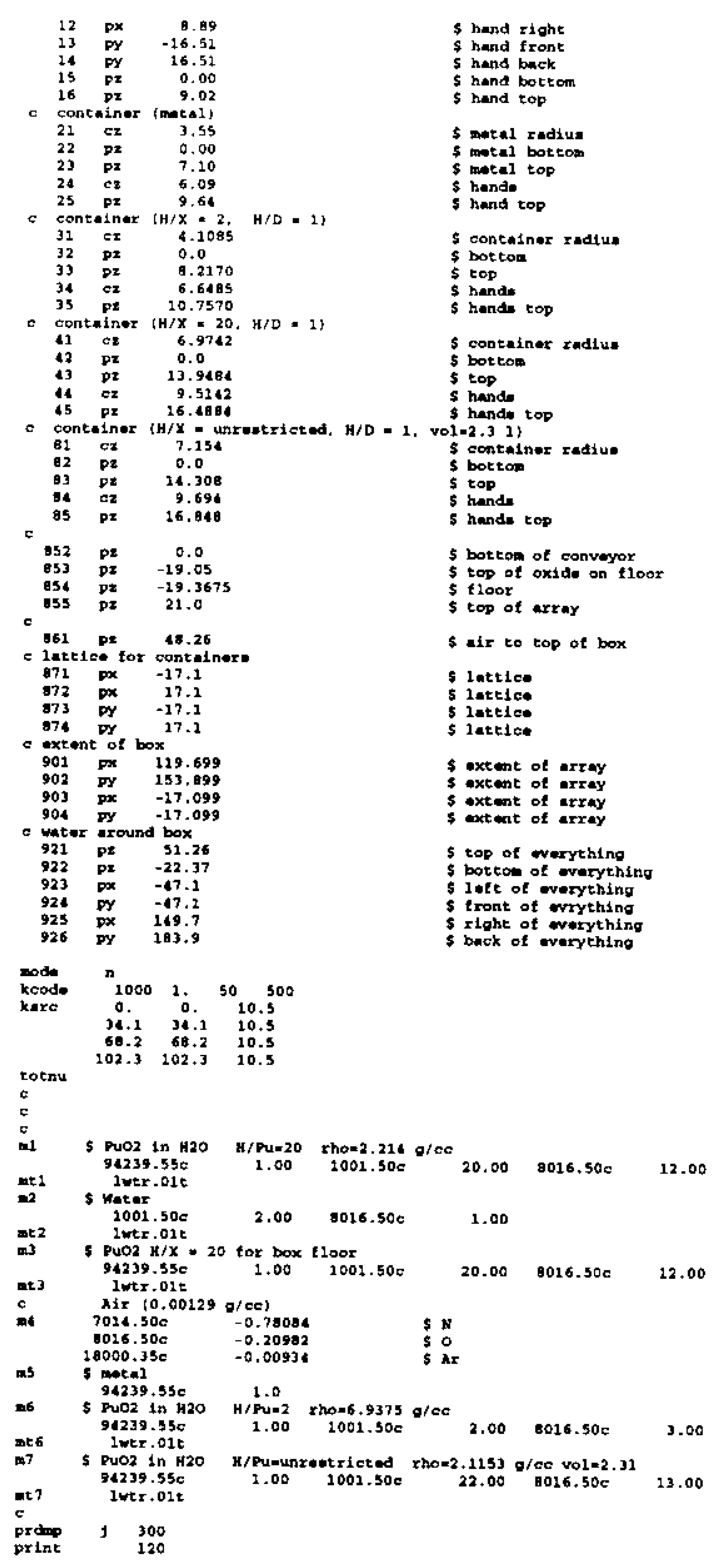

Case 18bs-n-51; Table 5-3

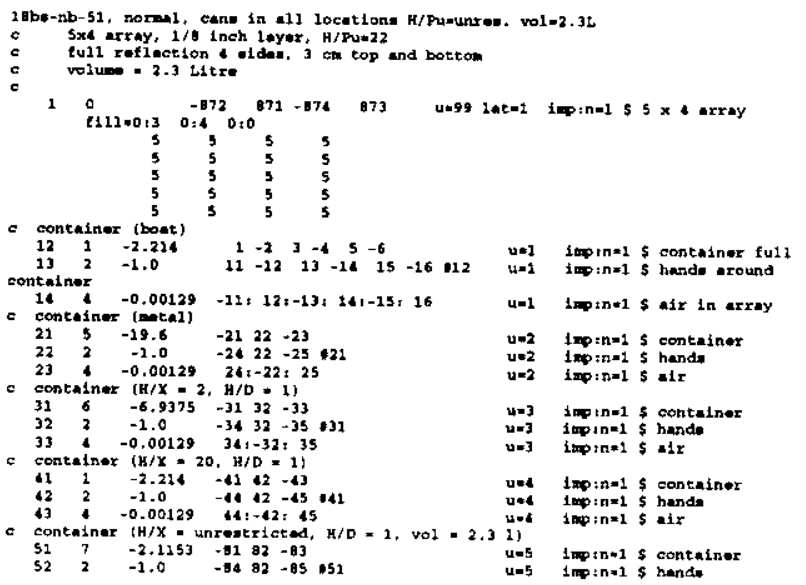

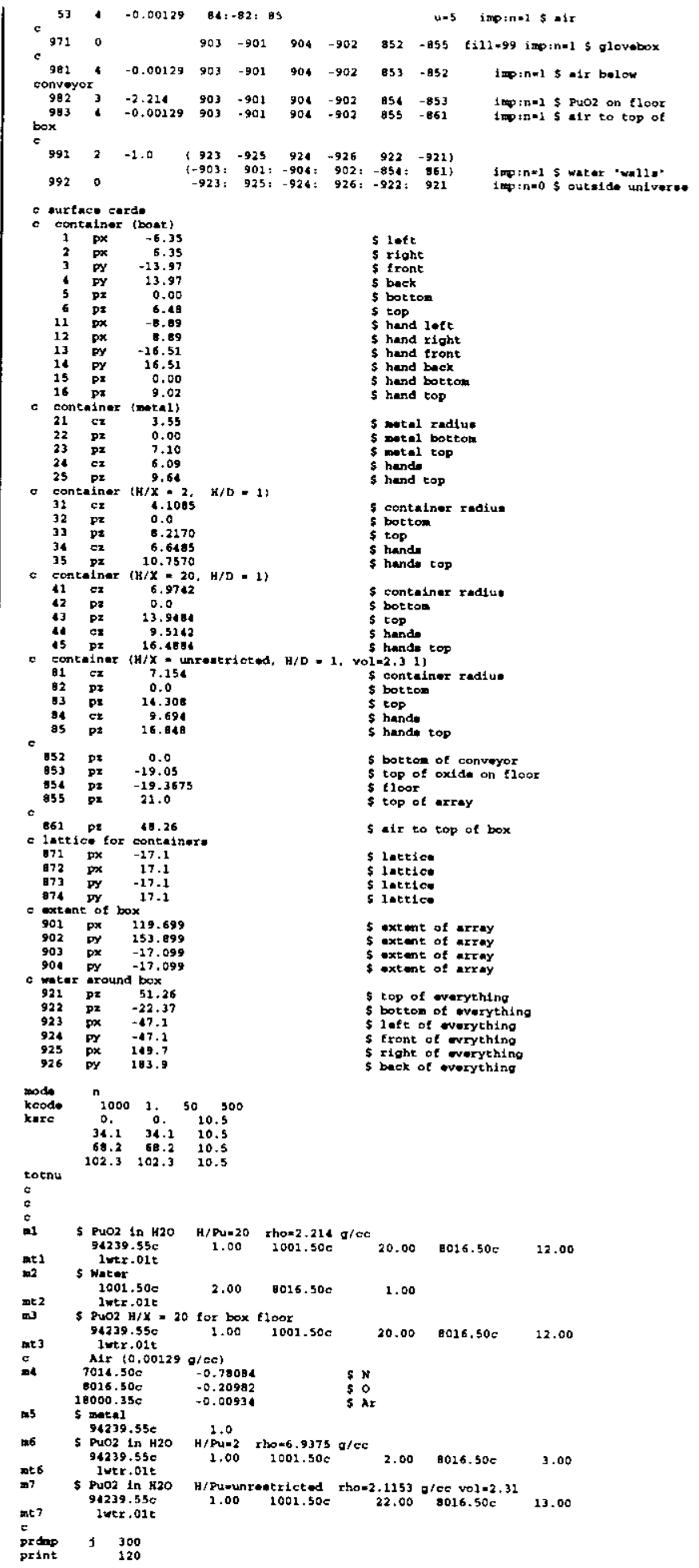

Case 18bs-n-52; Table 5-3

Comparing tileo $1 \mathrm{gbe}-\mathrm{n}-51.1$ and $1 \mathrm{ges}-\mathrm{N}-\mathrm{S2} . \mathrm{I}$

18be-nb-51. normol, cane in all location H/Fumunres. val=2.3L

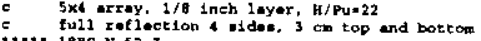

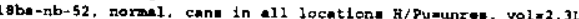

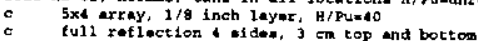




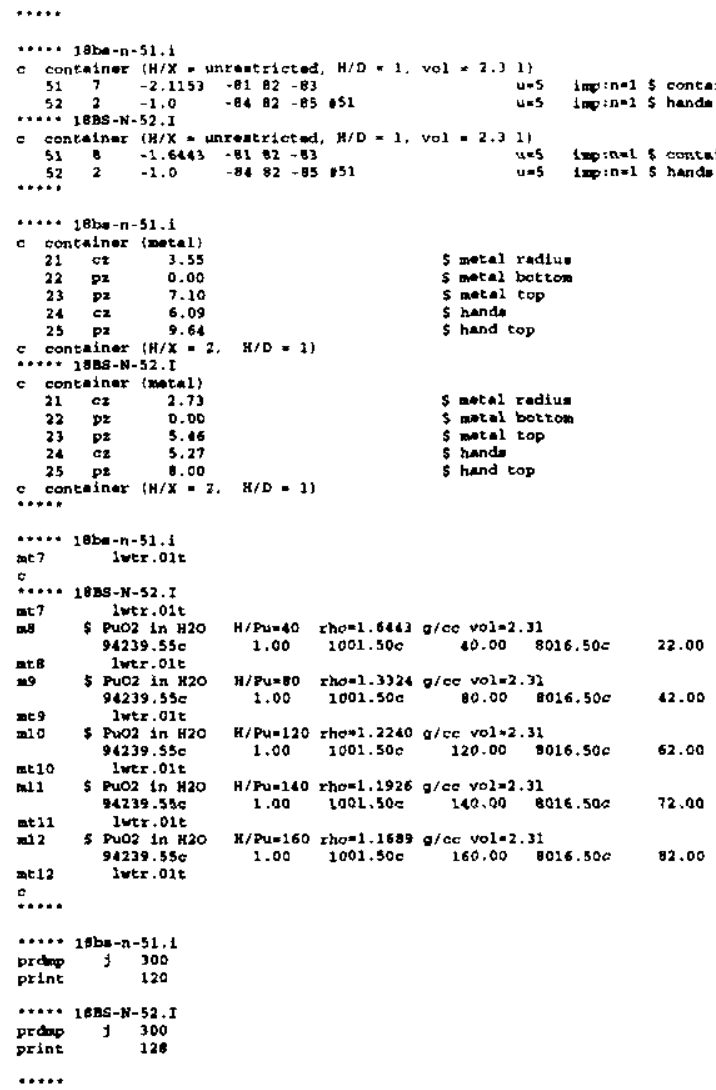

\section{Case 18bs-n-53; Table 5-3}

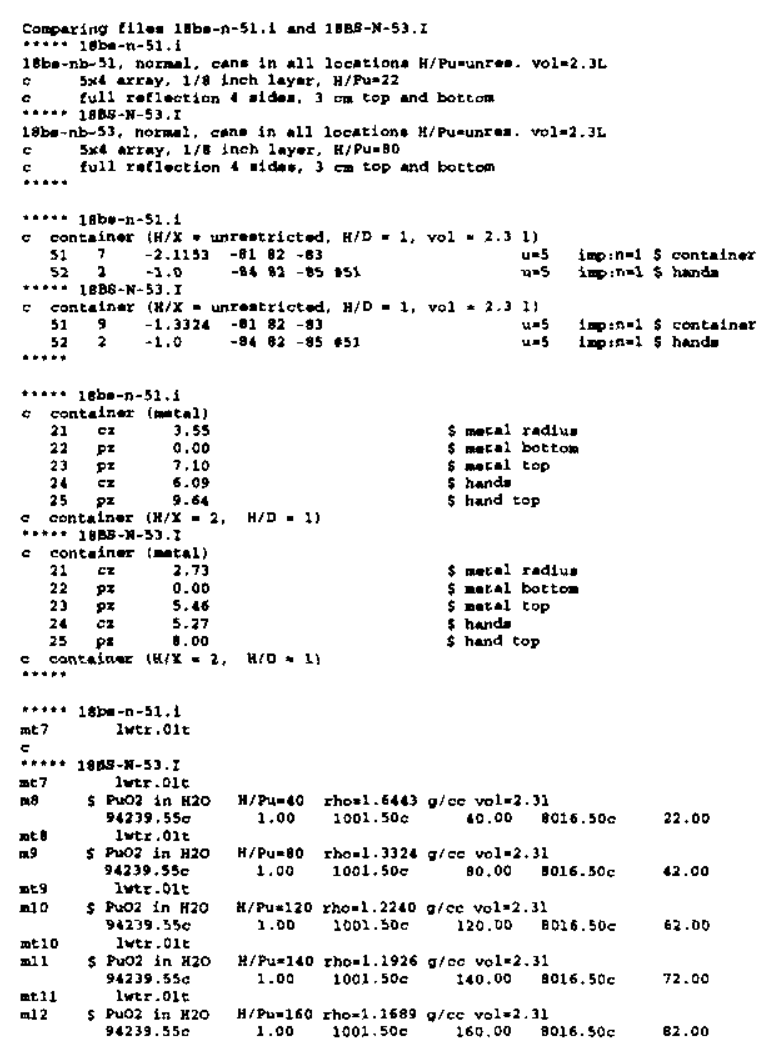

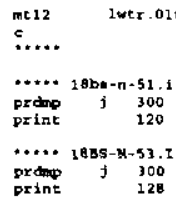

Case 18bs-n-54; Table 5-3

Comparing $1110.018 \mathrm{be}-\mathrm{n}-51.1$ and $18 \mathrm{BS}-\mathrm{N}-56.1$

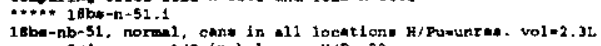

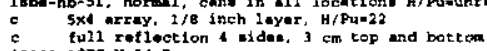

…. 2 2Bss-N-34.I

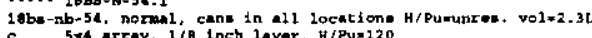

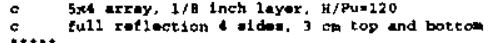

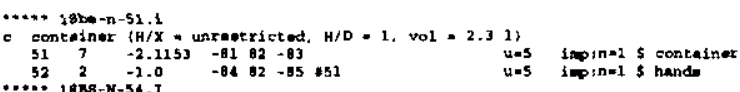

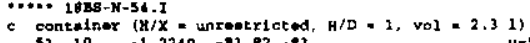

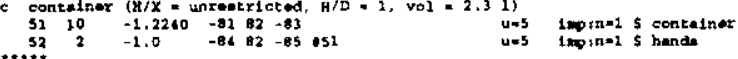

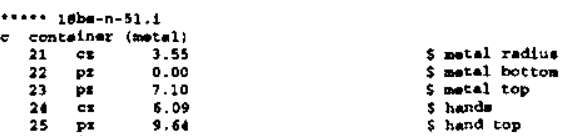

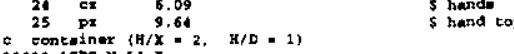

C contaliner (metel)

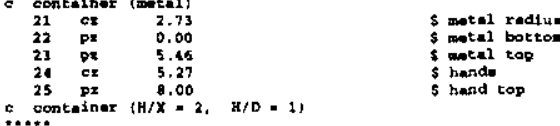

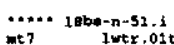

5.... 10Bs-N-54.1

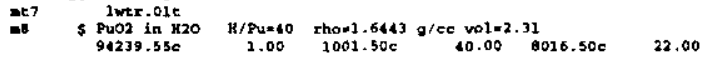

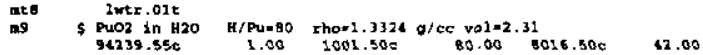

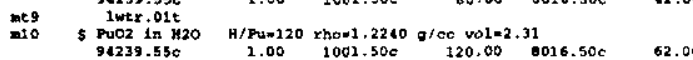

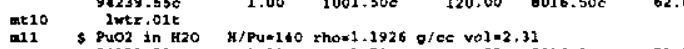

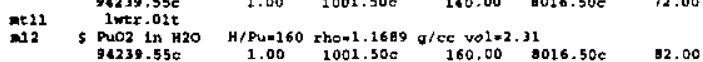

mt12 $\begin{gathered}9239.556 \\ 20 t r .016\end{gathered}$

.....

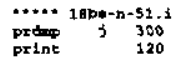

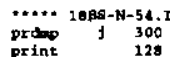

\section{Case 18bs-n-55; Table 5-3}

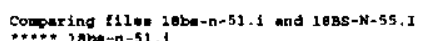

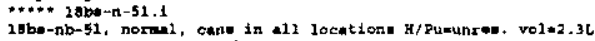

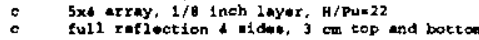

….. 18BB-N-5S.I

1ebe-nb-55, normel. cann in 11 locetione H/Pununzes. vol=2.3L.

c 5xt wrray, 1/8 inch leyer, Y/Pu=160

No**.* $186-n-51.1$

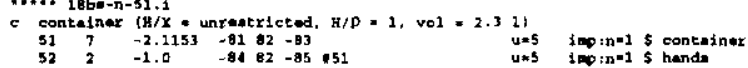

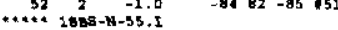

conteinar $(H / X=$ unreserietud, $H / D=1$, vol $=2.31$ )

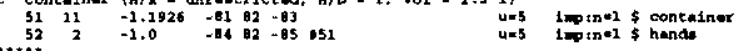

*... 1 abs $-\mathrm{n}-51.1$

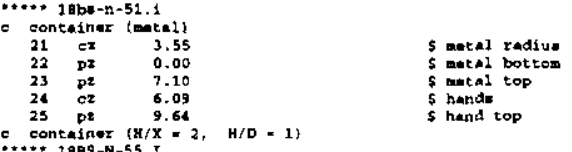




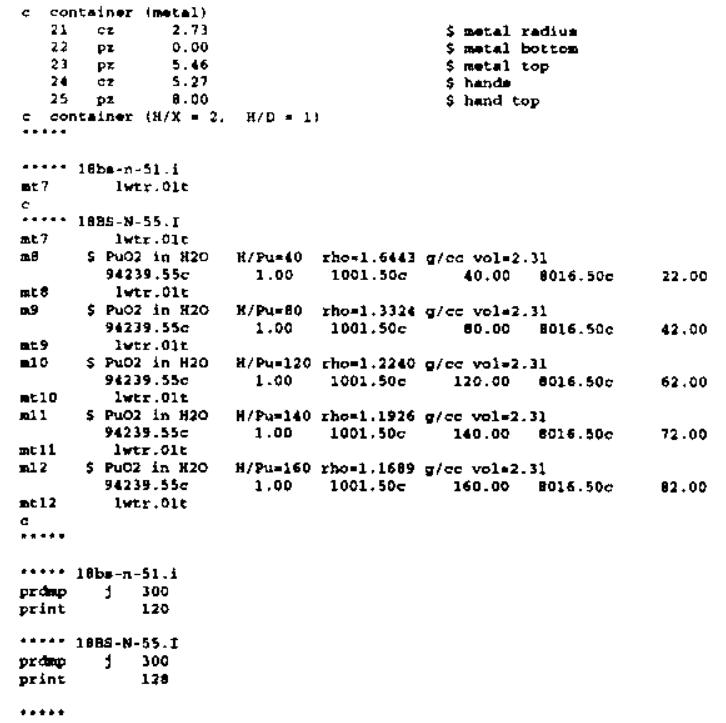

\section{Case 18bs-n-56; Table 5-3}

comparing f120: $28 b-n-51.1$ and $1838-\mathrm{N}-56.1$

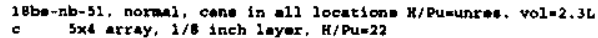
c... fu11 retlection i 1 ides. $3 \mathrm{~cm}$ top and bottom

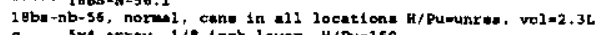

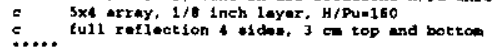

…. $18 \mathrm{ban}-\mathrm{n}-51.1 \mathrm{i}$

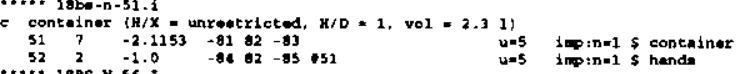

c contelner $(\mathrm{H} / \mathrm{X}=$ unxeetricted, H/D $=1$, vol $=2.3 \mathrm{l})$

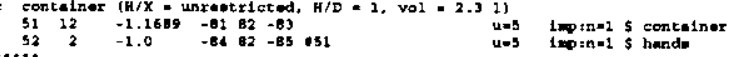

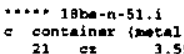

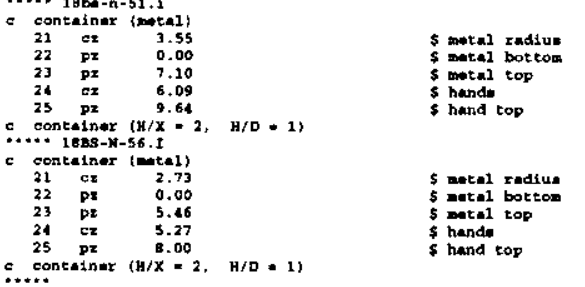

c.entesinux $(H / x=2, \quad H / D=1)$$$
\text { a.*. 1ebs-n-51.1 }
$$

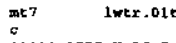$$
\text { …. } 18 \text { Bs -N-36.I }
$$

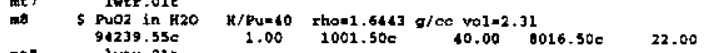$$
\text { ate letret }
$$

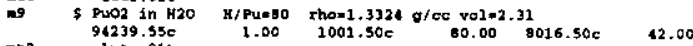$$
\text { De } 3 \text { iwtr.01 }
$$

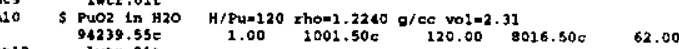$$
\text { at10 } 10
$$

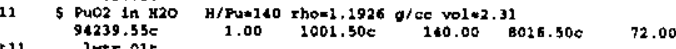$$
\text { mt11 \$ PuOz in }
$$$$
320
$$$$
\text { H/Pue } 160 \text { rho-1.1689 } g / c e \text { vol.2.31 }
$$$$
\text { at12 } 94239.350
$$

c.....

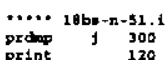

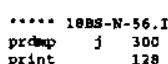

\section{Case 18bs-n-57; Table 5-3}

Comparing tiles 18be-n-51.1 and 1985-N-57.I

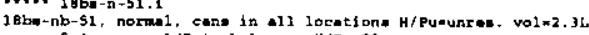

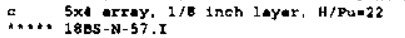

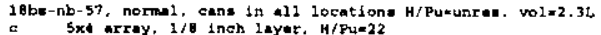

......

c... fu21 refiection 4 Addes. 3 ch top and bottoon

c volume $=2.3$ Litro

[..... $18 \mathrm{BS}-\mathrm{N}-57.1$

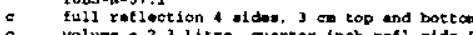

c.....

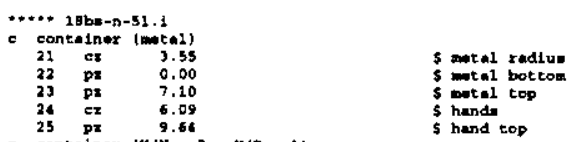

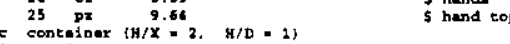

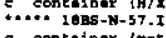

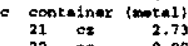

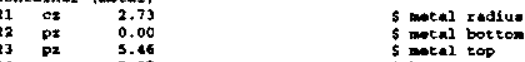

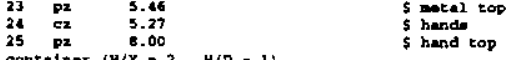

c...entainor $(\mathrm{H} / \mathrm{X}-2, \mathrm{H} / \mathrm{D}=1)$

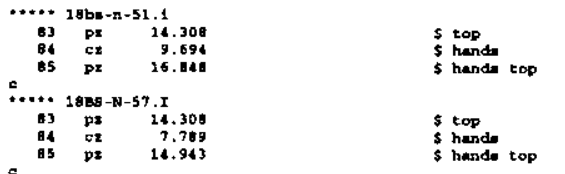

c.....

….. 18be-n-51.1

C.... 18BS-N-57.1

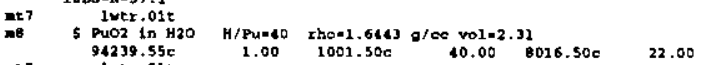

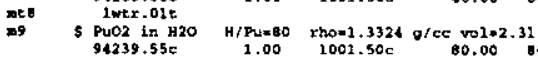

$\begin{array}{llllll}94239.55 \mathrm{C} & 1.00 & 1001.50 \mathrm{C} & 80.00 & 8016.50 \mathrm{C} & 42.00\end{array}$

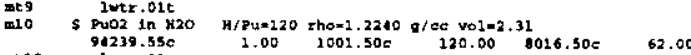

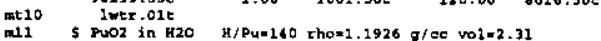

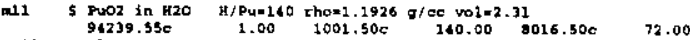

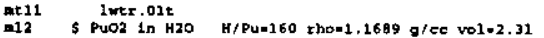

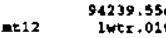

c.....

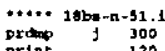

….. $18 \mathrm{BS}-\mathrm{N}-57 . \mathrm{I}$

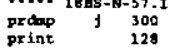

\section{Case 18bs-n-58; Table 5-3}

Comparing files $18 \mathrm{bm}-\mathrm{n}-51.1$ and $18 \mathrm{BS}-\mathrm{N}-58 . \mathrm{I}$

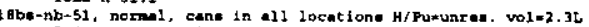
…. 5xt array. 110 ingh 1ayar. $\mathrm{H} / \mathrm{Pu}=22$

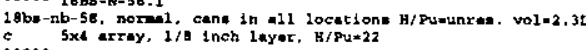

C.... 18bs-n-51.1

c full rotlection $1+1$ dow, $3 \mathrm{~cm}$ top and botton

c

C....* $198 \mathrm{BS}-\mathrm{N}-\mathrm{5R}, \mathrm{I}$

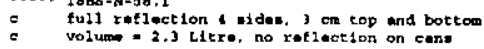

E.....

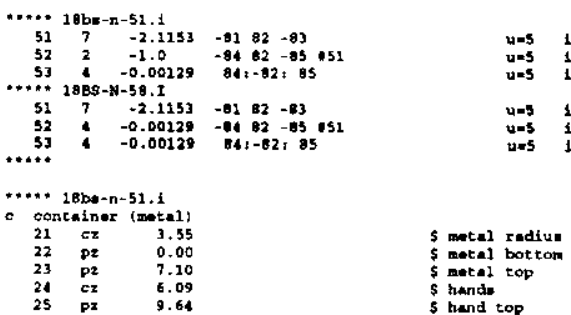




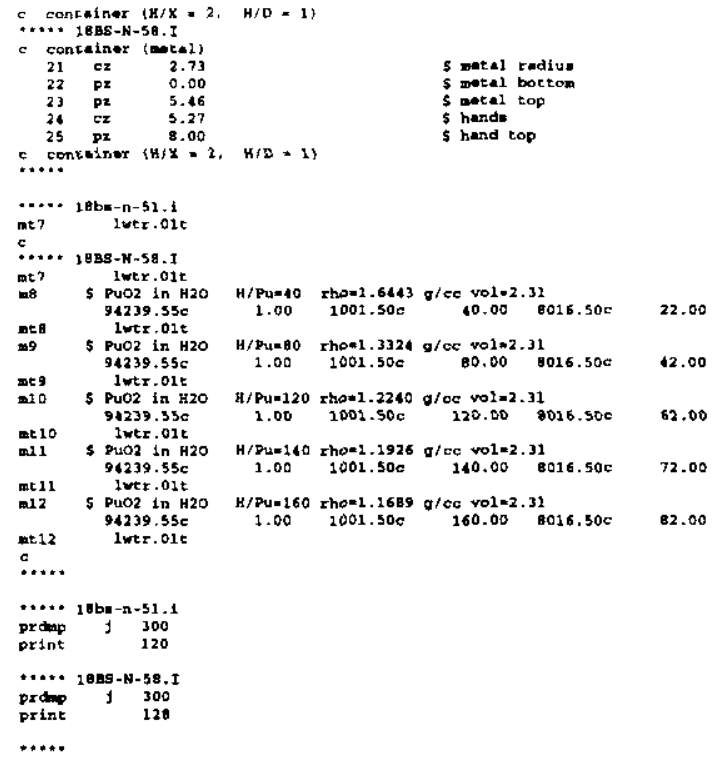

\section{Case 18bs-b-11; Table 5-4}

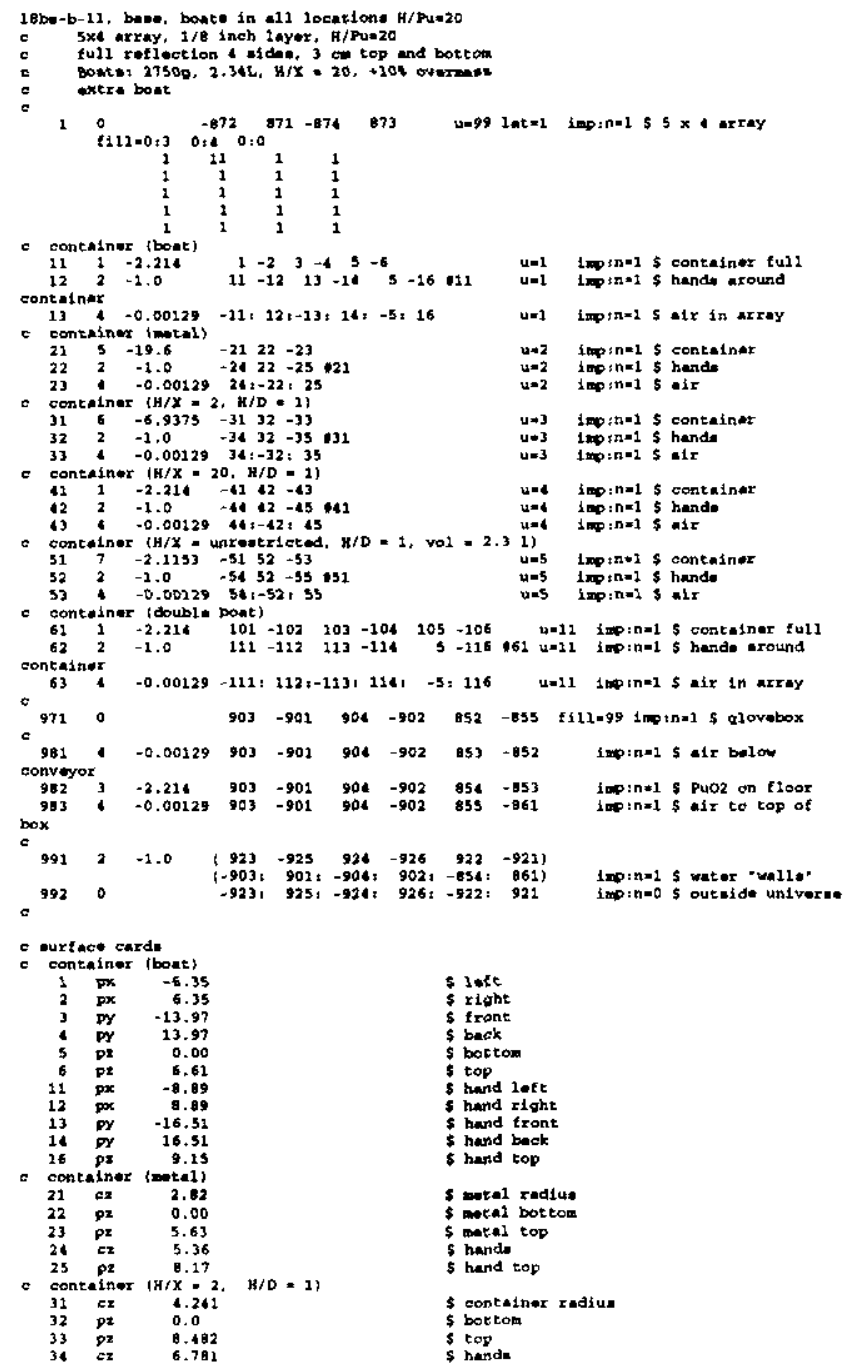

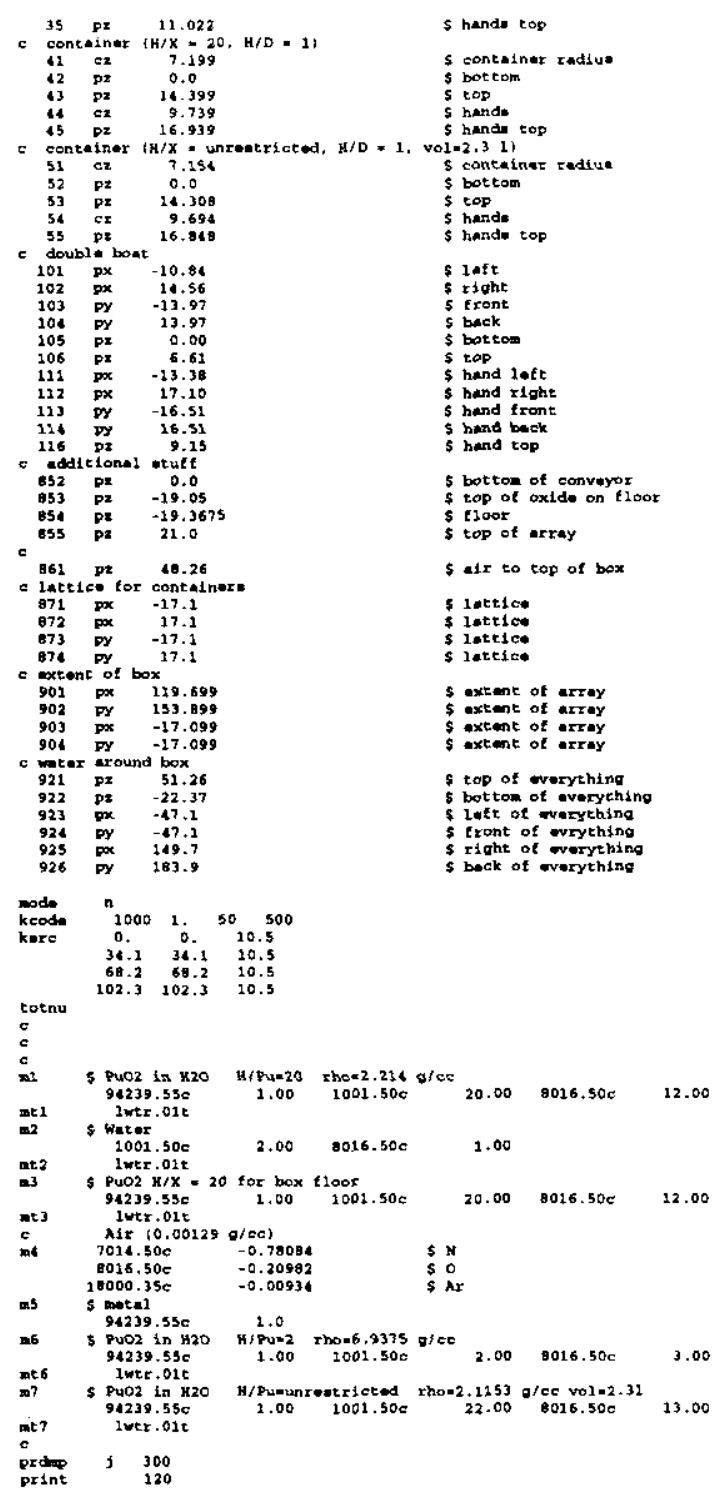

Case 18bs-b-21; Table 5-4

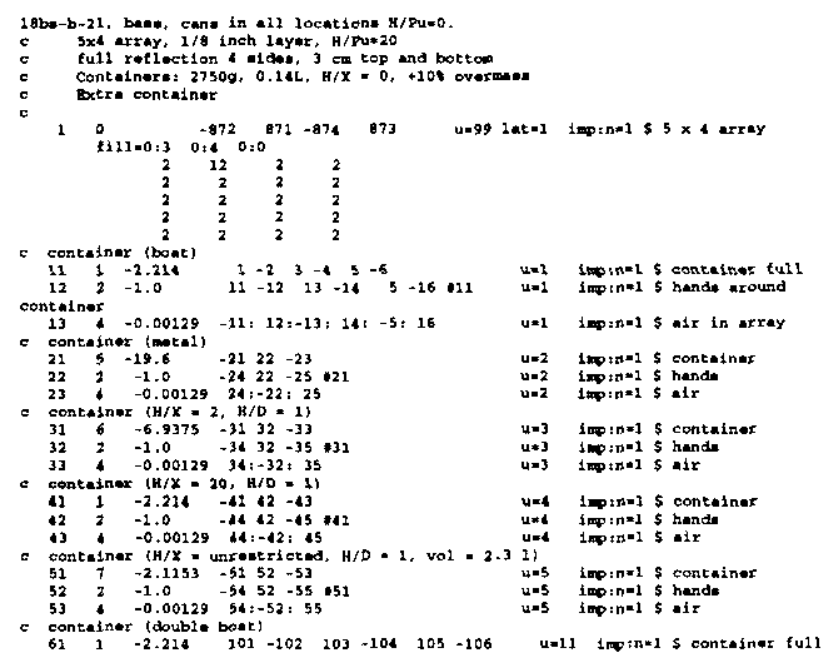




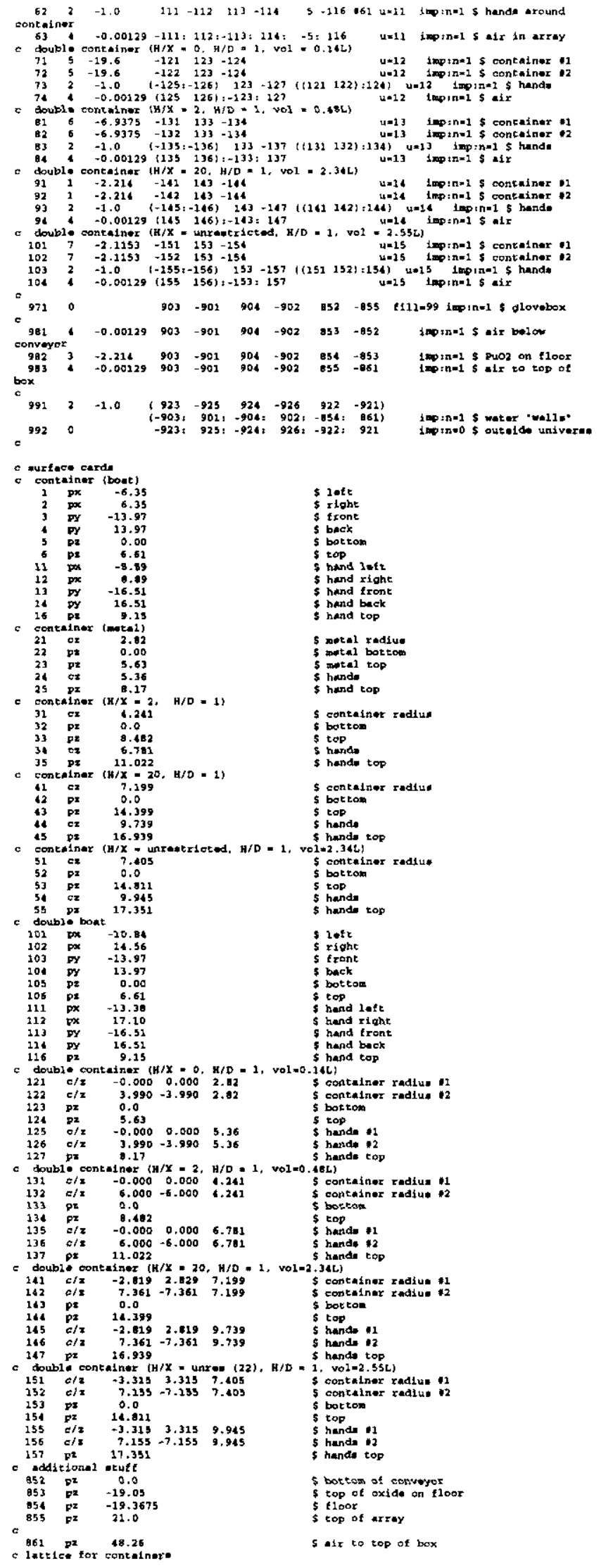

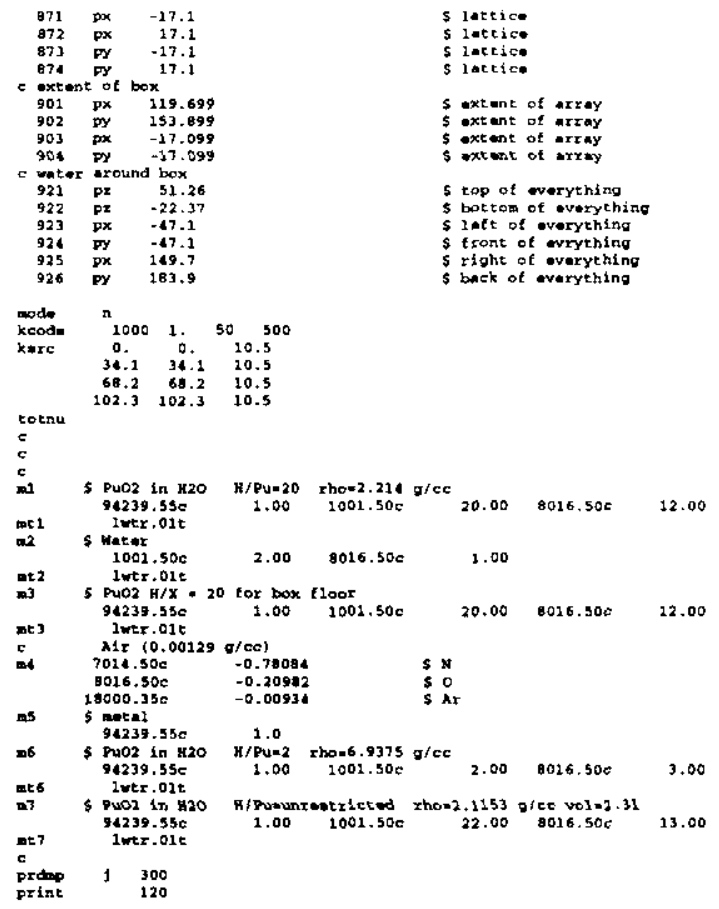

\section{Case 18bs-b-31; Table 5-4}

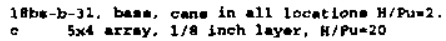

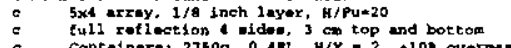

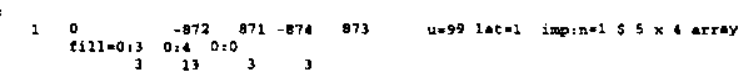

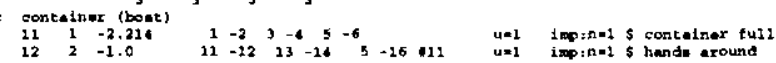

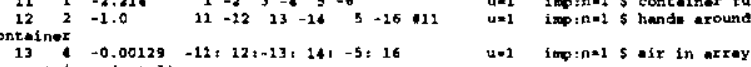

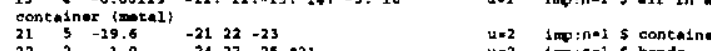

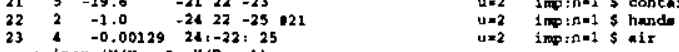

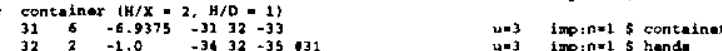

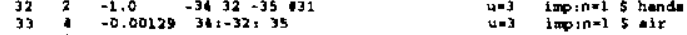

container $(H / X=20, H / D=1\}$
$11 \quad 1 \quad-2.214-41,22-43$

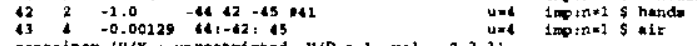

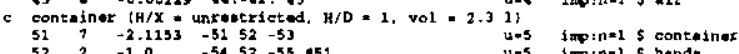

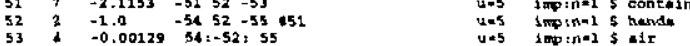

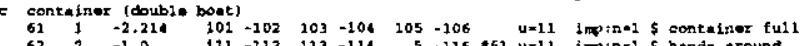
Containox $131-112113-1$

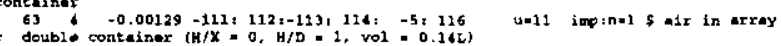

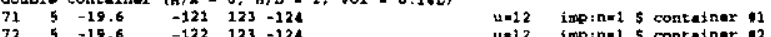

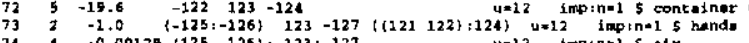

$74:-0.00129$ (125 126$):-123: 127$ (12) 0.406$)$

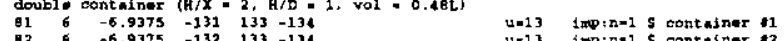

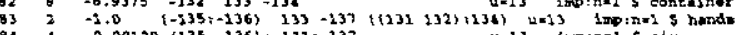

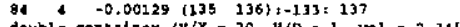

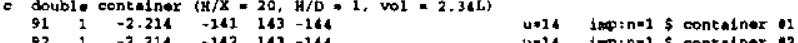

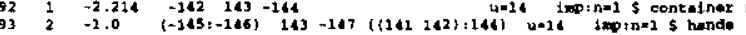

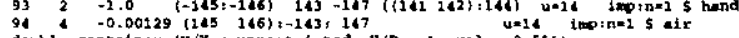

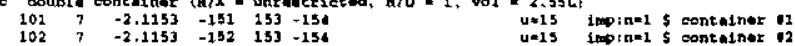

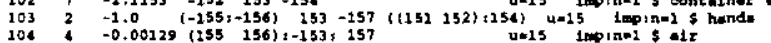

$9710 \quad 903 \quad-901 \quad 904 \quad-902 \quad 852 \quad-855 \quad 6111 \times 99$ 10p:n=1 $\$$ glovebox

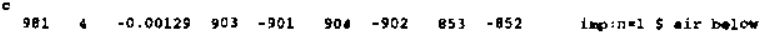

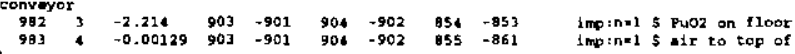

box 
HNF-6271, Rev. 0

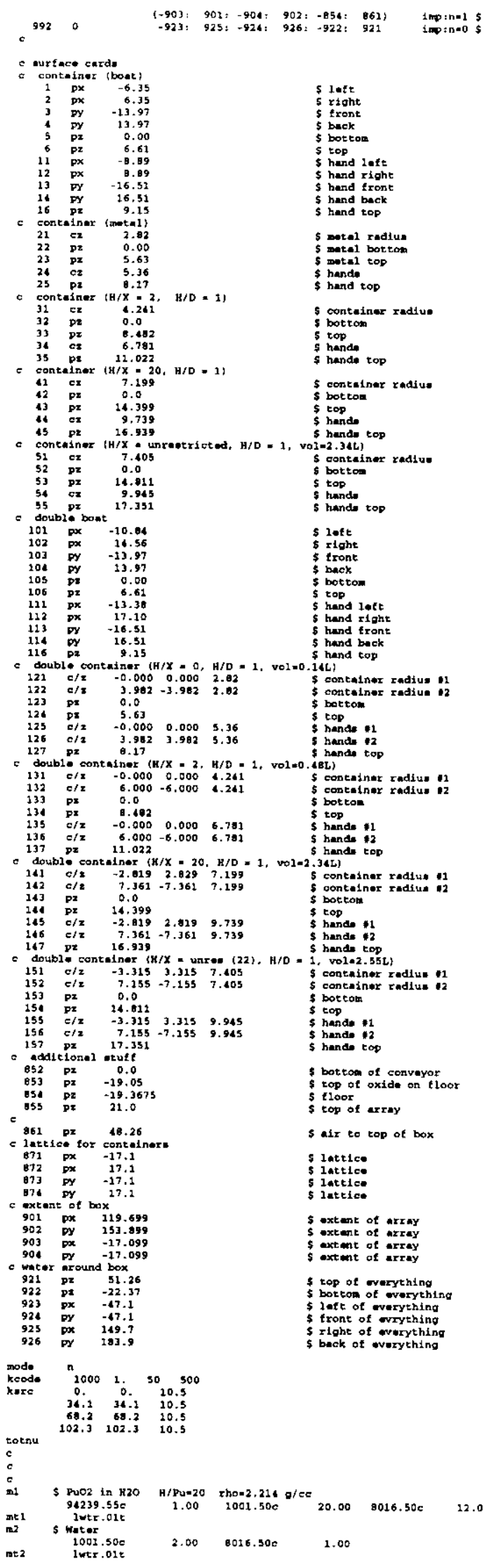

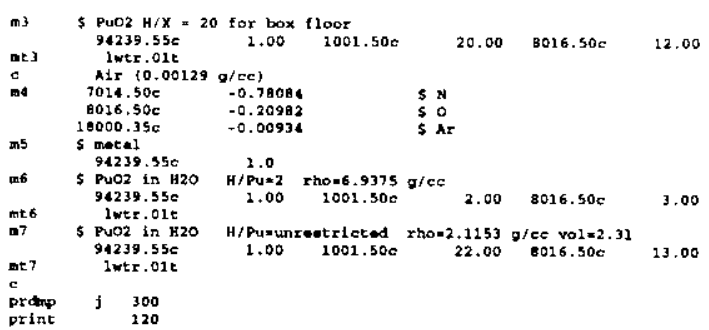

Case 18bs-b-41; Table 5-4

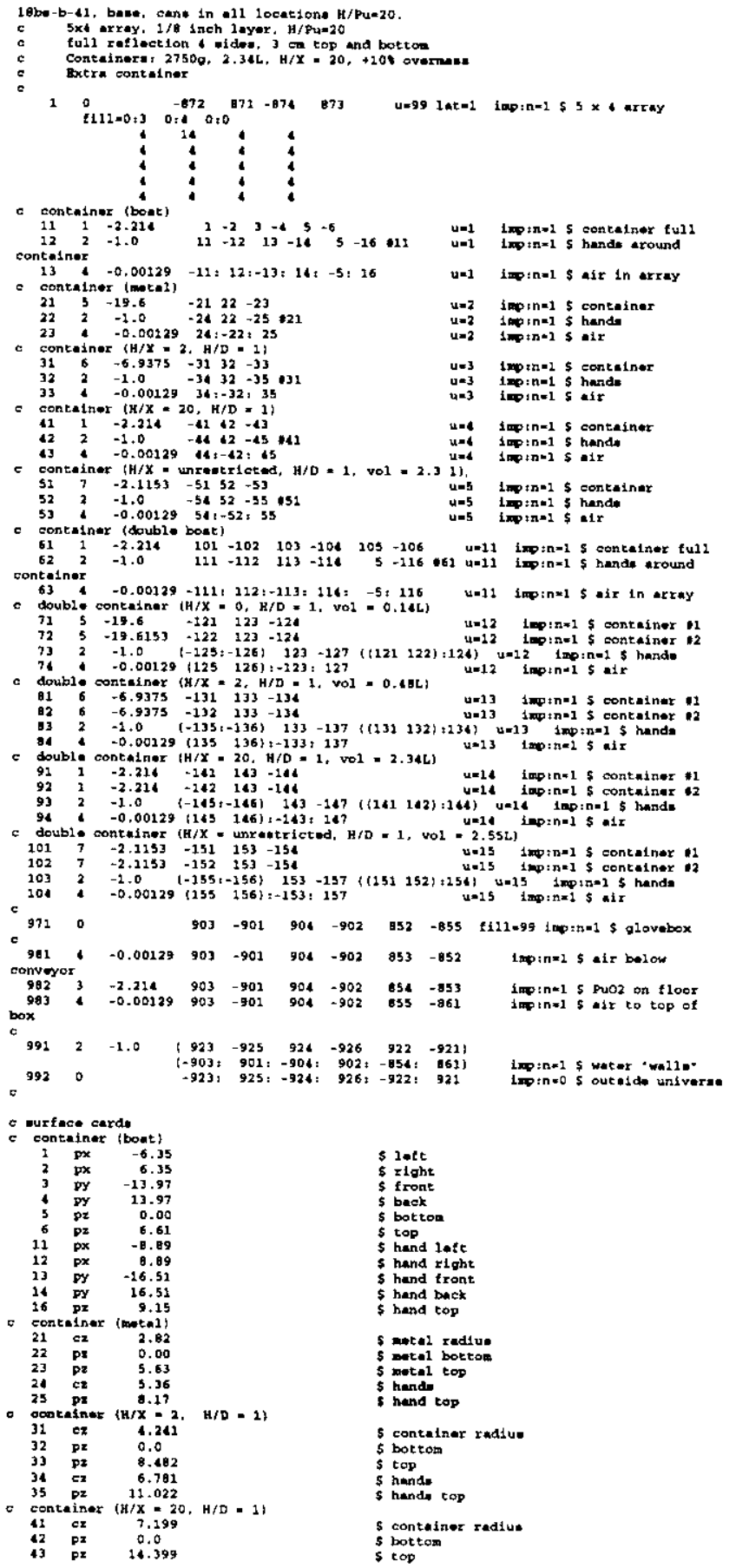




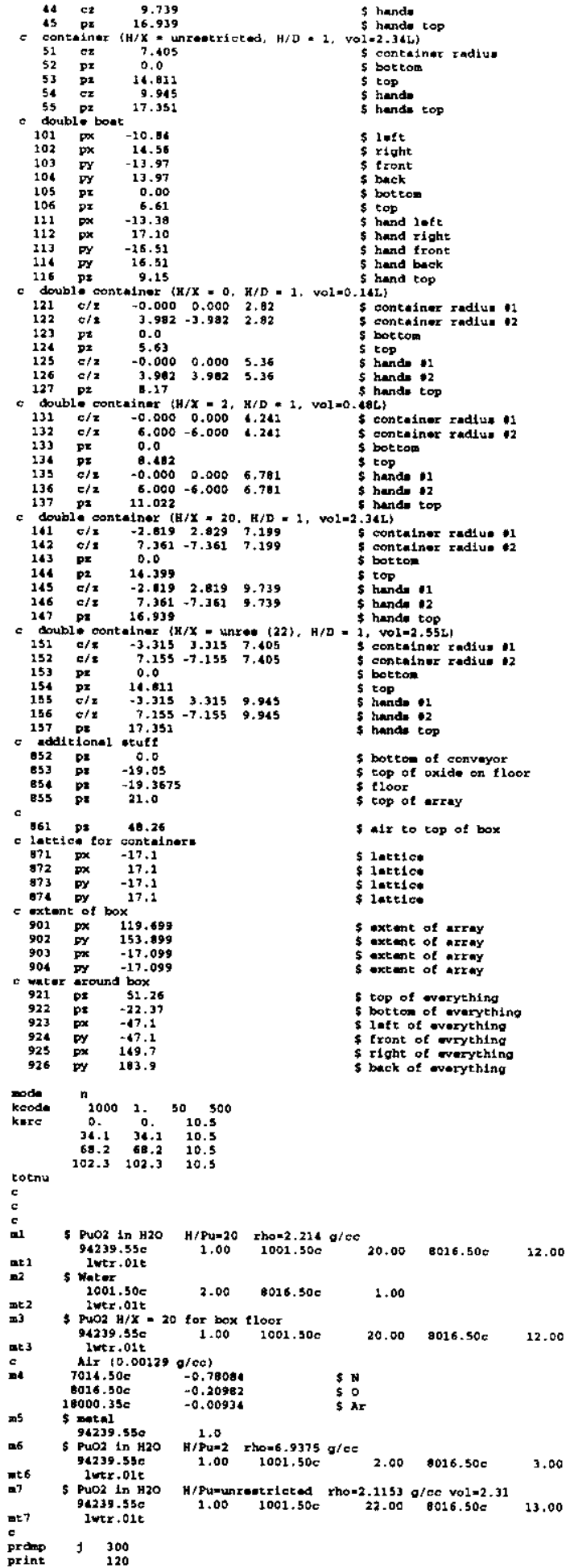

\section{Case 18bs-b-51; Table 5-4}

I9bu-b-51, bate, cane in 111 locatione $h / p u=22$.

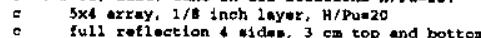

conteinars: 2750g, $2.55 \mathrm{~L}, \mathrm{H} / \mathrm{X}=22,+104$ overman:

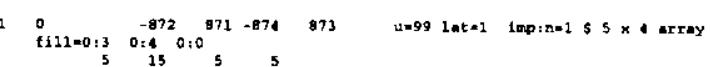

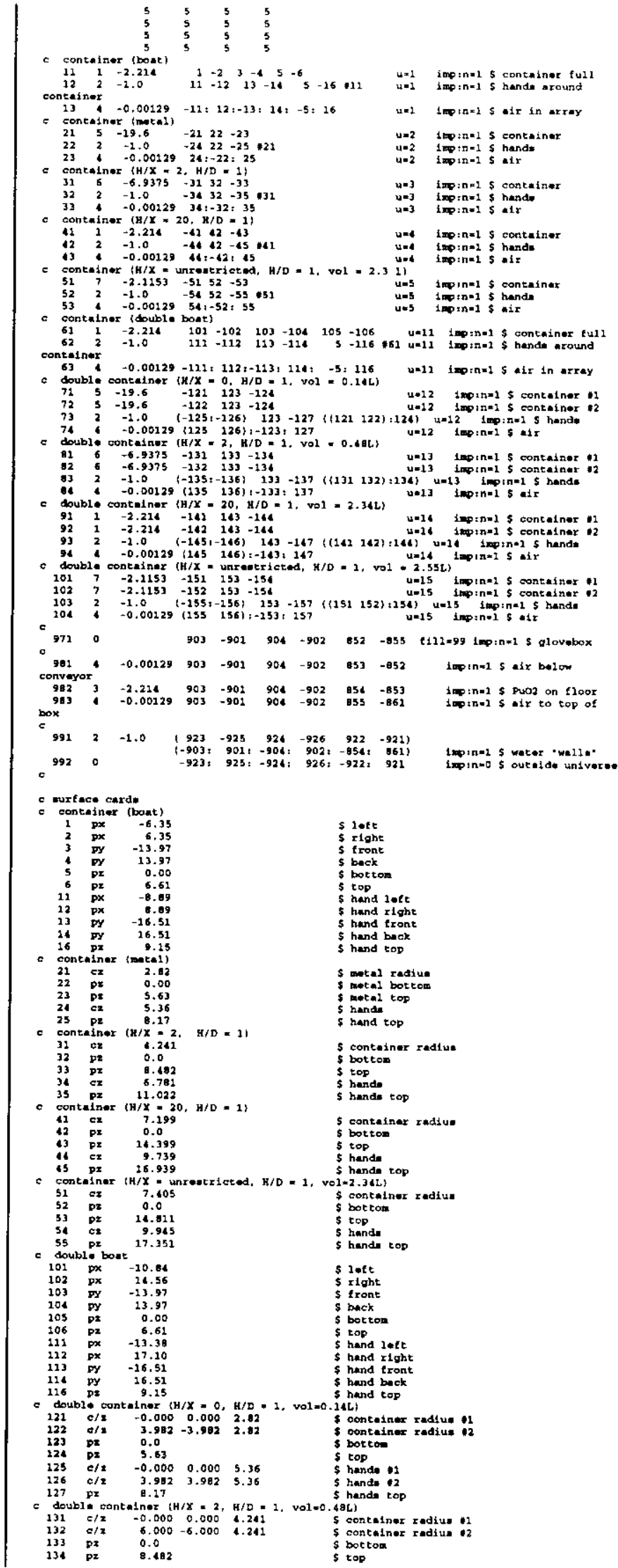




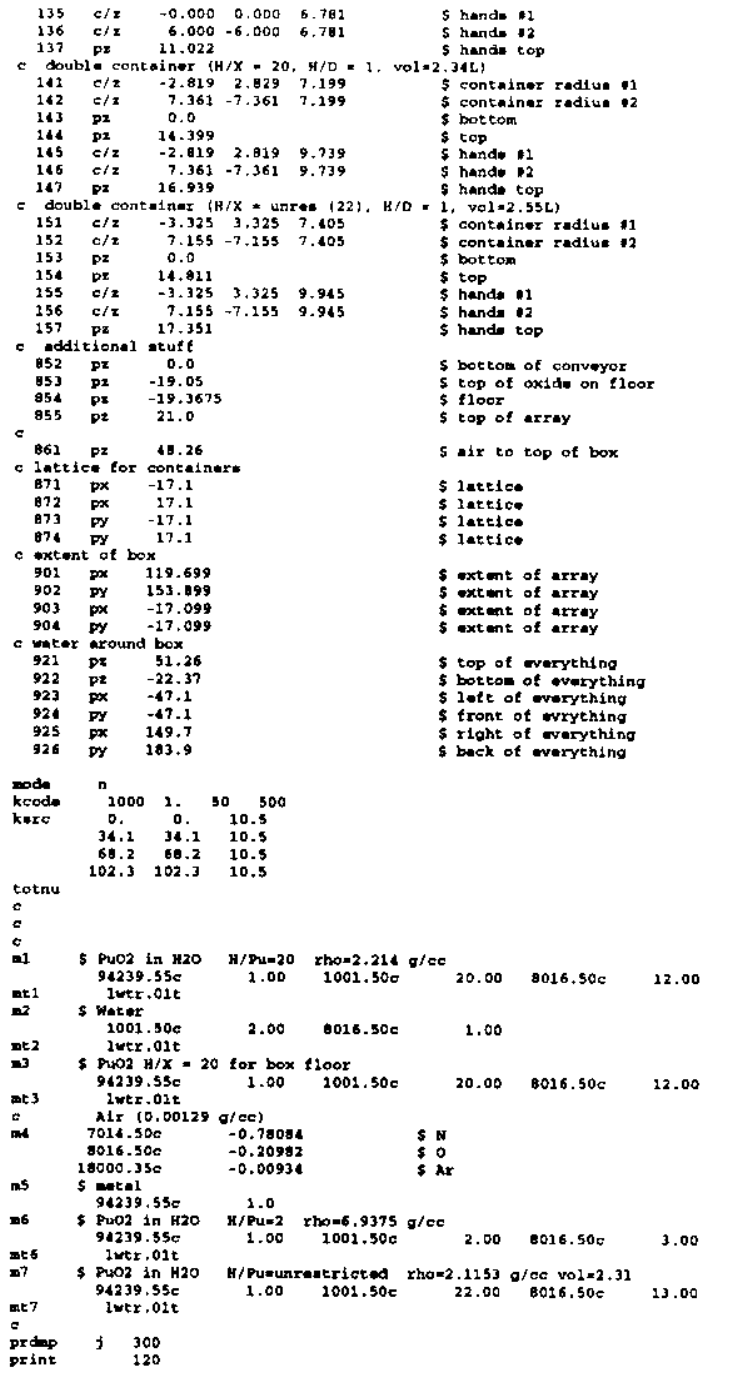

\section{Case 18bs-b-61; Table 5-4}

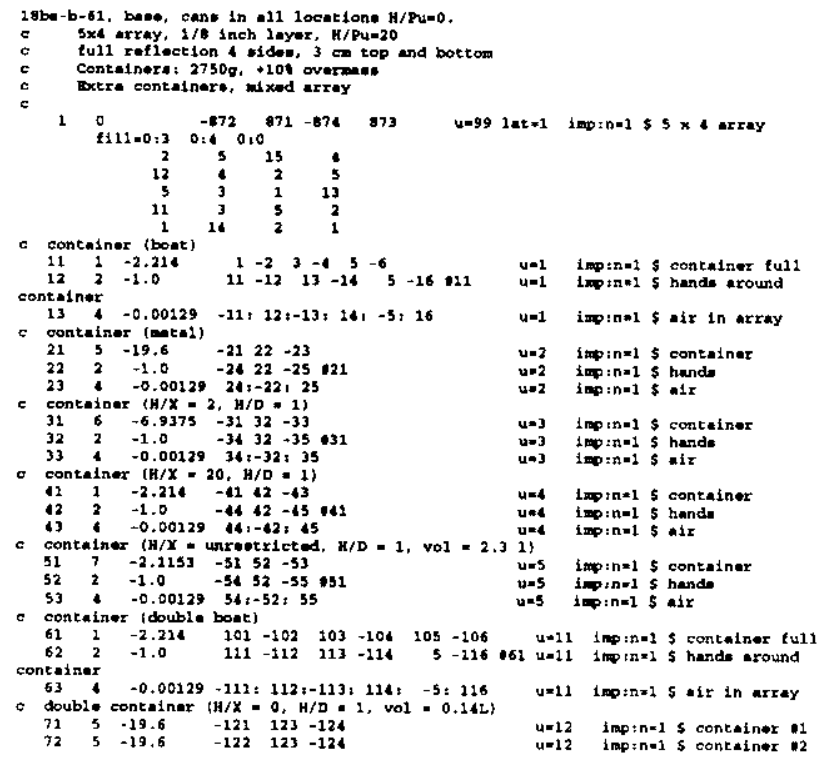

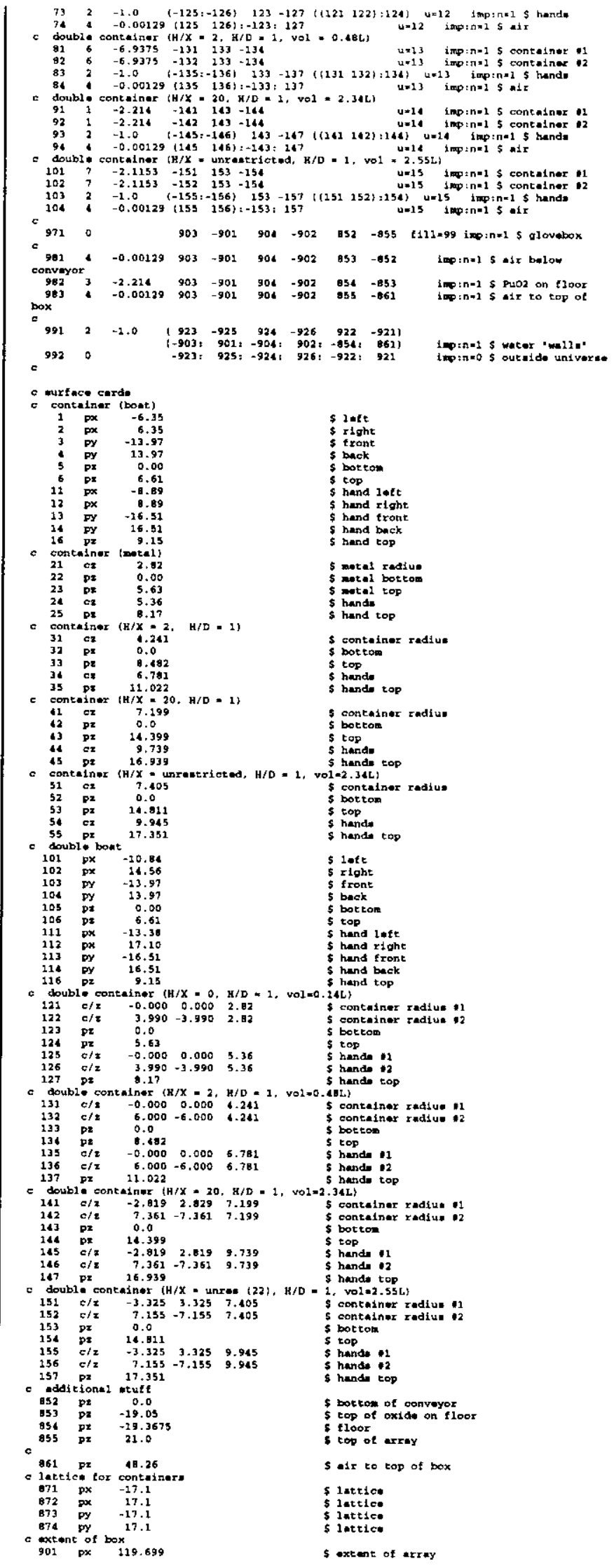


HNF-6271, Rev. 0

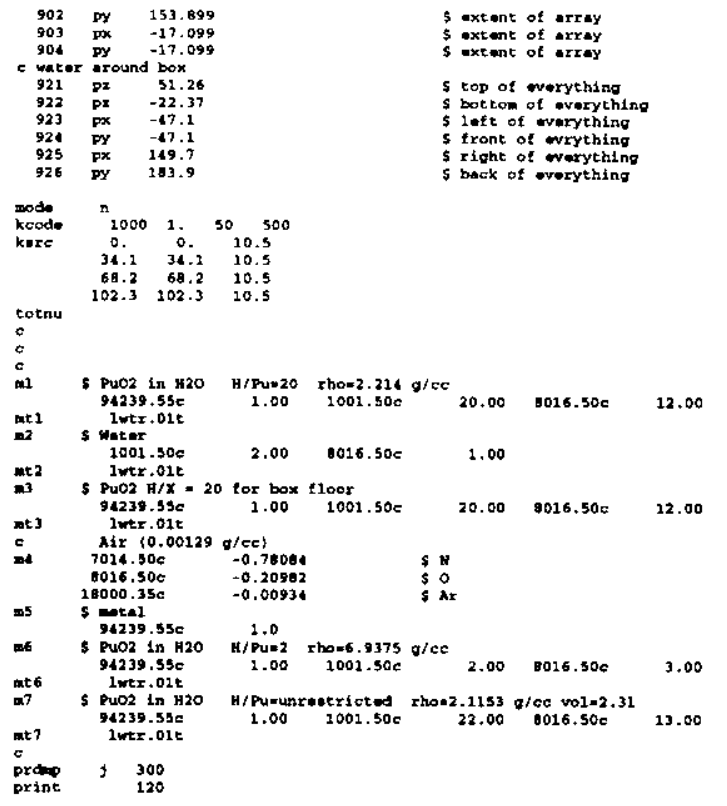

\section{Case 18bs-ou-25; Table 5-5}

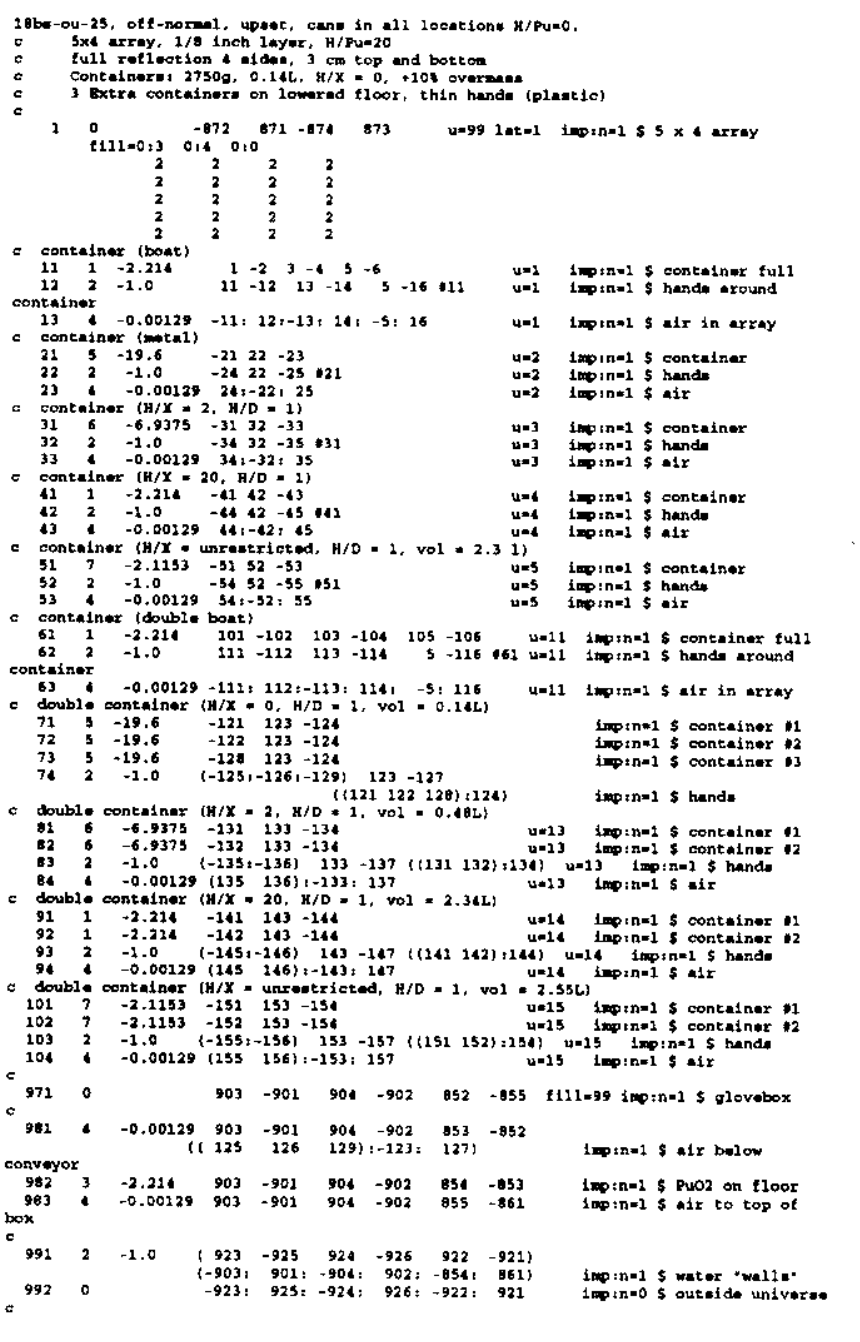

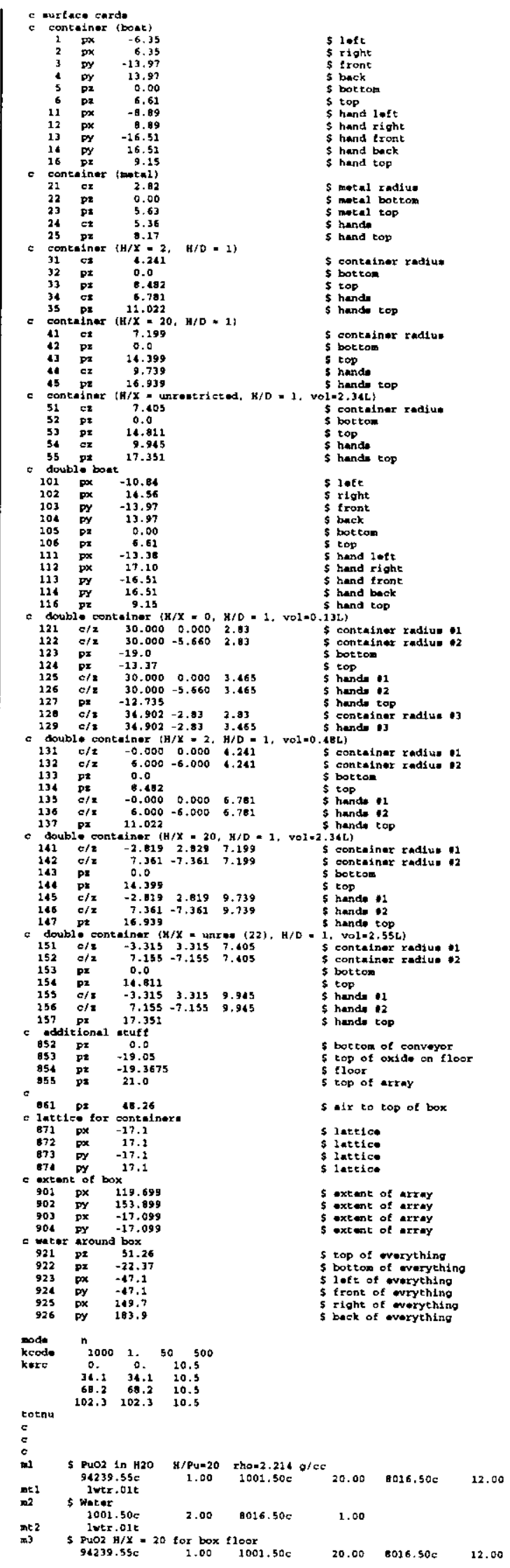


HNF-6271, Rev. 0

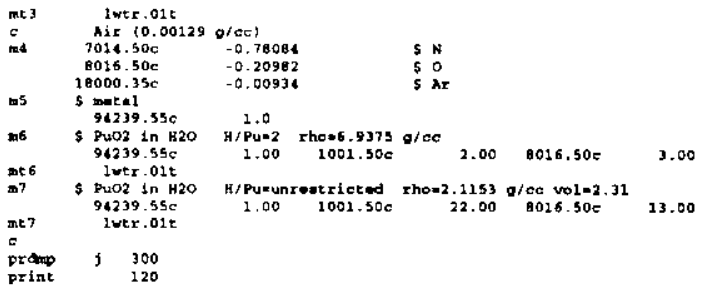

Case 18bs-ou-43; Table 5-5

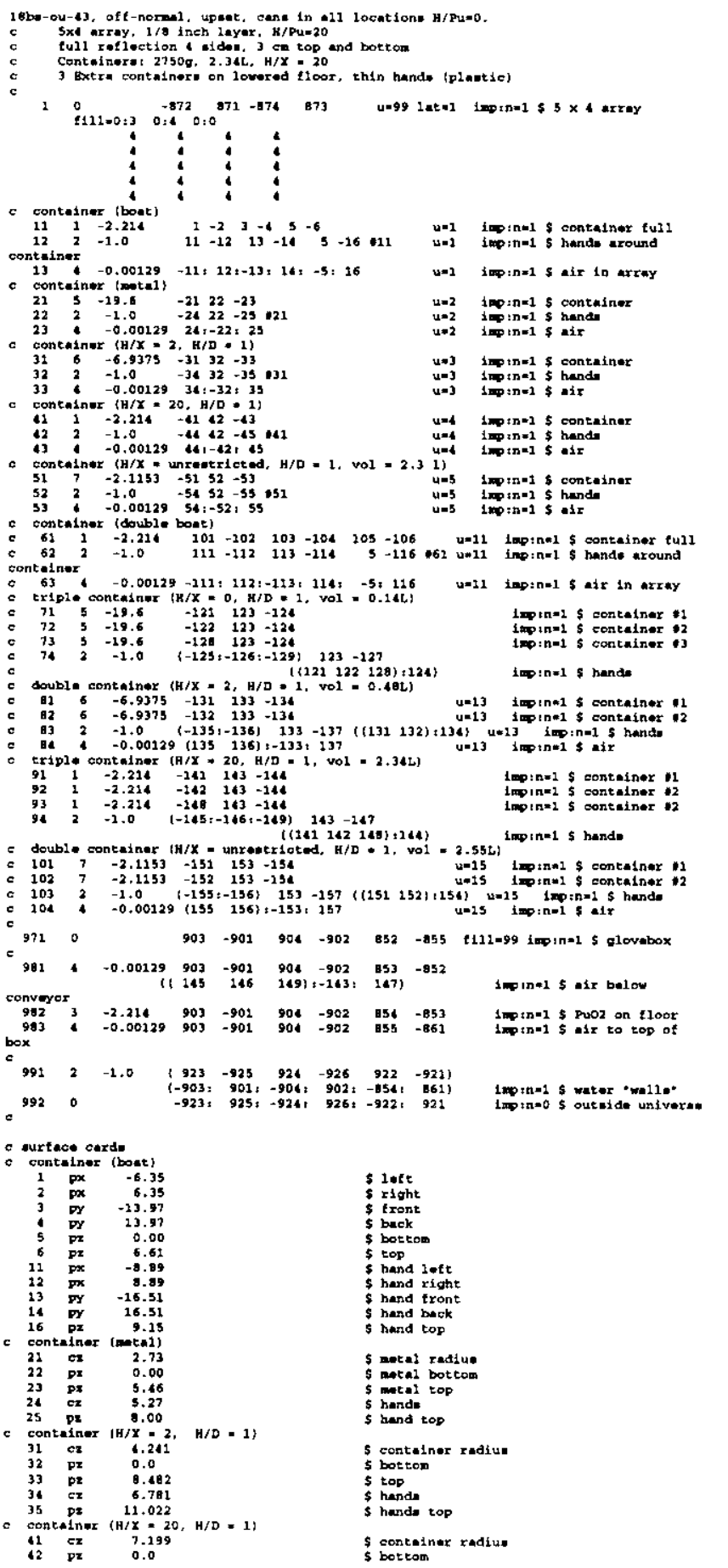

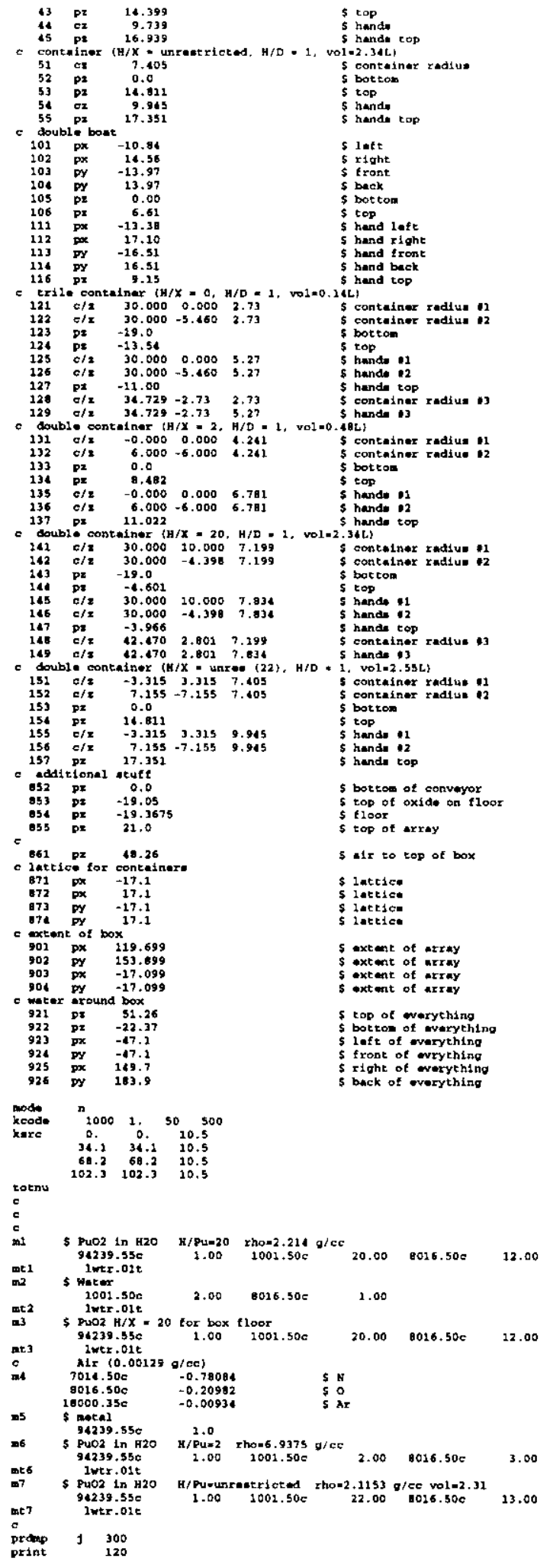


HNF-6271, Rev. 0

Case 18bs-ou-44; Table 5-5

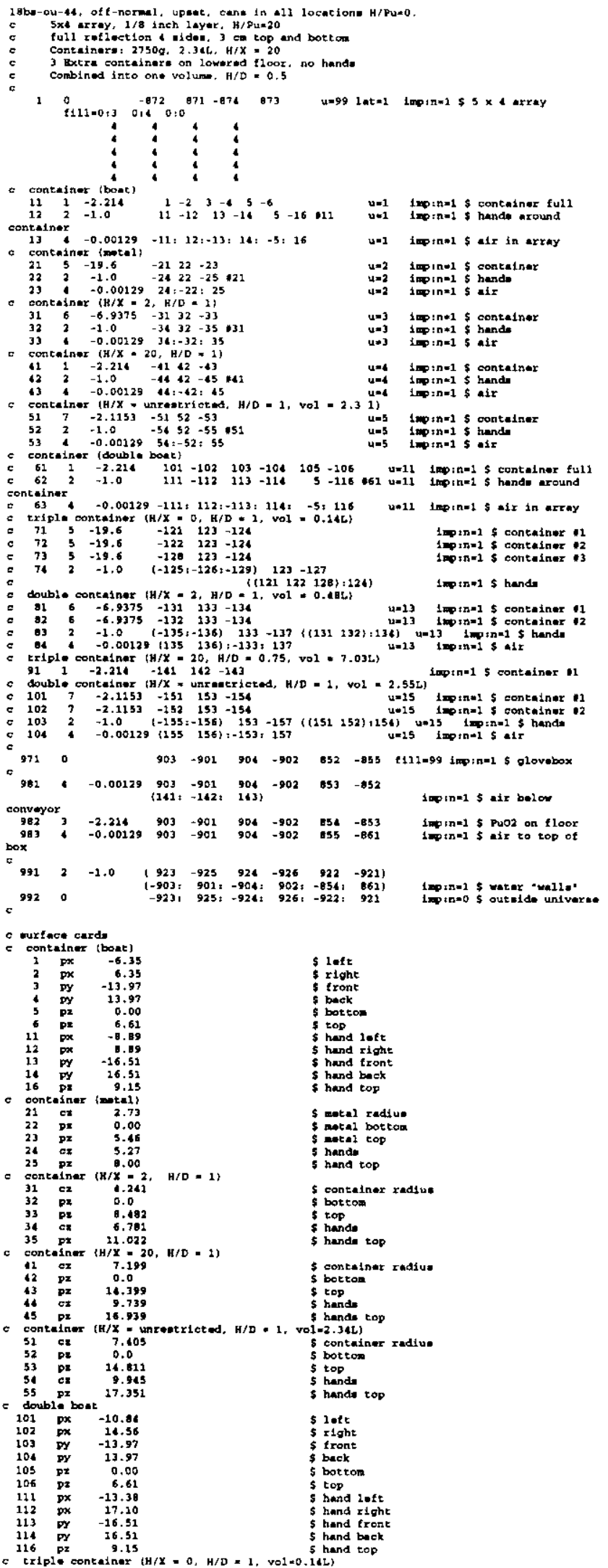

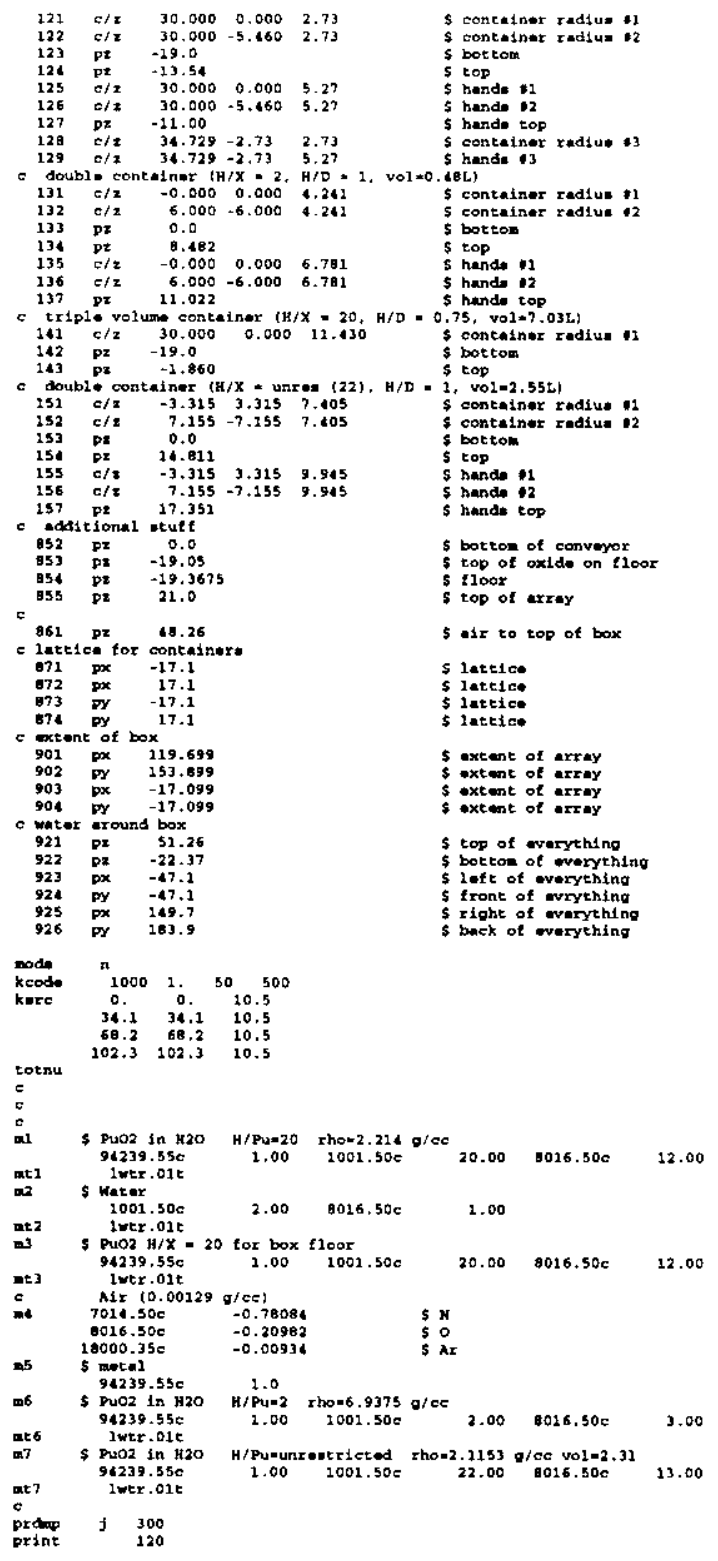

\section{Case 18bs-om-12; Table 5-6}

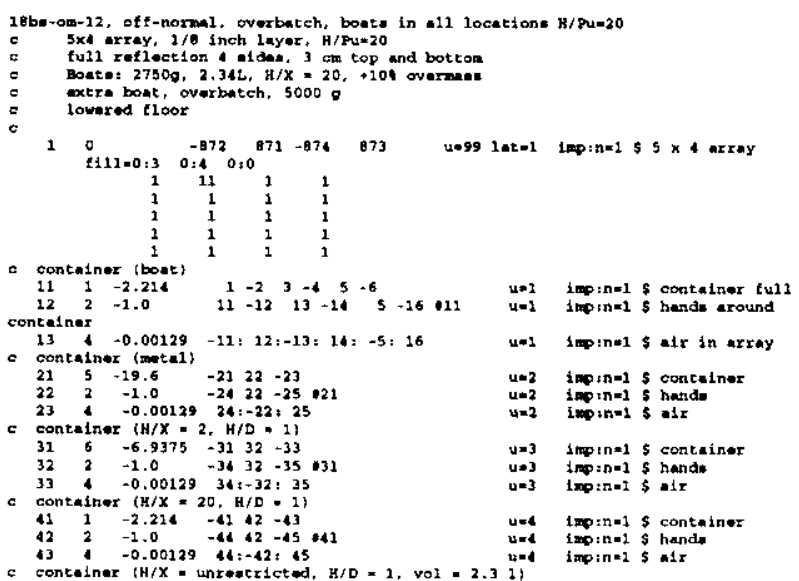


HNF-6271, Rev. 0

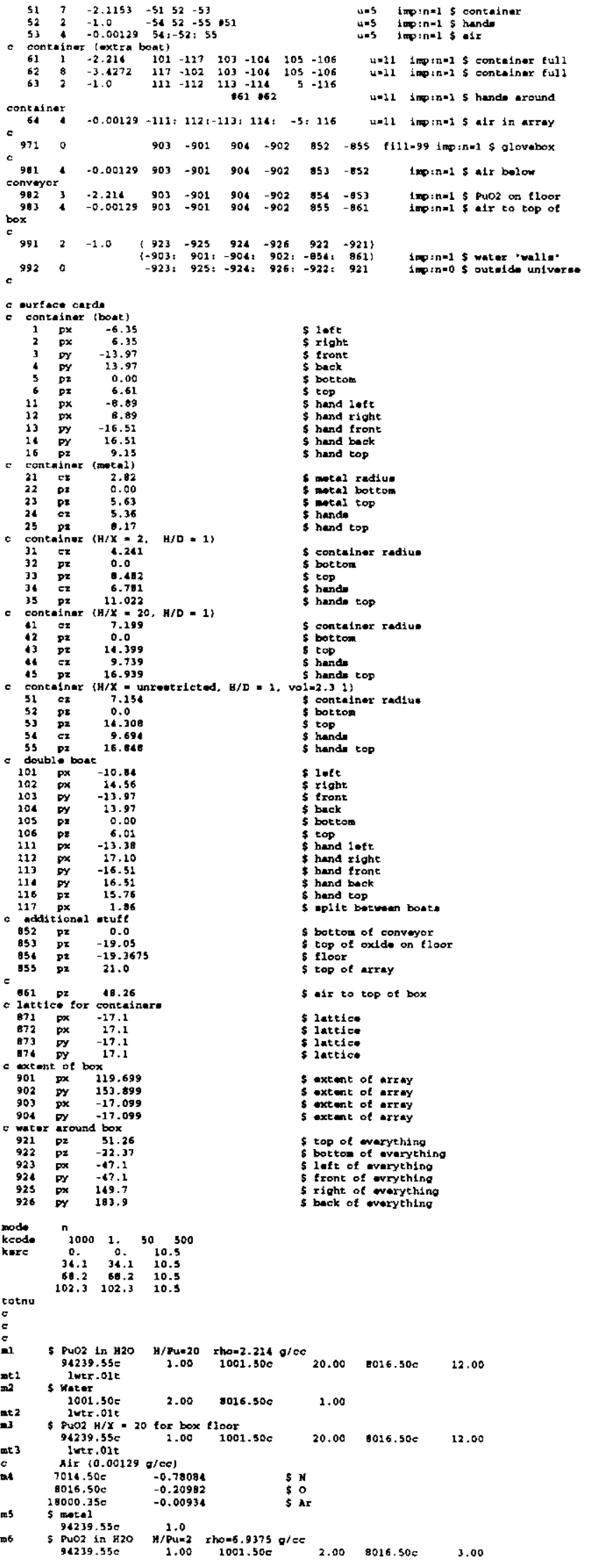

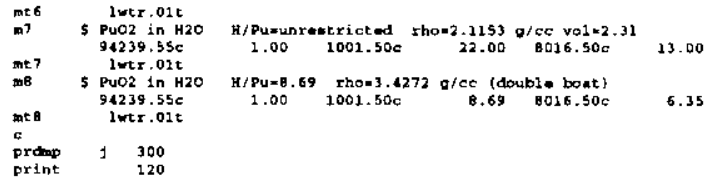

\section{Case 18bs-om-22; Table 5-6}

1labs-om-22. off-normel, overbetch, ome in all locetione H/PUNO. ful $x$ ef ect

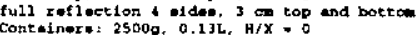

Rxtra. double mane, 5000 g

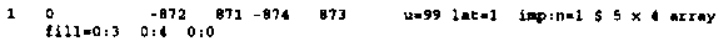
$\begin{array}{rrrr}011=0: 3 & 0: 4 & 0: 0 & \\ 2 & 12 & 2 & 2 \\ 2 & 2 & 2 & 2 \\ 2 & 2 & 2 & 2 \\ 2 & 2 & 2 & 2 \\ 2 & 2 & 2 & 2\end{array}$

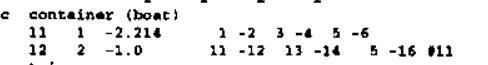

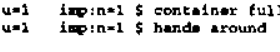

conteiner $-0.00129-11,12,-23,140$

containet (mete

$-11 \div 12:-13: 14:-5: 16$

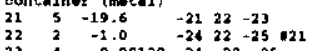

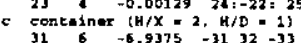

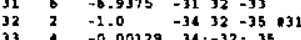

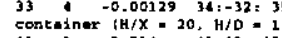

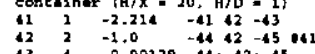

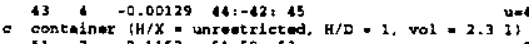

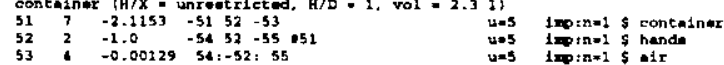

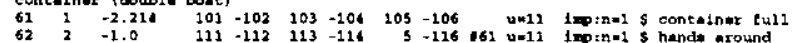

$63+-0.00129-111: 1121-113: 116:-5: 116$

C double container (H/X $=0, H / D=1$, vol $=0.136)$

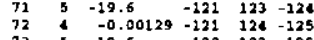

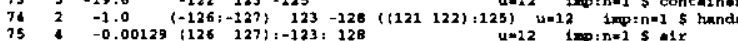

a doubl. container ( $\mathrm{H} / \mathrm{X}=2, \mathrm{H} / \mathrm{D}=1$, vol $=0.4 \mathrm{QL}$ )

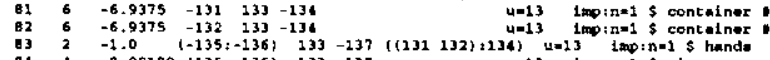

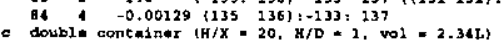

$\begin{array}{llllll}91 & 1 & -2.214 & -141 & 143 & -14 \\ 92 & 1 & -2.214 & -142 & 143 & -14\end{array}$

$9320 \quad \begin{aligned} & u=14 \\ & y=14 \\ & i m p i n=1\end{aligned}$

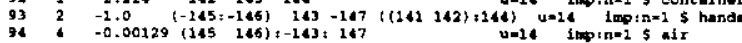

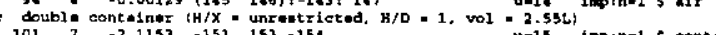

$\begin{array}{llllllll}101 & 7 & -2.1153 & -151 & 153 & -154 \\ 102 & 7 & -2.1153 & -152 & 153 & -154 & \text { un } & \end{array}$

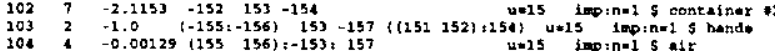

$9710 \quad 903 \quad-901 \quad 904 \quad 902 \quad 852$-855 $\quad 1111-99$ ixpin=1 5 glovebox

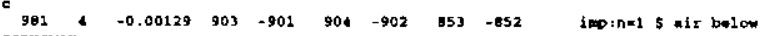

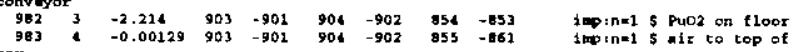

box

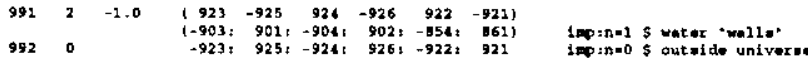

.

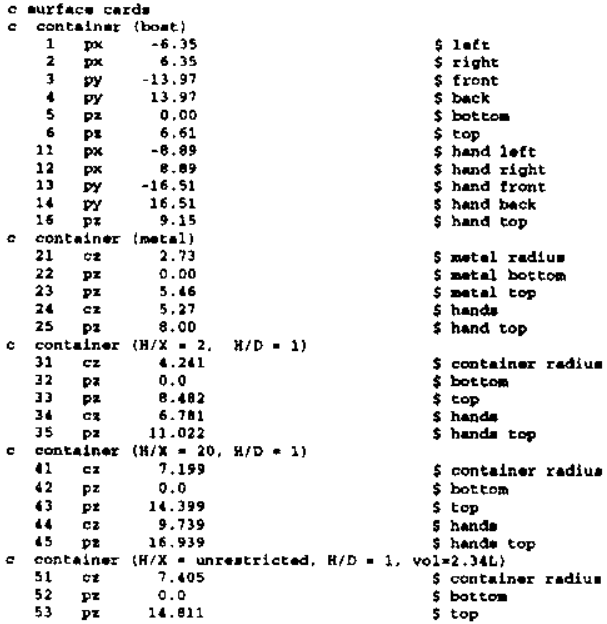


HNF-6271, Rev. 0

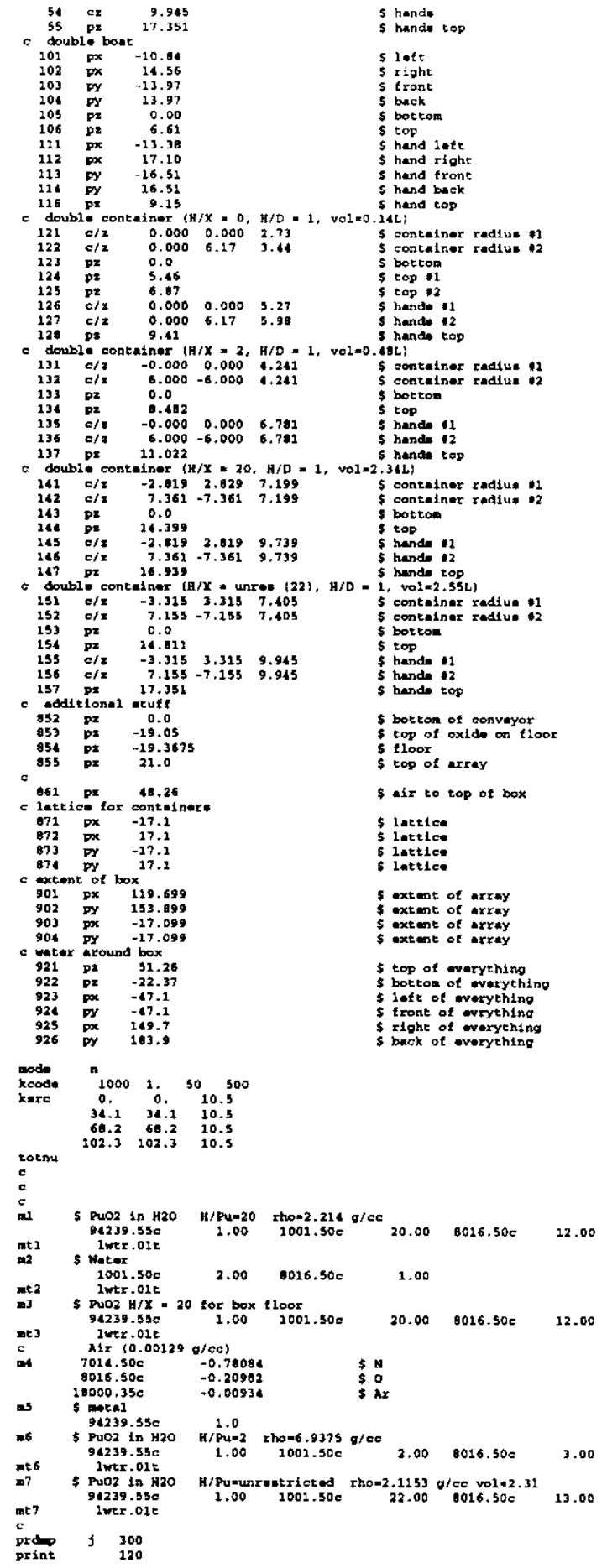

\section{Case 18bs-om-42, Table 5-6}

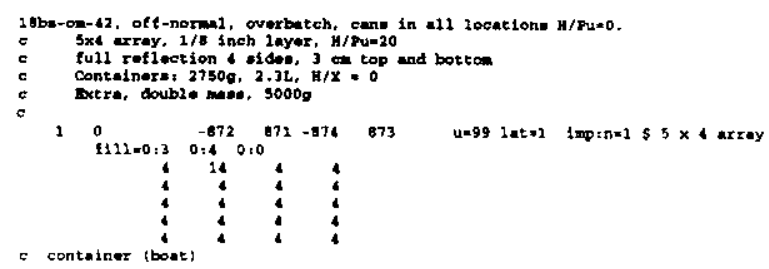

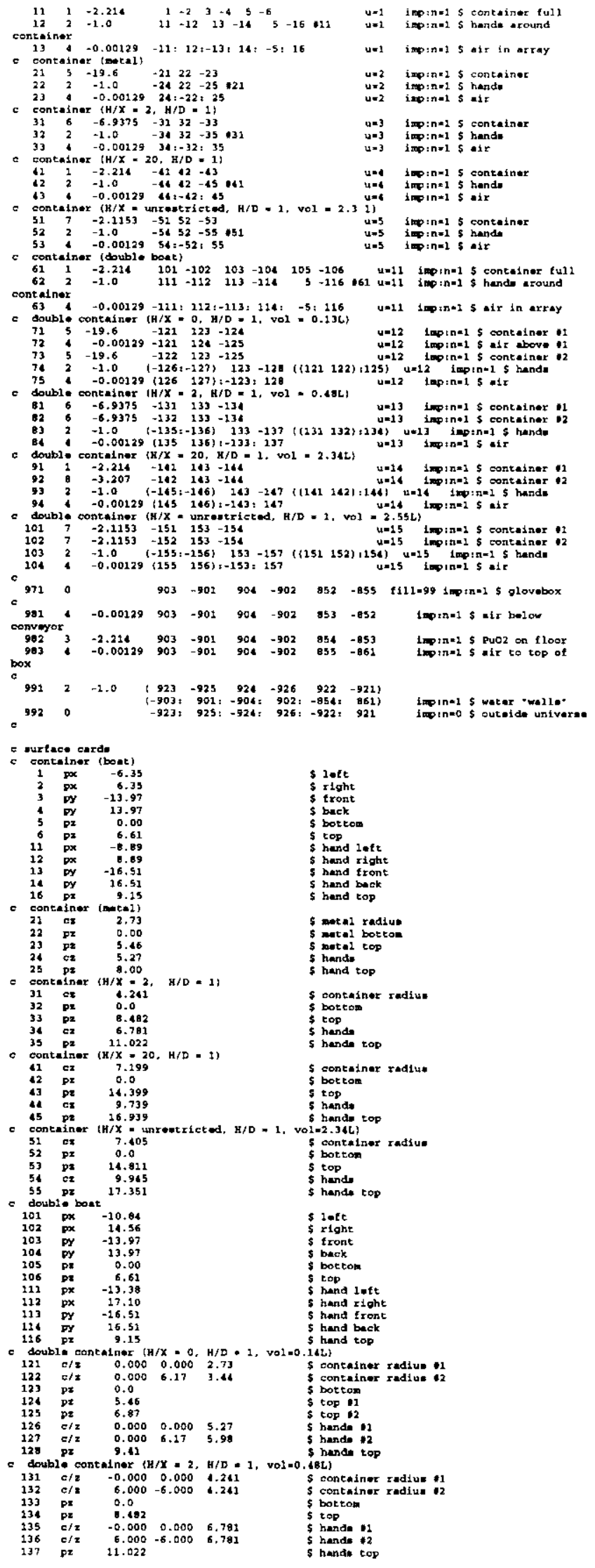




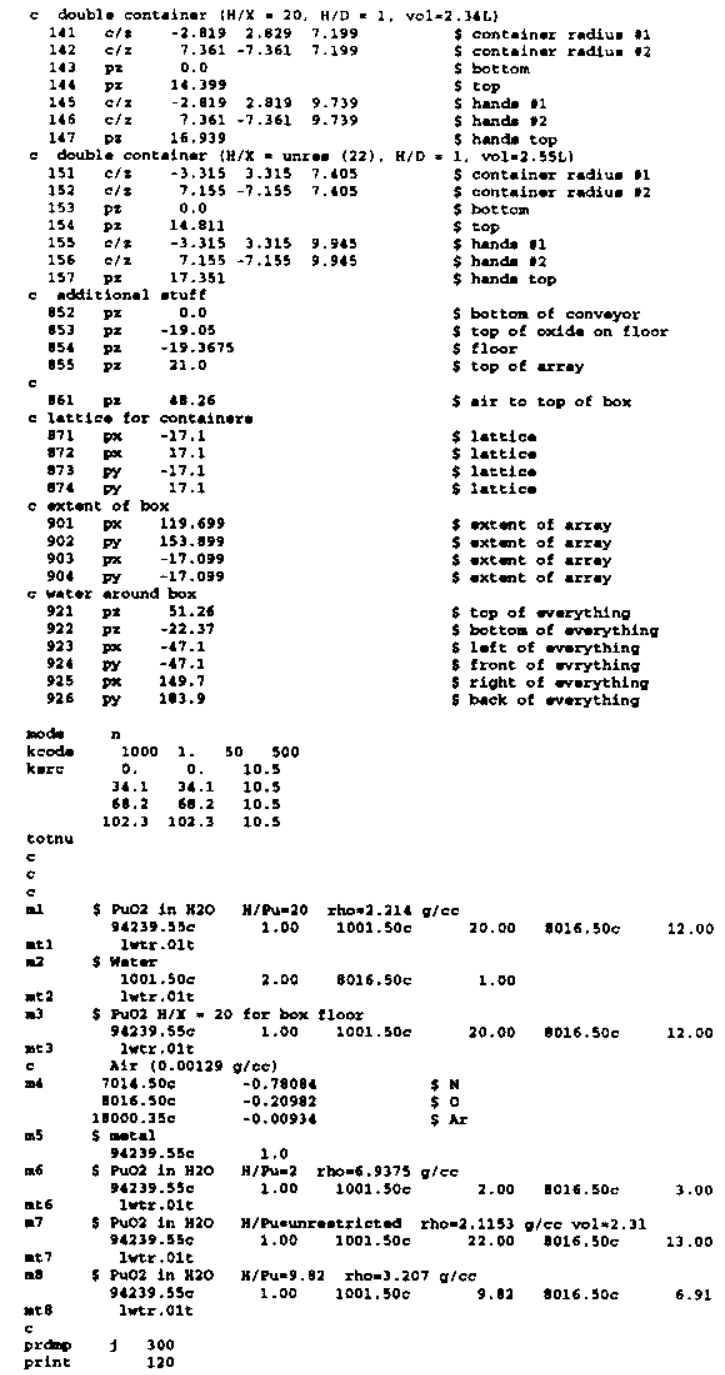

Case 18bs-os-23; Table 5-7

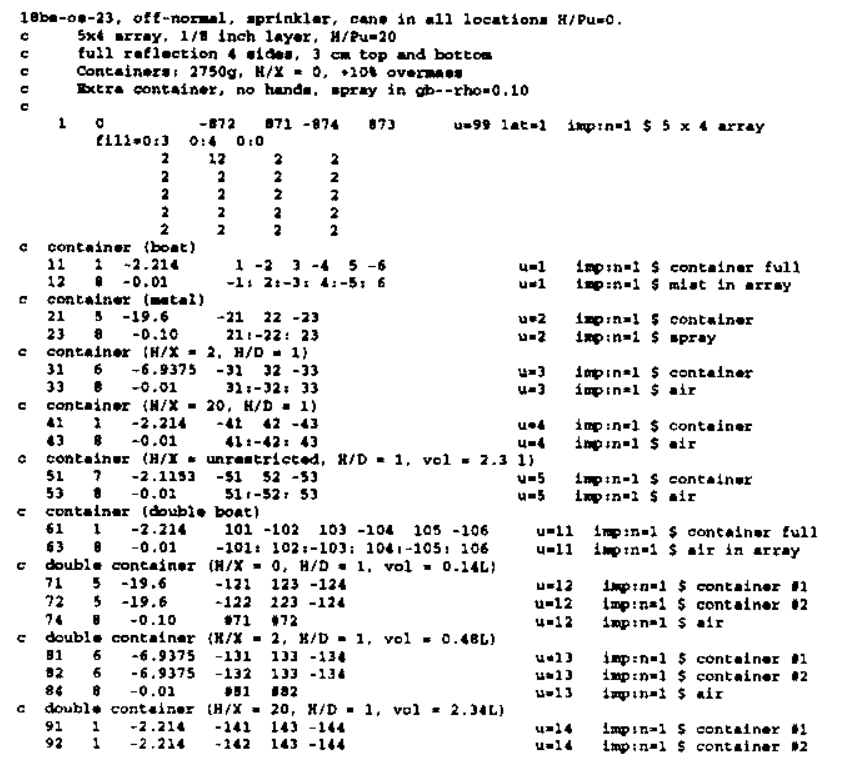

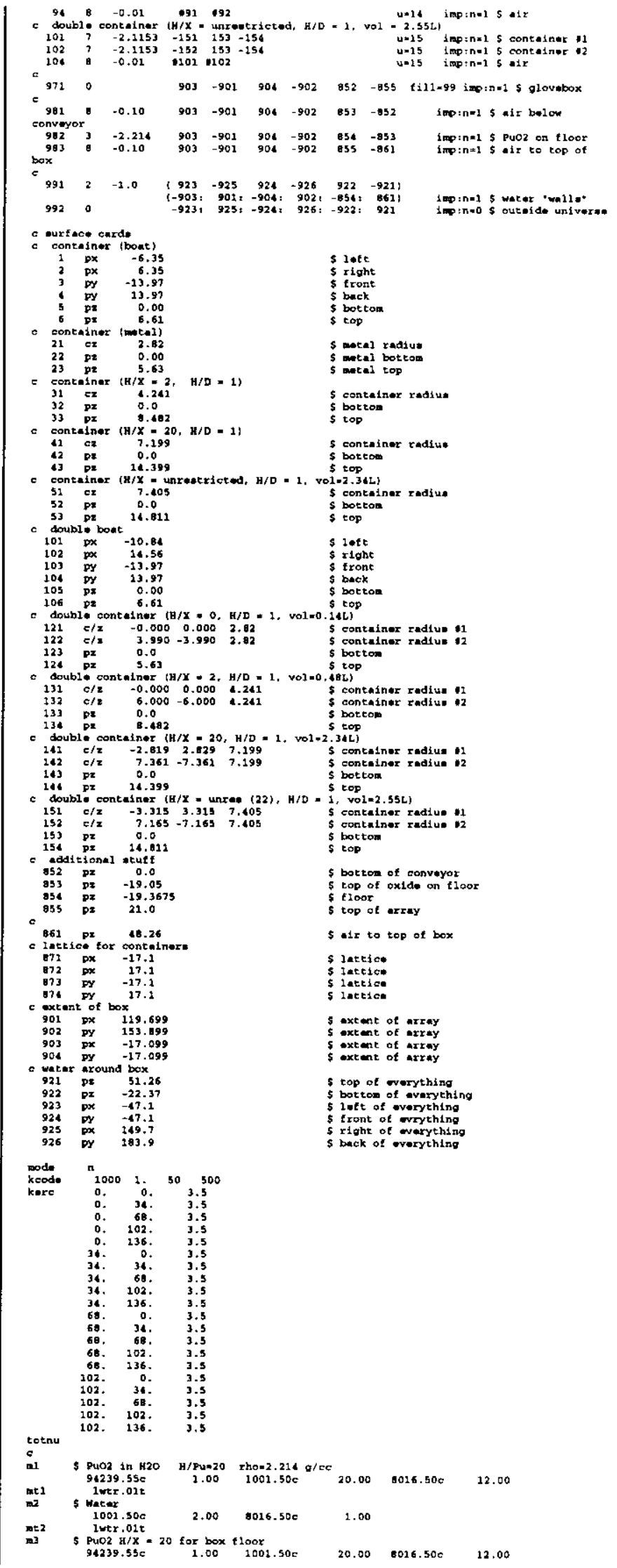


HNF-6271, Rev. 0

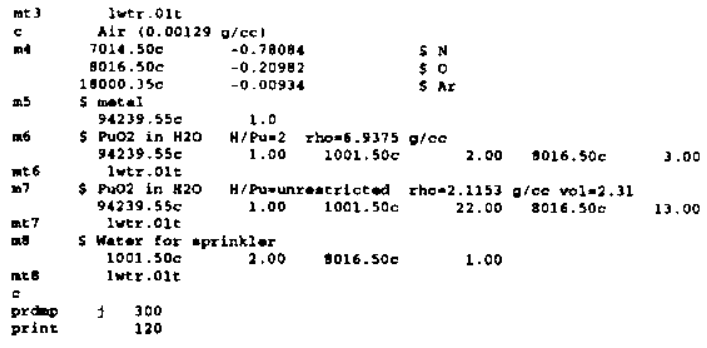

\section{Case 18bs-os-24; Table 5-7}

Conparting tiles 18b-on-23.1 and 1Bss-os-24.I

18bu-ou-23, oft-nomal, sprinklwx, ane in all locatione H/Pu=O.

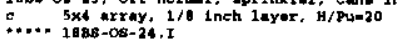

1 bbe-os-24, off-normal, Jprink1ex, case in 11 locations K/PUk0.

c... 5x4 array, 1/8 1nch 1ayer, K/Pue20

…. 19be-01-23.1

(10) overas

coxtre conteiner, no hendu, epray in ob--rho-0,10

..... 1ses-08-24.

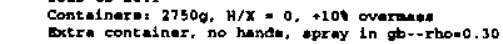
c....

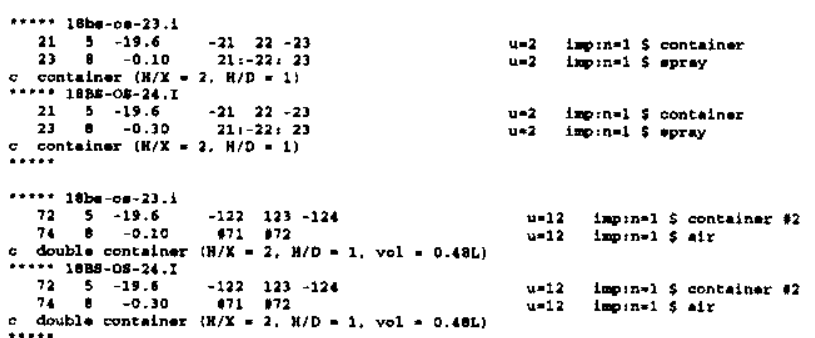

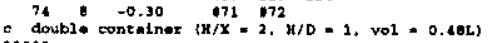

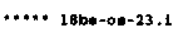

$\begin{array}{cccccccc}981 & -0.10 & 903 & -901 & 904 & -902 & 053 & -852\end{array}$

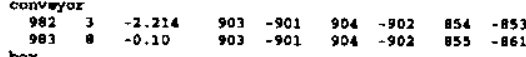

Imogin=1 $\$$ atr below

c.... 19as-os-24.1

$\begin{array}{ccccccccc}981 & -0.30 & 903 & -901 & 904 & -902 & 853 & -852\end{array}$

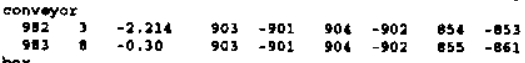
c.....

\section{Case 18bs-os-25; Table 5-7}

Comparing tiles 10bs-ou-23.i and 1ess-os-25.I

19.. 1tbos-op-23.1

c.... 5xe array, 1/8 1nch layor, h/Pu=20

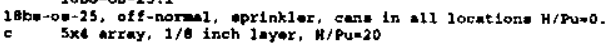

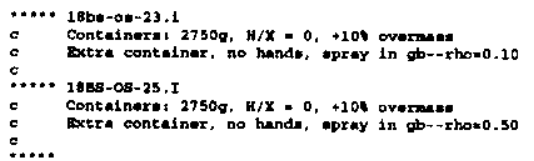

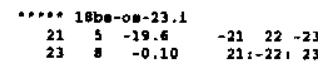

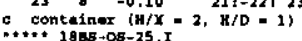

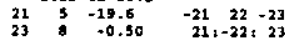

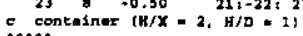

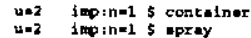

tn*1 s air belou

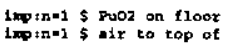

C.... 16bese -0.23 .1$

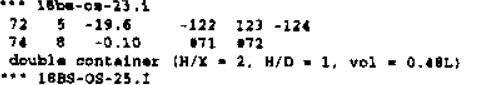

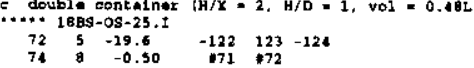

c doub2. conteiner $(H / X=2, g / D=1$, vol $=0.48 \mathrm{~L}$,

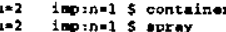

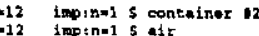

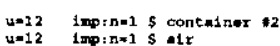

inpin=1 \$ PuO2 on tloor

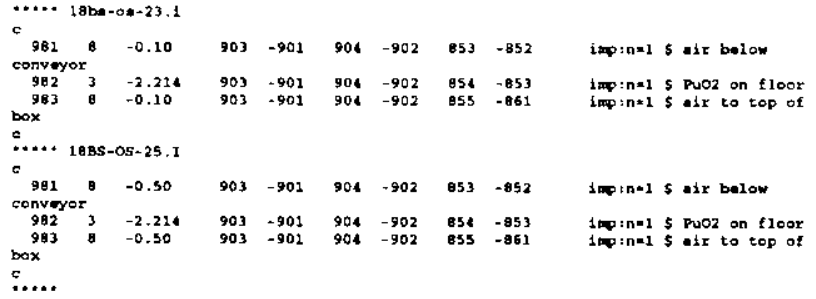

\section{Case 18bs-os-26; Table 5-7}

Conparing tiles 1 gba-on-23.1 and $1805-06-26 . I$

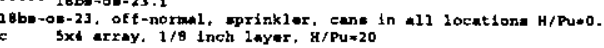

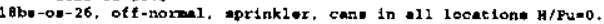

5xt erray, 1/8 inch layer, H/Pue 20

*... 10be-ou-23.1

c Contelnero: 2750g, H/X $=0,+104$ overaes.

C.*** 1abs-0s-26.I

Contalners: $27300, H / X=0,10$ averaega

Wetre contelner, no hands. epray in gt--rto=0.7s

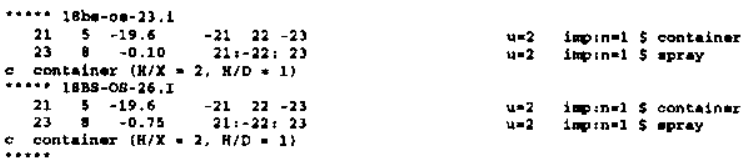

c container $\left(\mathrm{H} / \mathrm{X}=2, \mathrm{H} / \mathrm{O}^{2}, \mathrm{t}\right)$

012 inp: n=1 s containut 12

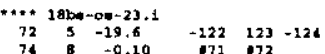

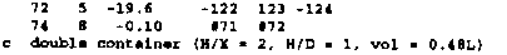

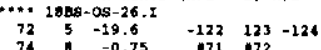

double container $(H / X=2, H / D=1$, vol $=0,48$

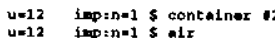

…. 18be-os-23.1

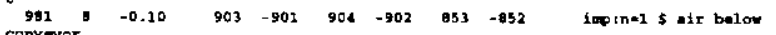

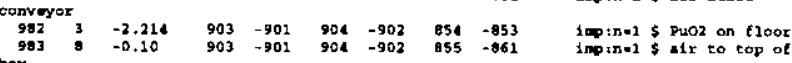

box

C.... 19Bs-os-26.

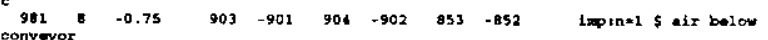

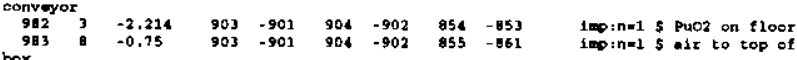
box

\section{Case 18bs-os-27, Table 5-7}

Conparing t110* 18bo-oz-23.i and 18Bs- $08-27$.

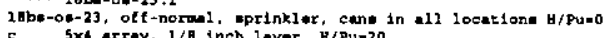

F.... 5xt array, $1 /$ B Ines layer, $\mathrm{B} / \mathrm{Pu}=20$

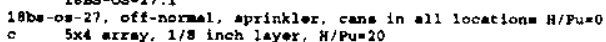

…. $186 \mathrm{bs}-0 \mathrm{~s}-23$.

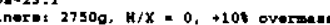

Bxtro conteiner, no hands, ppray in mb-rho $=0.10$

c.... 19as-0s-27.1

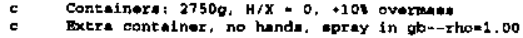

c....

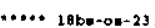

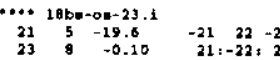

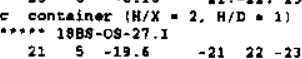

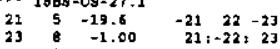

c. doubsto conteiner $(K / \mathrm{X}=2, \mathrm{H} / \mathrm{D}=1$, vol $=0.4 \mathrm{BL})$

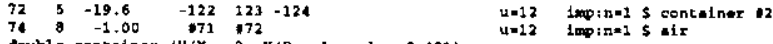

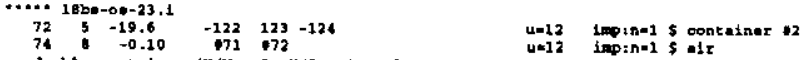

c. double contelnor $(H / X=2, H / D=1$, vol $=0.406)$ 


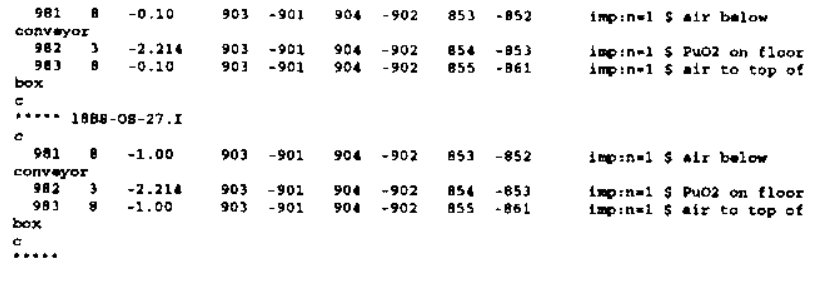

\section{Case 18bs-os-43; Table 5-8}

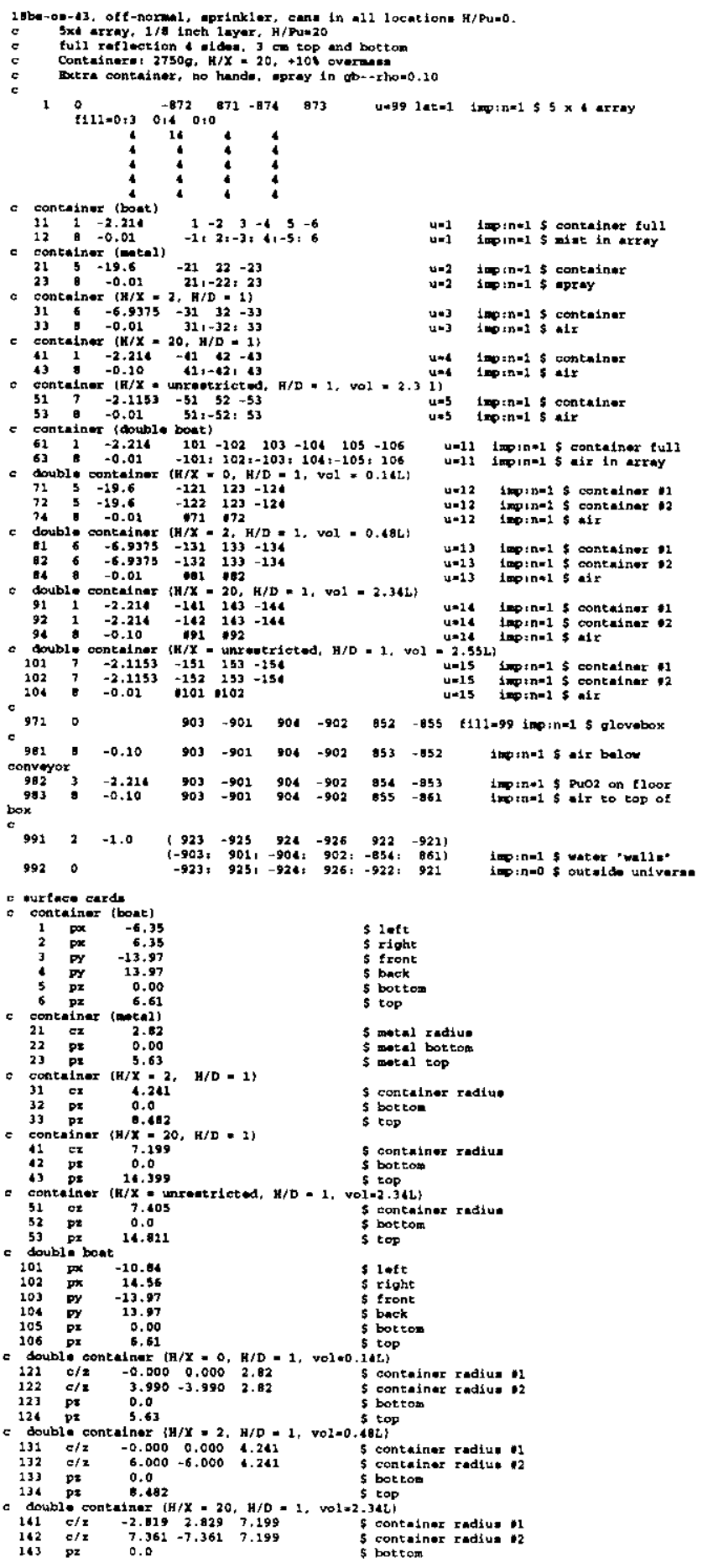

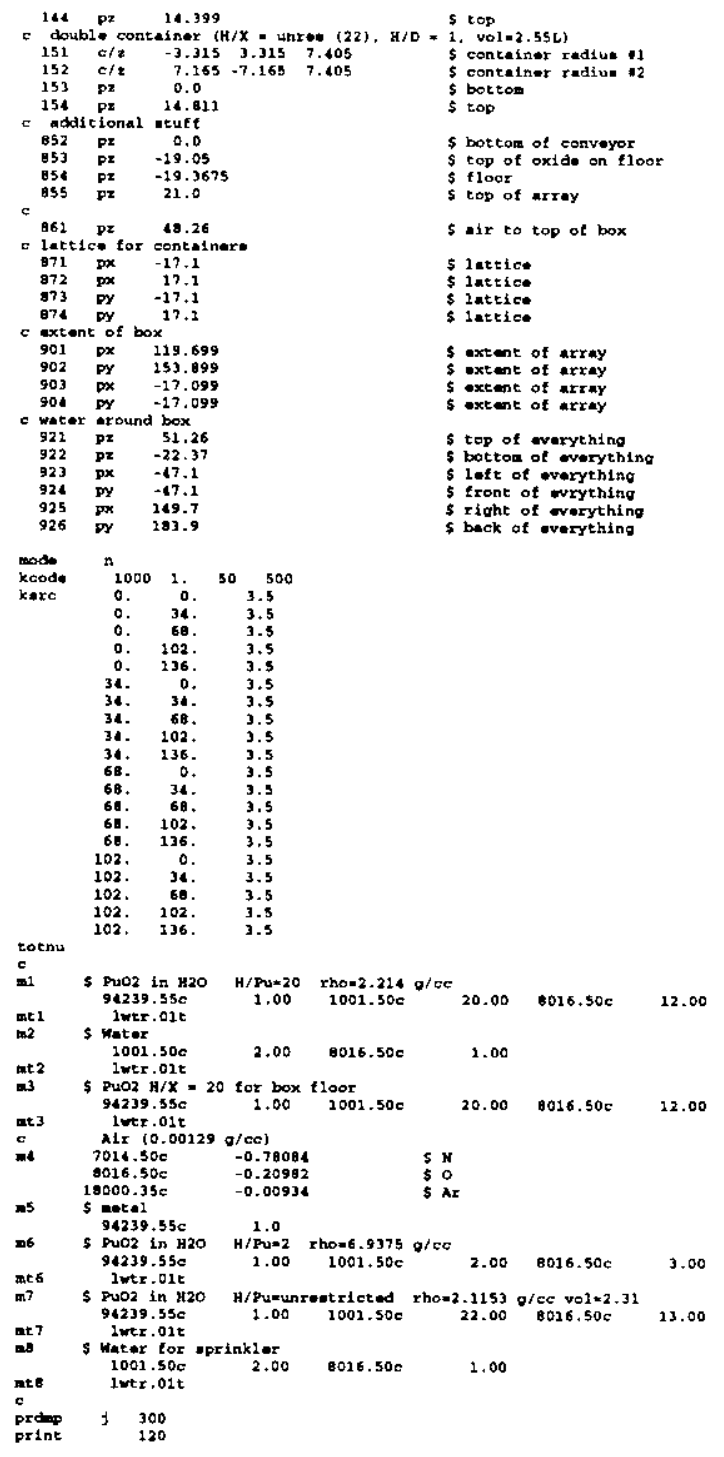

\section{Case 18bs-os-44; Table 5-8}

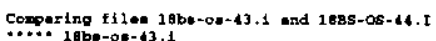

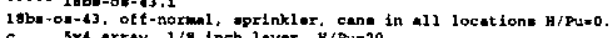

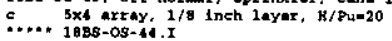

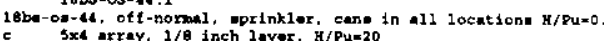

c. 5x4 srray, 1/8 inch leyer, $\mathrm{H} / \mathrm{Pu}=20$

N..... $10 \mathrm{bec}-0.04-43.1$

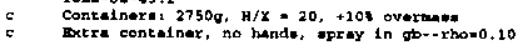

C..... 183s-os-44.I

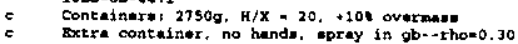

c......

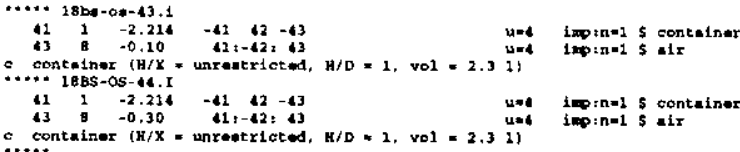

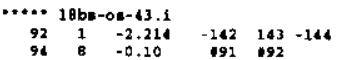

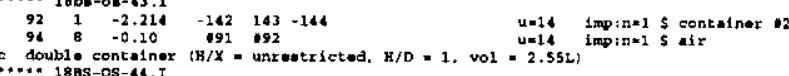

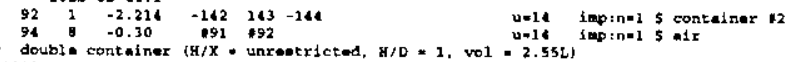


HNF-6271, Rev. 0

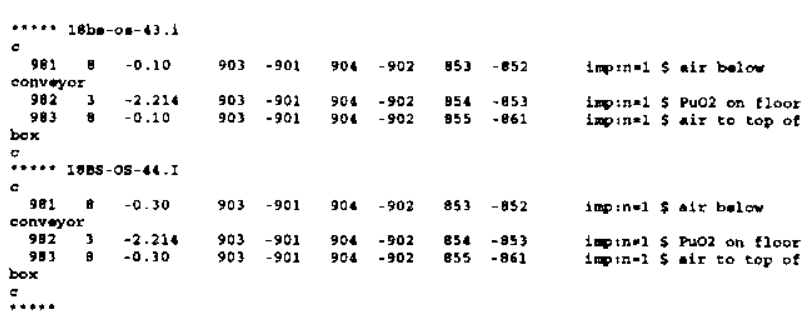

\section{Case 18bs-os-45; Table 5-8}

Cosparing tiles 10ba-0z-43.i and 18Bs-OS-45.I

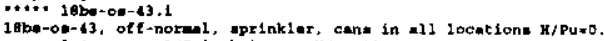

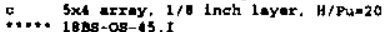

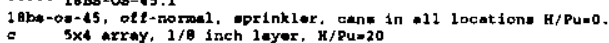

.......

c contelnet: 2750 g, $x / X=20,+10$ overam

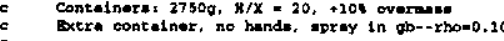

c.... 18se-0s-45.I

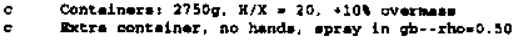

......

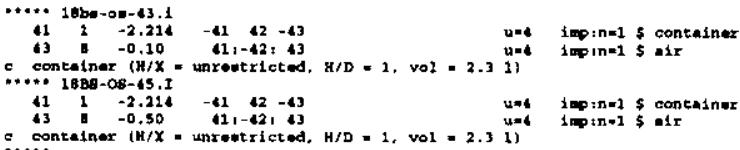

…. 1tbe-0s-43.1

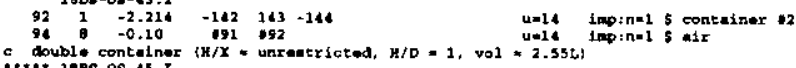

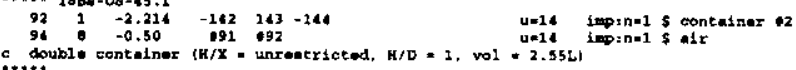

C..... 18ba-op--43

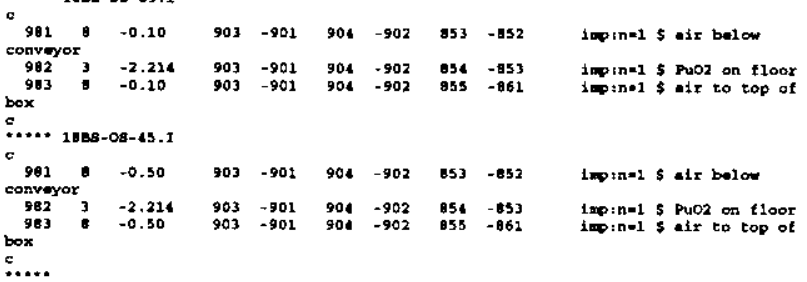

\section{Case 18bs-os-46; Table 5-8}

comparing t1100 10b-0u-43.1 and 188s-05-46.I

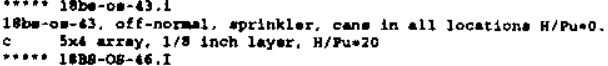

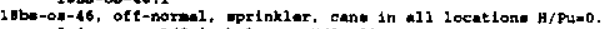

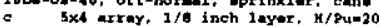

…. 1abse-on-43.1

Contelners: 2750g, H/X $=20,+10 \mathrm{~d}$ overames

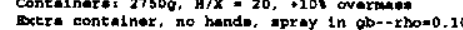

c.... 1808-08-46.I

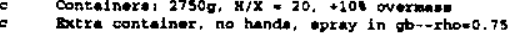
.....

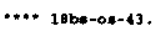

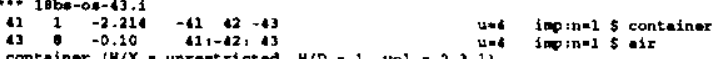

c containox $(H / X=$

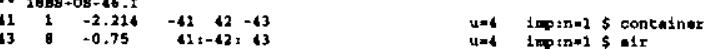

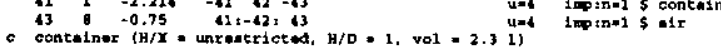

$\cdots \cdot 18 \mathrm{be}-00-43.1$

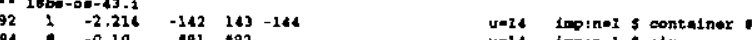

C. doubl cont niner (H/X $*$ unreatricted, $H / D=1$, vol $=2.55 \mathrm{~L}$ )

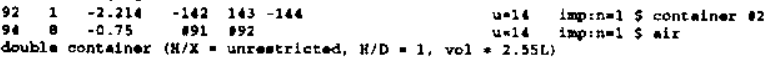

N*.. 18be-0e-43.1

\begin{tabular}{|c|c|c|c|c|c|c|c|c|c|}
\hline $\begin{array}{l}981 \\
\text { onver: }\end{array}$ & & -0.20 & 903 & -901 & 904 & -902 & 853 & -852 & isp: anel s eis below \\
\hline $\begin{array}{l}982 \\
983\end{array}$ & $\begin{array}{l}3 \\
8\end{array}$ & $\begin{array}{l}-2.216 \\
-0.10\end{array}$ & $\begin{array}{l}903 \\
903\end{array}$ & $\begin{array}{l}-901 \\
-901\end{array}$ & $\begin{array}{l}904 \\
904\end{array}$ & $\begin{array}{l}-502 \\
-902\end{array}$ & $\begin{array}{l}854 \\
855\end{array}$ & $\begin{array}{l}-853 \\
-861\end{array}$ & 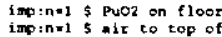 \\
\hline box & & & & & & & & & \\
\hline ...... & $\mathrm{aBs}$ & $O S-46 . I$ & & & & & & & \\
\hline $\begin{array}{c}981 \\
\text { convery }\end{array}$ & $x^{8}$ & -0.75 & 903 & -901 & 904 & -902 & 053 & -852 & Ing:tral \& air bolow \\
\hline $\begin{array}{l}9 \mathrm{E2}_{2} \\
9 \mathrm{BH}^{2}\end{array}$ & 3 & $\begin{array}{l}-2.214 \\
-0.75\end{array}$ & $\begin{array}{l}903 \\
903\end{array}$ & $\begin{array}{l}-901 \\
-901\end{array}$ & 904 & $\begin{array}{l}-902 \\
-902\end{array}$ & As, & -853 & 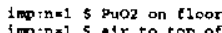 \\
\hline $0 x$ & & & & & & & & & \\
\hline
\end{tabular}

\section{Case 18bs-os-47, Table 5-8}

Cotoparing f110. $18 b-00-43.1$ and 19bs-08-47.I

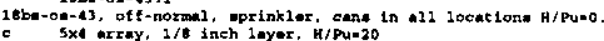

c.... 5x4 array, 1/6 ineh beyer, K/Pu=20

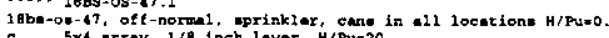

C..... 5x4

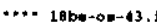

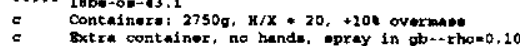

C.*.. 1828-0s-47.I

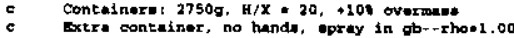
…..

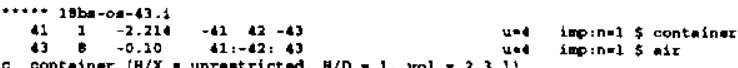

c. conteiner $(\mathrm{H} / \mathrm{X}=$ unrestricted, $\mathrm{H} / \mathrm{D}=$

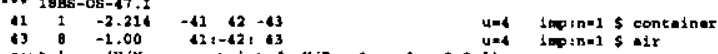

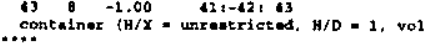

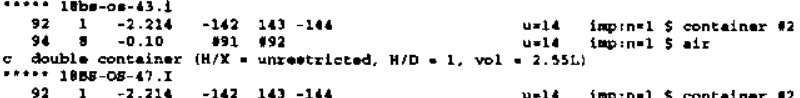

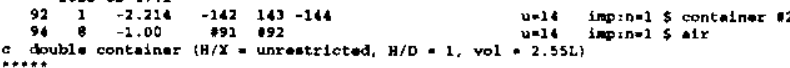

1.... 1 stbe-0.-43.1

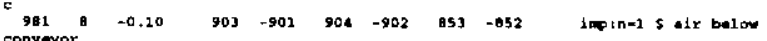

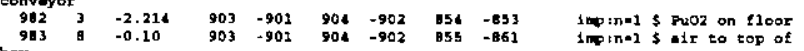

box

[.... 19:0s-05-47.

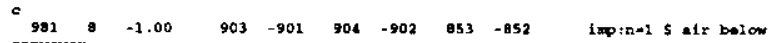

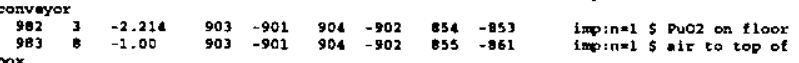

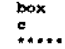

\section{Case 18bs-oe-24; Table 5-9}

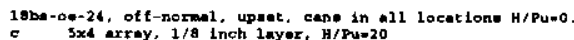

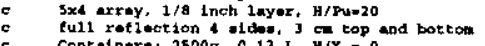
Miet $=0.10$

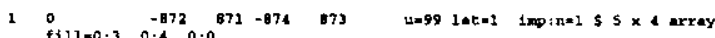
$\begin{array}{cccc}2 & 2 & 2 & 2 \\ 98 & 2 & 2 & 2 \\ 2 & 98 & 2 & 2 \\ 90 & 98 & 2 & 2 \\ 2 & 2 & 2 & 2\end{array}$

y=98 impin=1 5 eir ln erray

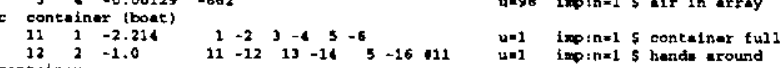

conteininer $-0.00129-11: 12:-13: 14:-5: 16 \quad u=1$ jogin=1 5 ir in array

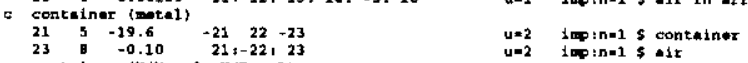

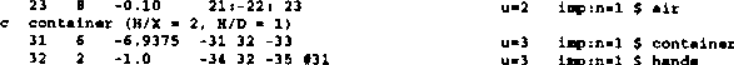

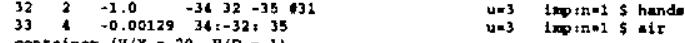

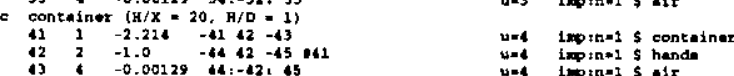

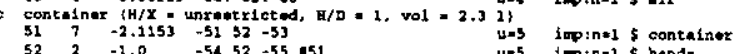

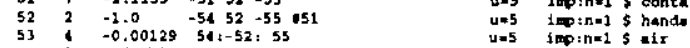

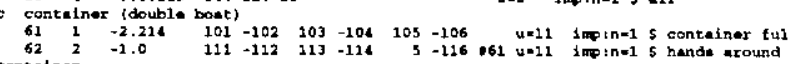

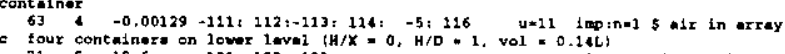


HNF-6271, Rev. 0

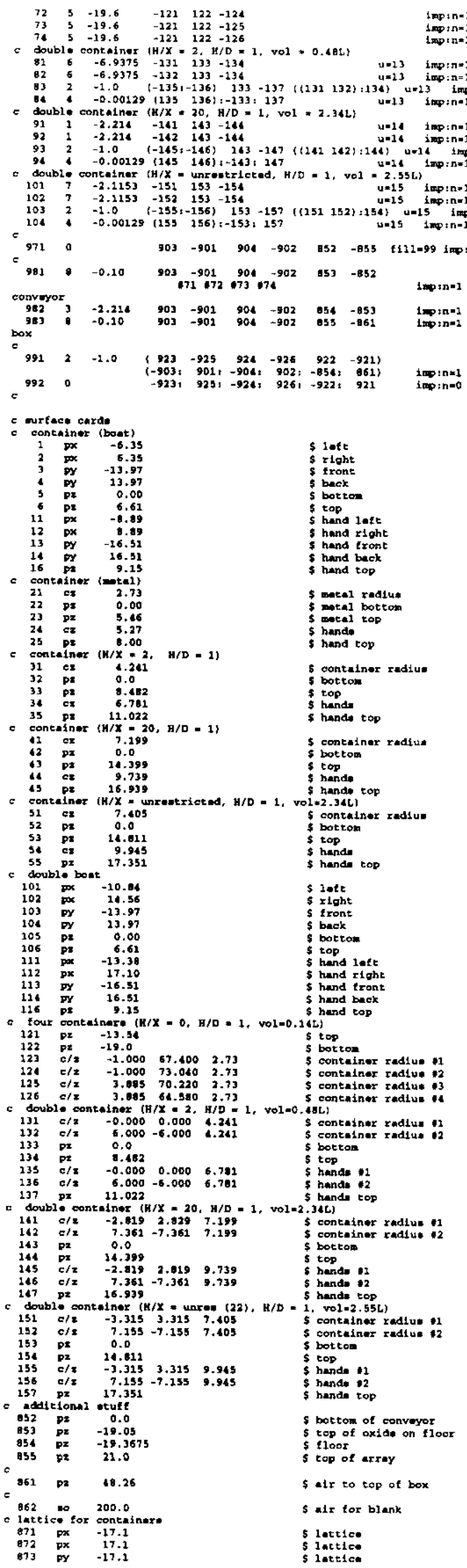

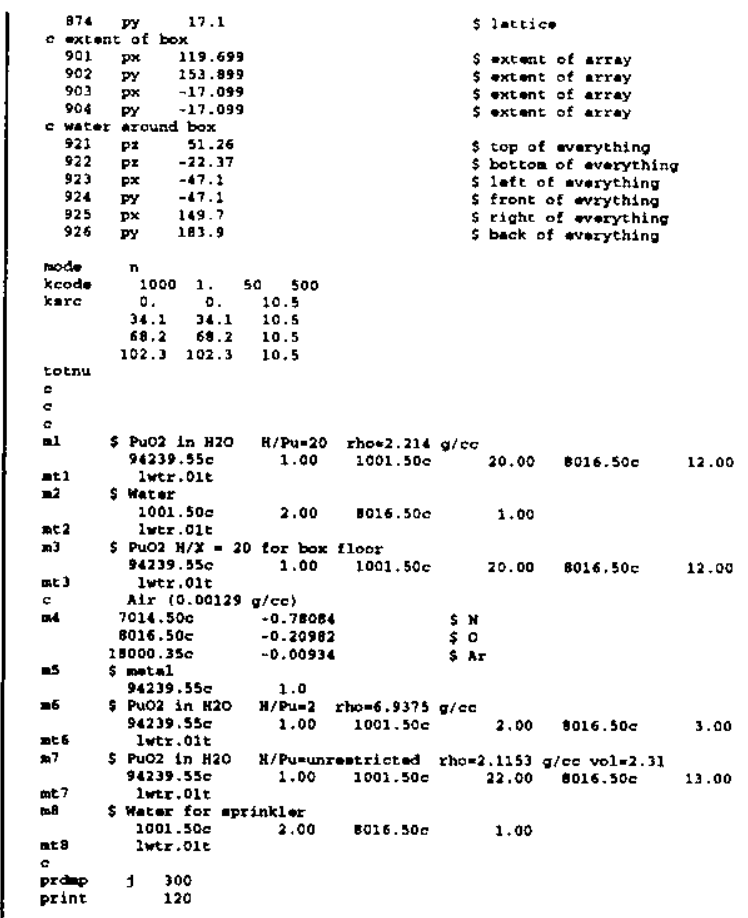

\section{Case 18bs-oe-44; Table 5-9}

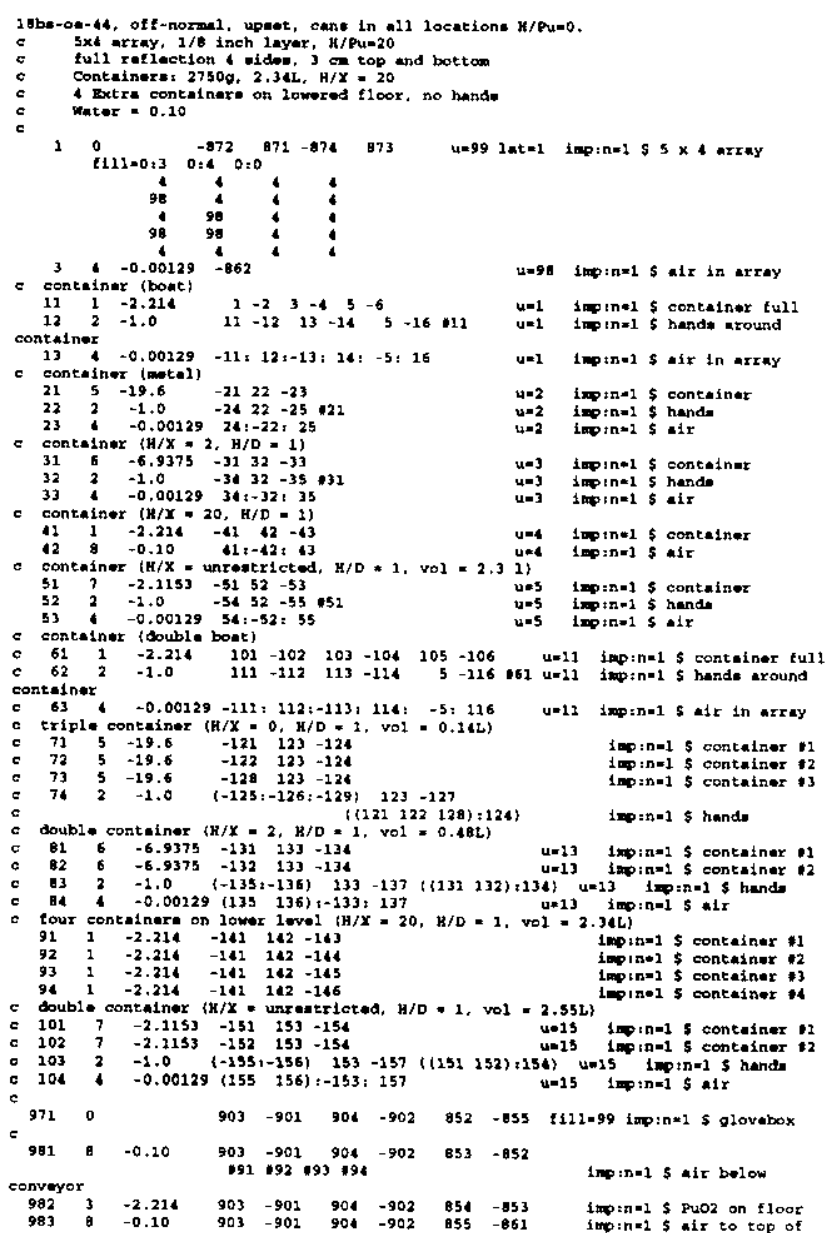


HNF-6271, Rev. 0

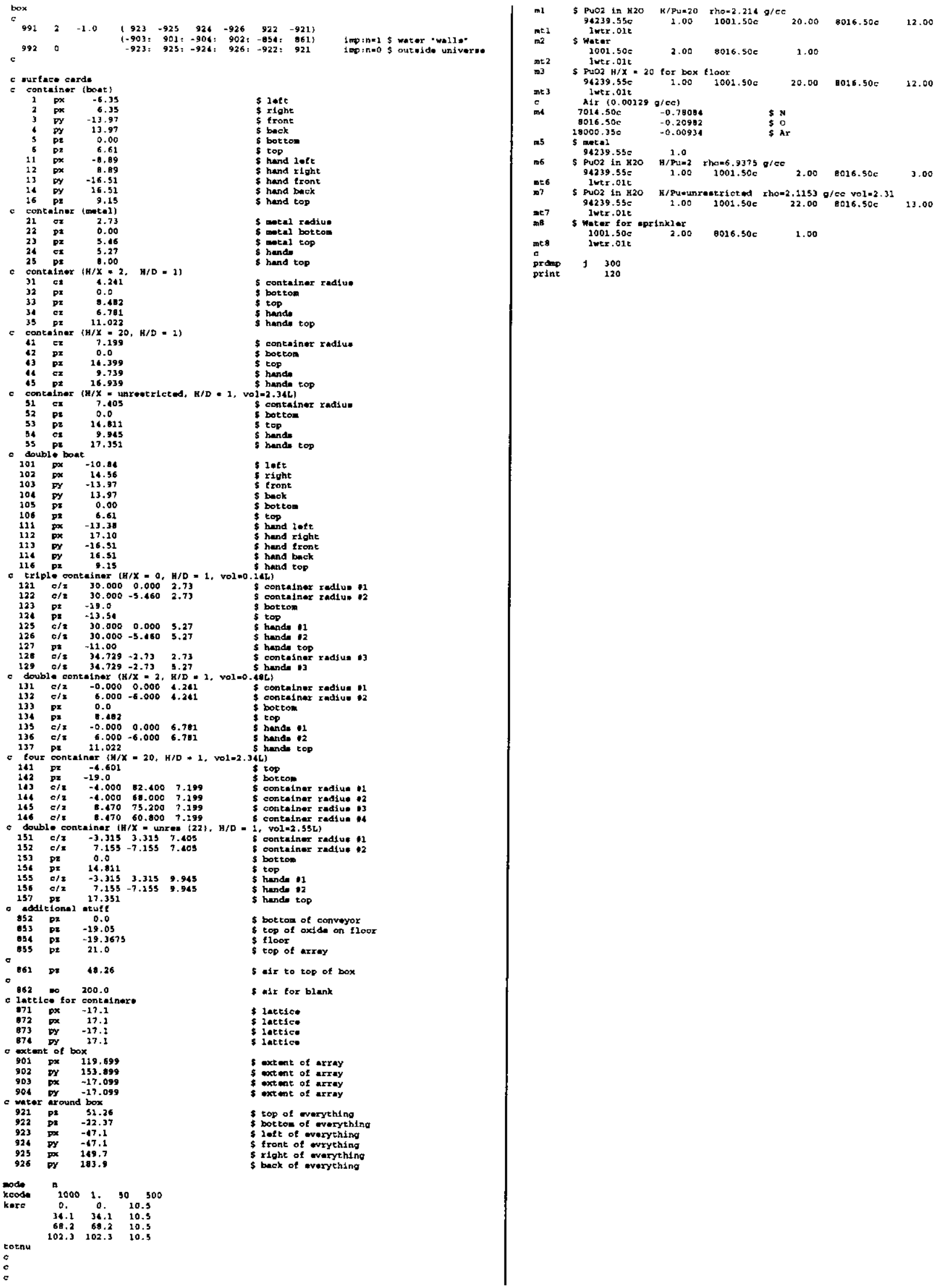

